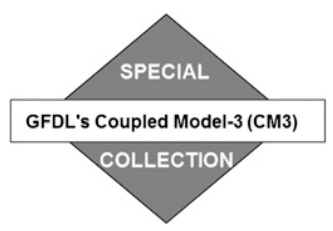

\title{
The Dynamical Core, Physical Parameterizations, and Basic Simulation Characteristics of the Atmospheric Component AM3 of the GFDL Global Coupled Model CM3
}

\author{
LeO J. DONnER, ${ }^{a}$ Bruce L. WyMAn, ${ }^{a}$ Richard S. Hemler, ${ }^{a}$ LARry W. Horowitz, ${ }^{\text {a }}$ Yi Ming, ${ }^{a}$ \\ Ming ZhaO, ${ }^{\mathrm{b}}$ JeAn-Christophe Golaz, ${ }^{\mathrm{a}}$ PAUl GinOUX, ${ }^{\mathrm{a}}$ S.-J. Lin, ${ }^{\mathrm{a}}$ M. DANIEl SCHWARZKOPF, ${ }^{\mathrm{a}}$ \\ John Austin, ${ }^{\mathrm{b}}$ GHASSAN Alaka, ${ }^{\mathrm{c}}$ William F. COOKe, ${ }^{\mathrm{d}}$ ThOMAS L. DelWORTh, ${ }^{\mathrm{a}}$

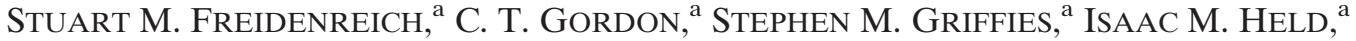 \\ William J. Hurlin, ${ }^{a}$ STEPHEN A. Klein,,${ }^{\mathrm{e}}$ ThOmAs R. KnUtson, ${ }^{\mathrm{a}}$ Amy R. LANGEnHORst, ${ }^{\mathrm{d}}$ \\ Hyun-Chul Lee, ${ }^{\mathrm{d}}$ YANluan Lin, ${ }^{\mathrm{b}}$ Brian I. Magi, ${ }^{\mathrm{f}}$ Sergey L. Malyshev ${ }^{\mathrm{f}}$ P. C. D. Milly, ${ }^{\mathrm{g}}$

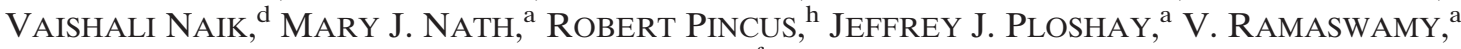 \\ Charles J. Seman, ${ }^{a}$ Elena SheVliakova, ${ }^{\mathrm{f}}$ Joseph J. Sirutis, ${ }^{\mathrm{a}}$ William F. Stern, ${ }^{\mathrm{a}}$ \\ Ronald J. Stouffer, ${ }^{a}$ R. John Wilson, ${ }^{a}$ Michael Winton, ${ }^{a}$ Andrew T. Wittenberg, ${ }^{a}$ \\ AND FANRONG ZENG ${ }^{\mathrm{a}}$

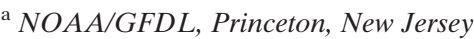 \\ ${ }^{\mathrm{b}}$ UCAR/GFDL, Princeton, New Jersey \\ ${ }^{\mathrm{c}}$ Colorado State University, Fort Collins, Colorado \\ ${ }^{\mathrm{d}}$ High Performance Technologies, Inc./GFDL, Princeton, New Jersey \\ e Program for Climate Model Diagnosis and Intercomparison, Lawrence Livermore \\ National Laboratory, Livermore, California \\ ${ }^{\mathrm{f}}$ Princeton University/GFDL, Princeton, New Jersey \\ ${ }^{\mathrm{g}}$ U.S. Geological Survey, Princeton, New Jersey \\ ${ }^{\mathrm{h}}$ University of Colorado/ESRL, Boulder, Colorado
}

(Manuscript received 29 July 2010, in final form 10 January 2011)

\begin{abstract}
The Geophysical Fluid Dynamics Laboratory (GFDL) has developed a coupled general circulation model (CM3) for the atmosphere, oceans, land, and sea ice. The goal of CM3 is to address emerging issues in climate change, including aerosol-cloud interactions, chemistry-climate interactions, and coupling between the troposphere and stratosphere. The model is also designed to serve as the physical system component of earth system models and models for decadal prediction in the near-term future-for example, through improved simulations in tropical land precipitation relative to earlier-generation GFDL models. This paper describes the dynamical core, physical parameterizations, and basic simulation characteristics of the atmospheric component (AM3) of this model. Relative to GFDL AM2, AM3 includes new treatments of deep and shallow cumulus convection, cloud droplet activation by aerosols, subgrid variability of stratiform vertical velocities for droplet activation, and atmospheric chemistry driven by emissions with advective, convective, and turbulent transport. AM3 employs a cubed-sphere implementation of a finite-volume dynamical core and is coupled to LM3, a new land model with ecosystem dynamics and hydrology. Its horizontal resolution is approximately $200 \mathrm{~km}$, and its vertical resolution ranges approximately from $70 \mathrm{~m}$ near the earth's surface to 1 to $1.5 \mathrm{~km}$ near the tropopause and 3 to $4 \mathrm{~km}$ in much of the stratosphere. Most basic circulation features in AM3 are simulated as realistically, or more so, as in AM2. In particular, dry biases have been reduced over South America. In coupled mode, the simulation of Arctic sea ice concentration has improved. AM3 aerosol optical depths, scattering properties, and surface clear-sky downward shortwave radiation are more realistic than in AM2. The simulation of marine stratocumulus decks remains problematic, as in $\mathrm{AM} 2$. The most intense $0.2 \%$ of precipitation rates occur less frequently in AM3 than observed. The last two decades of the twentieth century warm in $\mathrm{CM} 3$ by $0.32^{\circ} \mathrm{C}$ relative to $1881-1920$. The Climate Research Unit (CRU) and Goddard Institute for Space Studies analyses of observations show warming of $0.56^{\circ}$ and $0.52^{\circ} \mathrm{C}$, respectively, over this period. CM3 includes anthropogenic cooling by aerosol-cloud interactions, and its warming by the late twentieth century is somewhat less realistic than in $\mathrm{CM} 2.1$, which warmed $0.66^{\circ} \mathrm{C}$ but did not include aerosol-cloud interactions. The improved simulation of the direct aerosol effect (apparent in surface clear-sky downward radiation) in CM3 evidently acts in concert with its simulation of cloud-aerosol interactions to limit greenhouse gas warming.
\end{abstract}

Corresponding author address: Leo J. Donner, Geophysical Fluid Dynamics Laboratory/NOAA, Princeton University Forrestal Campus, 201 Forrestal Rd., Princeton, NJ 08540.

E-mail: leo.j.donner@noaa.gov

DOI: 10.1175/2011JCLI3955.1

(C) 2011 American Meteorological Society 


\section{Introduction}

The study of climate and climate change using general circulation models (GCMs) continues to advance rapidly, with impetus from widespread societal concern about anthropogenic and natural climate change, unprecedented global and field observational programs, and advances in theoretical and process-level understanding of atmospheric, oceanic, cryospheric, and terrestrial processes. The purpose of this paper is to describe recent development in the atmospheric component (AM3) of the Geophysical Fluid Dynamics Laboratory (GFDL) coupled model (CM3). AM3 is built upon the scientific and software framework of GFDL AM2 (Anderson et al. 2004). Its major developmental thrusts were chosen to enable AM3 to explore several key, emerging questions in climate and climate change that could not be addressed with AM2, such as: 1) What are the roles of aerosol-cloud interactions, specifically indirect effects of aerosols? 2) What are the dominant chemistry-climate interactions? AM3 development also aimed at enhanced capabilities for addressing emerging questions when coupled with biogeochemical and ocean models: 3) What is the interplay between climate and key biogeochemical cycles? 4) To what extent is decadal prediction possible? The model also includes advances in the dynamical core, radiation, and other components.

Addressing these scientific questions implies particular approaches to AM3 development. To model aerosolcloud interactions using a physically based treatment of aerosol activation, parameterizations for subgrid variability of vertical velocity are important. This is because aerosol activation depends strongly on local vertical velocity, which, for both stratiform and convective clouds, can depart strongly from the large-scale (in AM3, grid-scale) average. AM3 parameterizes subgrid vertical velocities for all clouds. To study chemistry-climate interactions, AM3 specifies chemical emissions and includes largescale and convective transport, wet and dry removal, and key tropospheric and stratospheric reactions. The AM3 stratospheric resolution has been increased, and its upper boundary has been raised, to treat stratospheric processes more comprehensively. AM3 itself does not include carbon, nitrogen, or other biogeochemical cycles, but particular attention has been given to improving its simulation of tropical precipitation in order to enhance its usefulness as a component of earth system models. AM3's improved stratospheric resolution is also necessary for future research on phenomena such as the Southern Hemisphere annular mode, which likely plays a role in interannual variability important for decadal prediction (Thompson and Solomon 2006).
Section 2 describes the AM3 dynamical core. Section 3 presents its physical parameterizations, while appendix A presents brief summaries of the land, ocean, and sea ice models used with AM3 in CM3. Section 4 illustrates basic simulation characteristics of AM3 with prescribed sea surface temperatures and, as CM3, in coupled mode. The inclusion of aerosol-cloud interactions in CM3 links cloud radiative properties to aerosols, whose optical properties and direct effects on shortwave radiation agree better with observations than in CM2. CM3's simulation of the increase in global-mean surface temperature from $1880-1920$ to $1980-2000$ is smaller than observed. The corresponding CM2 simulated increase is larger than observed. The magnitude of CM3's underestimate is about $0.1^{\circ} \mathrm{C}$ larger than the $\mathrm{CM} 2$ overestimate.

\section{Dynamical core}

As in CM2.1 (Delworth et al. 2006), the dynamical core used in AM3/CM3 follows the finite-volume algorithms described in Lin and Rood $(1996,1997)$ and Lin $(1997,2004)$, with the following major modifications.

In an effort to enhance the model's parallel computing efficiency and to improve simulation quality in polar regions, the dynamical core formulated on, and optimized specifically for, the latitude-longitude grid has been significantly modified to use a general curvilinear coordinate system. The nonorthogonal gnomonic projection in the general cubed-sphere geometry described by Putman and Lin (2007) is chosen for its excellent grid uniformity and better overall accuracy. The spatially more uniform gnomonic projection was chosen over the conformal projection for its computational efficiency. The largest dynamical time step allowed with the gnomonic grid is several times larger than that of the conformal grid. In idealized tests (Putman and Lin 2007), the solution with the gnomonic grid is also slightly more accurate. The use of the nonorthogonal coordinate system necessitated major changes to the transport operators (Putman and Lin 2007) and the need to compute both covariant and contravariant wind components (e.g., Sadourny 1972).

Compared to the original latitude-longitude grid formulation, the use of the cubed-sphere grid in the new finite-volume core greatly improved the computational efficiency owing to two major algorithmic modifications. First, the flux-form semi-Lagrangian extension (Lin and Rood 1996) needed to stabilize the (large time step) transport processes near the poles is no longer needed with the use of the cubed-sphere grid. Second, and related to the first, the polar Fourier filtering required for the stabilization of fast waves is also no longer needed. Both modifications led to greatly improved computation 
and communication load balancing, enabling the efficient use of 2D domain decomposition on each of the six faces of the cube.

The model's horizontal resolution is denoted as $\mathrm{Cn}$, where $n$ is an integer number indicating the total number of cells (finite volumes) along each edge of the cube. In AM3, the model's resolution is $\mathrm{C} 48$. The total number of cells on the sphere is therefore $6 \times 48 \times 48=13824$, and the size of the grid cell varies from $163 \mathrm{~km}$ (at the six corners of the cubed sphere) to $231 \mathrm{~km}$ (near the center of each face). The $\mathrm{C} 48$ resolution model scales roughly an order of magnitude better (can use 864, versus 30 , central processing units) than its latitude-longitude counterpart $\left(2^{\circ} \times 2.5^{\circ}\right.$ resolution) used in CM2.1, enabling nearly the full use of the GFDL 1024-core SGI Altix-3000 system.

The vertical coordinate in AM3 follows Simmons and Burridge (1981), but the number of layers has been increased to 48 (from 24 layers in AM2). The uppermost level in AM3 has a pressure of $1 \mathrm{~Pa}$, a height of about $86 \mathrm{~km}$ for a surface pressure of $1013.25 \mathrm{hPa}$, and scale height of $7.5 \mathrm{~km}$ (equivalently, isothermal with a temperature of approximately $256.2 \mathrm{~K}$ ), compared to around $35 \mathrm{~km}$ in AM2. The augmentation in vertical levels is aimed at resolving the stratosphere sufficiently well that its basic chemical and dynamical processes can be reasonably simulated. Between the earth's surface and about $430 \mathrm{hPa}$, the vertical levels are positioned within $10 \mathrm{hPa}$ of those in AM2. Additional layers are added at lower pressures. Table 1 shows the positions of the intermediate levels, which bound the AM3 layers.

\section{Physical parameterizations}

\section{a. Radiation}

The basic shortwave and longwave radiation algorithms are described in Freidenreich and Ramaswamy (1999) and Schwarzkopf and Ramaswamy (1999), respectively, modified as in Anderson et al. (2004). Total and spectral solar irradiances are from the Total Irradiance Monitor (TIM) (Kopp et al. 2005), as recommended for Climate Model Intercomparison Project 5 (CMIP5) (http://www.geo.fu-berlin.de/en/met/ag/strat/forschung/ SOLARIS/Input_data/CMIP5_solar_irradiance.html).

\section{1) SUBGRID VARIABILITY AND OVERLAP}

All-sky radiative transfer calculations account for the effect of clouds using the Monte Carlo independent column approximation (Pincus et al. 2003), which treats variability by creating a set of subcolumns consistent with cloud properties (including variability) and vertical
TABLE 1. Coefficients $a_{k}$ and $b_{k}$ for calculation of interface pressures using $p=a_{k}+b_{k} \times p_{s}$, where $p$ is pressure and $p_{s}$ is surface pressure (Simmons and Burridge 1981). Pressures and heights of interface levels corresponding to a scale height of $7.5 \mathrm{~km}$ and $p_{s}=1013.25 \mathrm{hPa}$ are also shown. See appendix B for description and units.

\begin{tabular}{|c|c|c|c|c|}
\hline$k$ & $a_{k}(\mathrm{~Pa})$ & $b_{k}$ & $p(\mathrm{hPa})$ & $z(\mathrm{~km})$ \\
\hline 1 & 1 & 0 & 0.01 & 86.45 \\
\hline 2 & 2.6972 & 0 & 0.03 & 79.00 \\
\hline 3 & 5.1714 & 0 & 0.05 & 74.12 \\
\hline 4 & 8.8946 & 0 & 0.09 & 70.05 \\
\hline 5 & 14.248 & 0 & 0.14 & 66.52 \\
\hline 6 & 22.072 & 0 & 0.22 & 63.24 \\
\hline 7 & 33.613 & 0 & 0.34 & 60.08 \\
\hline 8 & 50.481 & 0 & 0.50 & 57.03 \\
\hline 9 & 74.800 & 0 & 0.75 & 54.08 \\
\hline 10 & 109.40 & 0 & 1.09 & 51.23 \\
\hline 11 & 158.00 & 0 & 1.58 & 48.48 \\
\hline 12 & 225.44 & 0 & 2.25 & 45.81 \\
\hline 13 & 317.90 & 0 & 3.18 & 43.23 \\
\hline 14 & 443.19 & 0 & 4.43 & 40.74 \\
\hline 15 & 611.12 & 0 & 6.11 & 38.33 \\
\hline 16 & 833.74 & 0 & 8.34 & 36.00 \\
\hline 17 & 1125.8 & 0 & 11.3 & 33.75 \\
\hline 18 & 1505.2 & 0 & 15.1 & 31.57 \\
\hline 19 & 1993.2 & 0 & 19.9 & 29.46 \\
\hline 20 & 2614.9 & 0 & 26.2 & 27.43 \\
\hline 21 & 3399.8 & 0 & 34.0 & 25.46 \\
\hline 22 & 4382.1 & 0 & 43.8 & 23.56 \\
\hline 23 & 5600.9 & 0 & 56.0 & 21.72 \\
\hline 24 & 7100.7 & 0 & 71.0 & 19.94 \\
\hline 25 & 8931.8 & 0 & 89.3 & 18.22 \\
\hline 26 & 11150 & 0 & 111 & 16.55 \\
\hline 27 & 13817 & 0 & 138 & 14.94 \\
\hline 28 & 17001 & 0 & 170 & 13.39 \\
\hline 29 & 20776 & 0 & 208 & 11.88 \\
\hline 30 & 23967 & 0.01253 & 252 & 10.43 \\
\hline 31 & 25528 & 0.04887 & 305 & 9.01 \\
\hline 32 & 25671 & 0.10724 & 365 & 7.65 \\
\hline 33 & 24609 & 0.18455 & 433 & 6.37 \\
\hline 34 & 22641 & 0.27461 & 505 & 5.23 \\
\hline 35 & 20147 & 0.36914 & 576 & 4.24 \\
\hline 36 & 17478 & 0.46103 & 642 & 3.42 \\
\hline 37 & 14860 & 0.54623 & 702 & 2.75 \\
\hline 38 & 12415 & 0.62305 & 755 & 2.20 \\
\hline 39 & 10201 & 0.69099 & 802 & 1.75 \\
\hline 40 & 8241.5 & 0.75016 & 843 & 1.38 \\
\hline 41 & 6534.4 & 0.80110 & 877 & 1.08 \\
\hline 42 & 5066.2 & 0.84453 & 906 & 0.84 \\
\hline 43 & 3815.6 & 0.88127 & 931 & 0.63 \\
\hline 44 & 2758.6 & 0.91217 & 952 & 0.47 \\
\hline 45 & 1870.6 & 0.93803 & 969 & 0.33 \\
\hline 46 & 1128.3 & 0.95958 & 984 & 0.22 \\
\hline 47 & 510.48 & 0.97747 & 996 & 0.13 \\
\hline 48 & 0 & 0.99223 & 1005 & 0.06 \\
\hline 49 & 0 & 1 & 1013 & 0 \\
\hline
\end{tabular}


structure (i.e., overlap). The in-cloud distribution of ice and water content in stratiform clouds is diagnosed from the cloud fraction and condensate amount (Pincus et al. 2006), and vertical structure assumes that the rank correlation of total water falls off exponentially with the distance between layers using a scale height of $1 \mathrm{~km}$ (Pincus et al. 2005). These formulations differ from those in AM2 and allow cloud optical properties to be used as predicted, rather than being arbitrarily multiplied by 0.85 as in AM2. The radiative properties of shallow and deep convective clouds (section 3e) are also included. Convective clouds are assumed to be internally homogeneous and to obey maximum overlap. When convective clouds occur in a subcolumn they replace any stratiform clouds in layers where both clouds occur, which slightly decreases the overall stratiform cloud amount. In AM2, convective clouds were excluded from radiative transfer.

The effective radius in each subcolumn is computed assuming that the predicted cloud drop number is uniform for each cloud type within each grid-scale column. As will become evident in sections $3 \mathrm{~d}$ and $3 \mathrm{f}$, information on the subgrid distribution of cloud drop number is available but, as a simplification, has not been incorporated into the subcolumns. In stratiform clouds and shallow cumulus, drop size depends on aerosol activation, as described in section $3 \mathrm{f}$.

\section{2) Cloud optics}

The sizes of cloud droplets in stratiform and shallow cumulus clouds depend on aerosol activation and are determined using the procedures described in section $3 \mathrm{f}$. In deep cumulus updraft cells, the sizes of liquid droplets follow Bower et al. (1994). Size-dependent shortwave optical properties for cloud liquid follow Slingo (1989). Longwave liquid optical properties follow Held et al. (1993) and depend on water path but not particle size. AM3 does not treat ice nucleation or link ice nucleation to crystal sizes. In shallow cumulus and stratiform ice clouds, ice particle sizes are diagnosed as a function of temperature, based on aircraft observations (Donner et al. 1997) with radiative properties following $\mathrm{Fu}$ and Liou (1993). In mesoscale updrafts associated with deep convection, ice crystals increase in size with distance from the top of the updraft, as in McFarquhar et al. (1999), except that McFarquhar et al.'s heights are replaced with equivalent normalized fractional distances between the top and base of the mesoscale updraft. Ice crystals in cumulus cell updrafts are assigned a generalized effective size of $18.6 \mu \mathrm{m}$, based on observations of the early temporal evolution (most likely dominated by deep cells) of a convective system in the Central Equatorial Pacific Experiment (Fu 1996). Solar and infrared radiative properties of ice crystals in cell updrafts and mesoscale anvils are obtained from $\mathrm{Fu}$ (1996) and $\mathrm{Fu}$ et al. (1998), respectively.

\section{3) Gas CONCENTRATIONS}

Historical concentrations of carbon dioxide, nitrous oxide, methane, and halocarbons (CFC-11, CFC-12, CFC113, and HCFC-22) were obtained online (from www. iiasa.ac.at/web-apps/tnt/RcpDb/, where the Representative Concentration Pathways may also be found). Note that the methane specification for radiation differs from the methane obtained from the chemistry calculations described in section $3 \mathrm{~g}$. Tropospheric and stratospheric ozone are modeled as described in section $3 \mathrm{~g}$.

\section{4) Aerosol optics}

The effects of volcanoes are included in the AM3 and CM3 simulations described in section 4. Sulfur dioxide emissions from volcanoes are described in section $3 \mathrm{f}$. Direct injection of sulfur into the stratosphere from volcanic eruptions is not included, nor is carbonyl-sulfide chemistry, a major source of background stratospheric aerosol. To compensate, in the stratosphere, a time series of volcanic optical properties is specified as in Stenchikov et al. (2006).

Aerosol optical properties (i.e., extinction efficiency, single-scattering albedo, and asymmetry factor) are based on Mie theory, assuming that all particles spherical. Lognormal size distribution is assumed for sulfate and carbonaceous aerosols. The geometric mean radius and standard deviation of the lognormal distribution for sulfate and black carbon are from Haywood and Ramaswamy (1998), and for organics from Hess et al. (1998). The mass size distribution of dust and sea salt is assumed constant within five bins from 0.1 to $10 \mu \mathrm{m}$. Hygroscopic growth is considered for sulfate, sea salt, and aged (hydrophilic) organic carbon. We model the hygroscopic growth of sulfate after that of pure ammonium sulfate (Tang and Munkelwitz 1994), of sea salt as pure sodium chloride (Tang et al. 1997), and of hydrophilic organics as a mixture of acids and insoluble organics (Ming et al. 2005). The refractive indices of sulfate and black carbon are from Haywood and Ramaswamy (1998), organics from Hess et al. (1998), sea salt from Tang et al. (1997), and dust from Balkanski et al. (2007), assuming a $2.7 \%$ content of hematite. Internal mixture of sulfate and aged (hydrophilic) black carbon is calculated by volume-weighted average of their refractive index. All other aerosols are assumed externally mixed.

\section{b. Gravity wave drag}

Orographic gravity wave drag is parameterized using Stern and Pierrehumbert (1988), as described in Anderson et al. (2004). Nonorographic gravity wave 
drag is parameterized using Alexander and Dunkerton (1999), which treats vertical propagation of wave components of a spectrum of gravity waves with a range of phase speeds and horizontal wavelengths, assuming that the momentum associated with each wave component is deposited locally at the level of linear wave breaking. There are uncertainties in the seasonal, latitudinal, and height dependencies of gravity wave sources and sinks. Alexander and Rosenlof (2003) found that parameters related to the sources and sinks varied from the tropics to the extratropics. In the AM3 application of Alexander and Dunkerton (1999), the momentum source is represented by a broad spectrum of wave speeds (halfwidth of $40 \mathrm{~m} \mathrm{~s}^{-1}$ ) with a resolution of $2 \mathrm{~m} \mathrm{~s}^{-1}$ and a single horizontal wavelength of $300 \mathrm{~km}$. The amplitude of the momentum source is $0.005 \mathrm{~Pa}$ in the northern middle and high latitudes, $0.004 \mathrm{~Pa}$ in the tropics, and $0.003 \mathrm{~Pa}$ in the southern middle and high latitudes, with smooth transitions around $30^{\circ} \mathrm{N}$ and $\mathrm{S}$. The sources themselves are not observationally based but have been chosen based on the circulation they yield. For example, the asymmetry in the northern and southern sources improves the simulation of stratospheric zonal winds and polar temperatures. The wave launch height decreases smoothly from $350 \mathrm{hPa}$ at the equator to near the surface at the poles. Optimizing the input parameters was eased by limiting the influence of the orographic wave drag parameterization to below $30 \mathrm{hPa}$. The scheme yields a reasonable semiannual oscillation. However, the vertical resolution employed here is not sufficiently fine to enable simulation of the quasi-biennial oscillation (Giorgetta et al. 2006).

\section{c. Turbulence and planetary boundary layer}

Turbulence and planetary boundary layers (PBLs) in AM3 are treated as in AM2. Lock et al. (2000) is used for convective PBLs and stratocumulus layers. Louis (1979) is employed for other unstable layers. Stability functions with thresholds dependent on Richardson number are adopted for stable layers. Variations in vertical diffusion coefficients are damped. Full details can be found in Anderson et al. (2004).

\section{d. Stratiform clouds}

Cloud fraction, liquid, and ice in AM3 are prognosed based on Tiedtke (1993) with modifications mostly as described in Anderson et al. (2004). Detrainment of cloud liquid, cloud ice, and cloud fraction are treated slightly differently than in Anderson et al. (2004) to be consistent with the Donner et al. (2001) deep and Bretherton et al. (2004) shallow cumulus parameterizations in AM3. Denoting the mixing ratio of liquid or ice or the cloud fraction by $X$, its stratiform tendency due to deep convection is

$$
g D_{\text {meso }} X_{\text {meso }}-g \frac{\partial\left(M_{\text {deep }} \bar{X}\right)}{\partial p} .
$$

Here $D_{\text {meso }}$ is the rate of change with pressure of the mass flux in the detraining layers of mesoscale updrafts in convective systems. The sum of upward mass fluxes in deep cells and mesoscale updrafts, reduced by the downward mass fluxes in mesoscale downdrafts, is $M_{\text {deep }}$, while $g$ and $p$ denote the gravity constant and pressure, respectively. An overbar denotes a large-scale average. Detrainment from deep convective cells in Donner et al. (2001) is directed to the mesoscale circulations, which are part of the cumulus parameterization. Thus, detrainment into the stratiform clouds is from the mesoscale updrafts only. See the list of symbols and description of the parameters in appendix $B$.

The corresponding stratiform tendency due to shallow cumulus is

$$
g D_{\text {shal }}\left(X^{*}-\bar{X}\right)-g M_{\text {shal }} \frac{\partial \bar{X}}{\partial p}
$$

where $X^{*}$ denotes a property within shallow cumulus.

Microphysical processes except for activation of liquid cloud drops (described in section 3f) follow Rotstayn (1997) and Rotstayn et al. (2000), as described in Anderson et al. (2004). The number of activated aerosols depends on aerosol mass, composition, and vertical velocity. To account for the effect of subgrid variability, the vertical velocity is assumed to be normally distributed within each model grid box and the activation computed by integration over this distribution following Ghan et al. (1997). The mean of the distribution is the velocity driving the stratiform condensation in the Tiedtke (1993) parameterization, and the standard deviation is related to the turbulence mixing coefficients. A minimum standard deviation of $0.7 \mathrm{~m} \mathrm{~s}^{-1}$ is imposed. The integration is performed numerically using a 64 point Gauss-Hermite quadrature. Through its control on aerosol activation, subgrid variability in vertical velocity is a major factor in the magnitude of aerosol indirect effects (Golaz et al. 2011).

Several parameters in the Tiedtke (1993) parameterization have been altered from their Anderson et al. (2004) values. The critical droplet radius for autoconversion is $8.2 \mu \mathrm{m}$. Autoconversion thresholds as low as $4.5 \mu \mathrm{m}$ have been used in GCMs. [See Rotstayn (2000) for a detailed discussion]. The threshold value was $10.6 \mu \mathrm{m}$ in AM2 (Anderson et al. 2004) and $8.0 \mu \mathrm{m}$ 
in AM2.1 (Delworth et al. 2006). The erosion constants when vertical diffusion is active, when convection (shallow, deep, or both) is active without vertical diffusion, and when neither convection nor diffusion is active are $7 \times 10^{-5} \mathrm{~s}^{-1}, 7 \times 10^{-5} \mathrm{~s}^{-1}$, and $1.3 \times 10^{-6} \mathrm{~s}^{-1}$, respectively. Erosion scales are larger in AM3 than in AM2/AM2.1, but we note that Anderson et al. (2004) pointed out that the erosion scale under convective conditions in AM2 might be 40 times too small compared to large-eddy simulation (LES) results from Siebesma et al. (2003).

The ice fall speeds follow Heymsfield and Donner (1990), multiplied by a factor of 1.5 . The Heymsfield and Donner (1990) fall speeds are not parameterized to include rimed particles, which have higher fall speeds than ice-only particles. The applied multiplicative factor produces slightly better agreement between the AM3 fall speeds and fall speeds observed at the Southern Great Plains site of the Atmospheric Radiation Program. Riming occurs in these observed particles and has been included in a new parameterization (Lin et al. 2011), which is likely to be used in future model development.

As the foregoing discussion indicates, the changes to autoconversion threshold, erosion constants, and fall speeds are regarded as within observational or conceptual uncertainties, given the design of the parameterizations. The changes were chosen to increase realism of the simulations, particularly with regard to radiation balance, precipitation, and implied ocean heat transports in AM3 integrations with prescribed sea surface temperatures (SSTs).

\section{e. Cumulus convection}

Deep cumulus systems consist of deep updraft cells, mesoscale updrafts, and mesoscale downdrafts (Donner 1993; Donner et al. 2001; Wilcox and Donner 2007). Several modifications have been made in AM3 for computational efficiency or simulation improvement. The plumes in the deep updraft cells are discretized on the AM3 vertical grid instead of a higher-resolution cloud grid. With the coarser plume resolution, entrainment coefficients have been increased relative to those in Donner (1993) by a factor of 1.65. Liquid/frozen-water static energy (conservative without precipitation) is used instead of temperature for plume thermodynamics. Aspects of the water budget in deep convective systems related to $R_{m}$, precipitation from mesoscale updrafts; $E_{\text {me }}$, condensate transfer from mesoscale updrafts to large-scale stratiform clouds (cf. section $3 \mathrm{~d}$ ); $C_{\mathrm{mu}}$, condensation and deposition in mesoscale updrafts; and $C_{A}$, lateral transfer of condensate from deep updraft cells to mesoscale updrafts, have been modified. In particular,
$R_{m} /\left(C_{\mathrm{mu}}+C_{A}\right)$ and $E_{\mathrm{me}} /\left(C_{\mathrm{mu}}+C_{A}\right)$ are 0.55 and 0.05 , respectively, compared to 0.50 and 0.10 in Donner (1993). In AM3, 10\% of the condensate in the cell updrafts at the detrainment level evaporates, while all remaining condensate that does not fall from the cell updrafts as precipitation is transferred to the mesoscale updraft. In Donner (1993), 13\% of the condensate in the cell updrafts that is not removed as precipitation evaporates near the detrainment level, while $25 \%$ evaporates in cell-scale downdrafts and $62 \%$ is transferred to the mesoscale updraft. The Donner partitionings are based on observations reported by Leary and Houze (1980). In AM3, the top of the mesoscale circulation is specified as the level of zero buoyancy (or at a pressure $10 \mathrm{hPa}$ less than the level of zero buoyancy if the deepest cell top is above the level of zero buoyancy due to overshooting). The top of mesoscale circulation is restricted to be no higher than the temperature minimum corresponding to the local tropopause.

The closure for deep cumulus results in heating by cumulus convection relaxing convective available potential energy (CAPE) toward a threshold over a relaxation time scale [cf. Eq. (2) in Wilcox and Donner (2007)]. The CAPE threshold is $1000 \mathrm{~J} \mathrm{~kg}^{-1}$, and the relaxation time scale is $8 \mathrm{~h}$. These choices were motivated primarily by their effect on the precipitation simulation.

Shallow cumulus follows Bretherton et al. (2004), modified as in Zhao et al. (2009). The shallow scheme of Bretherton et al. assumes a single bulk entraining and detraining plume with entrainment/detrainment rate determined by a parcel buoyancy sorting algorithm. The scheme includes a plume vertical momentum equation and a parameterization of cloud-top penetrative mixing of air between the level of neutral buoyancy and the maximum vertical extent of the plume. The buoyancy sorting representation of the inhomogeneous shallow cumulus mixing as well as the cloud-top penetrative mixing is supported by both observations (e.g., Paluch 1979; Grinnell et al. 1996) and large-eddy simulations of shallow cumulus clouds (e.g., Zhao and Austin 2005a,b). The closure for cloud-base mass flux in the plume is determined by estimates of the boundary layer turbulent kinetic energy and of the convective inhibition. The important nondimensional parameter controlling the strength of the lateral mixing [c0 in Eq. (18) in Bretherton et al. (2004)] is set to be 13.5 in AM3.

Both deep and shallow cumulus diffuse large-scale horizontal momentum in proportion to their mass fluxes, as in Anderson et al. (2004). The nondimensional constant $\gamma$ in Eq. (1) of Anderson et al. (2004), which is a factor with the cumulus mass flux in the term added to the vertical diffusion coefficient, takes the value 0.26 in AM3. The Anderson et al. (2004) value is 0.20. 
Finally, moist adiabatic adjustment (MAA) (Manabe et al. 1965) has been retained since a saturated atmosphere at grid scale should not be unstable or moist beyond saturation. The parameterizations for deep and shallow cumulus do not preclude these conditions, which produce small amounts of precipitation relative to other sources.

The changes in entrainment coefficients for deep convective plumes, water-budget partitioning for deep convective systems, maximum heights for mesoscale circulations in deep convective systems, and lateral entrainment for shallow cumulus relative to Donner (1993) and Bretherton et al. (2004) account for implementation issues in AM3 and simulation deficiencies using the referenced values. The Donner entrainment coefficients for deep cumulus updrafts were selected to yield cumulus vertical velocities in agreement with observations on a finer vertical grid for the cumulus updrafts than is used in AM3. Among other simulation characteristics, shortwave cloud forcing is sensitive to the water budget partitioning for deep convective systems. Restricting the maximum height for mesoscale circulations in deep convective systems is necessary to prevent excessive water vapor in the stratosphere. Increasing the lateral entrainment in shallow cumulus limits excessive low cloudiness. The nondimensional constant $\gamma$ related to diffusion of horizontal momentum in convection has been changed from its value in Anderson et al. (2004), where its impacts on tropical precipitation and surface wind stresses are noted. As with the stratiform parameter settings discussed in section $3 \mathrm{~d}$, these changes resulted in improved realism in key aspects of the atmospheric circulation-for example, precipitation and implied ocean heat transports (important for coupling and, in turn, depending strongly on shortwave cloud forcing and surface wind stress).

These changes are within observational or conceptual constraints. As noted above, the entrainment coefficients in Donner (1993) were chosen based on observed vertical velocities within the framework of the onedimensional plume model used to represent updrafts in the cumulus parameterization. The coarser grid, used for computational efficiency in AM3, changes the relationship between entrainment coefficients and vertical velocities in the plumes and can be compensated for by changing the entrainment coefficients. Leary and Houze (1980), the basis for the moisture-partitioning parameters in Donner (1993), show these parameters to depend strongly on assumptions regarding the extent of mesoscale activity in deep convection. The extensive range in observed sizes of tropical cloud clusters suggests a wide range in the extent of mesoscale activity associated with deep convection and that the altered moisture-partitioning parameters remain within observational constraints. [Mapes and Houze (1993) report a range from under 2000 to $100000 \mathrm{~km}^{2}$.] The strong temperature inversions generally observed at the tropopause support restricting the maximum height of the convective mesoscale circulations not to exceed the local tropopause as a reasonable approximation to observed behavior. Lateral entrainment in shallow cumulus departs by only $10 \%$ from Bretherton et al. (2004), whose value was obtained from a large-eddy simulation based on a single observed case. The value of $\gamma$ in AM3 is 30\% higher than the upper range reported to be consistent with cloud models in Anderson et al. (2004). That range required assumptions regarding the vertical structure of the mean flow and the relationship between convective mass fluxes and rain rate, which can be relaxed to allow $\gamma$ to vary $30 \%$.

In the AM3 integration described in section 4a, deep convective cells dominate in the middle and upper troposphere in the tropics, but at pressures of 100 to $200 \mathrm{hPa}$ the mass fluxes in mesoscale updrafts are comparable to those in the cells (Fig. 1). Mesoscale downdrafts have the smallest mass fluxes among the convective components but can extend to the PBL where changes by these downdrafts in thermodynamic and moisture structure can impact surface fluxes. Shallow cumulus can coexist with deep convection and, although its vertical extent is not imposed, generally is confined below about $500 \mathrm{hPa}$. Deep convection can only occur when the level of zero buoyancy is at a pressure less than $500 \mathrm{hPa}$. Both are called from the same atmospheric state. In AM3, deep convective precipitation dominates in the tropics, while stratiform precipitation prevails in the middle latitudes (Fig. 2a). The small values of precipitation associated with MAA indicate that the other precipitation parameterizations generally preclude the development of oversaturated, unstable conditions. The midlatitude maxima in precipitation from the MAA coincide with the edges of the faces of the cubed-sphere in the dynamical core. Relative to precipitation reported by version 2 of the Global Precipitation Climatology Project (GPCP v.2) (Adler et al. 2003), AM3 produces $16 \%$ excessive precipitation. In CM3, described in section 4 , sea surface temperatures depart from the observed values specified in the AM3 integrations when AM3 is coupled to ocean and sea ice models, with appreciable effects on precipitation patterns (Fig. 2b). Most notably, a double intertropical convergence zone (ITCZ), not evident in GPCP v.2, is apparent. This double maxima occurs in all of the parameterized sources of precipitation, despite wide variations in the ways in which the occurrence of precipitation in these parameterizations is related to large-scale flows. The departure of CM3 precipitation patterns from AM3 patterns is typical when 
(a) Total Cumulus

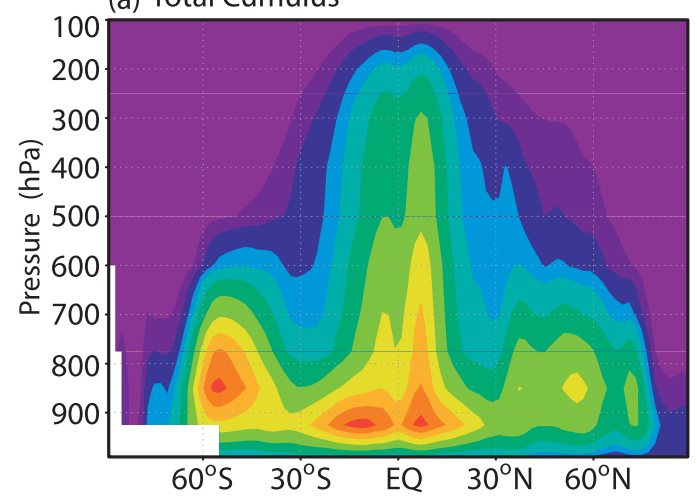

(b) Cell Updraft

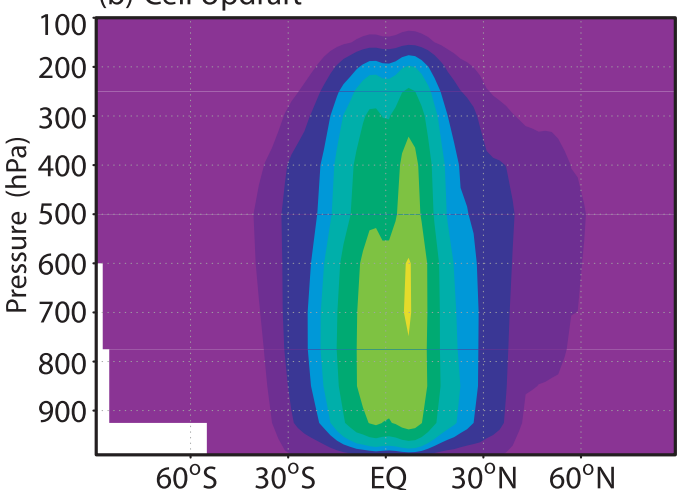

(c) Mesoscale Updraft

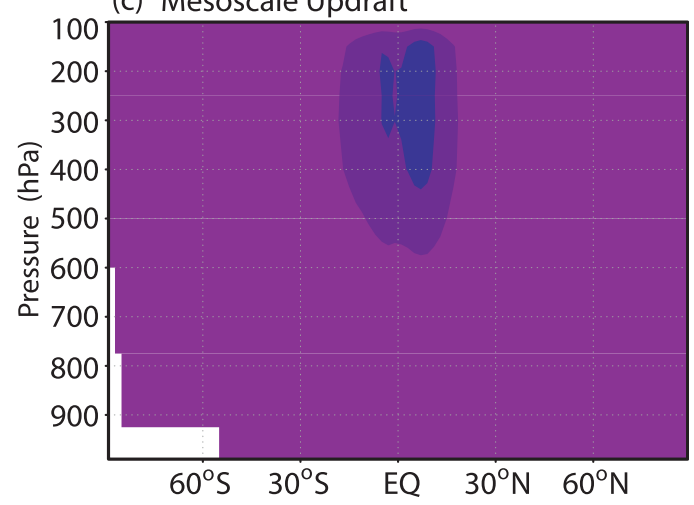

(d) Mesocale Downdraft

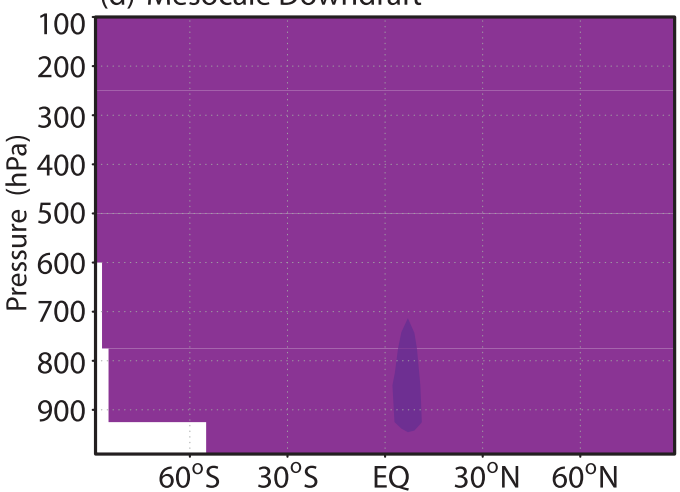

(e) Shallow Cumulus

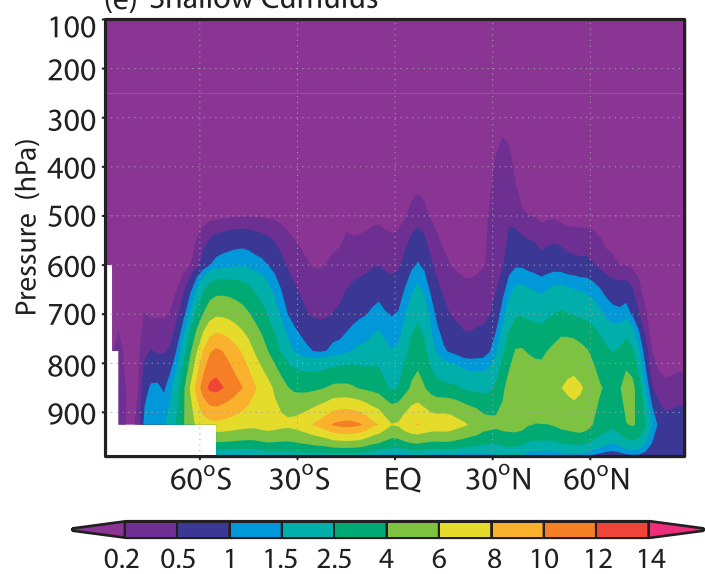

FIG. 1. AM3 annual-mean, zonally averaged cumulus mass fluxes $\left(\mathrm{g} \mathrm{m}^{-2} \mathrm{~s}^{-1}\right)$ for (a) all convection (except MAA),

(b) cell updrafts, (c) mesoscale updrafts, (d) mesoscale downdrafts, and (e) shallow cumulus.

coupling atmospheric and oceanic GCMs and is evidently a consequence of a chain of interactions between the ocean and atmosphere components (e.g., Zhang et al. 2007).

\section{f. Aerosols}

AM3 calculates the mass distribution and optical properties of aerosols based on their emission, chemical production, transport, and dry and wet removal. The transport processes include advection, convection, and eddy diffusion by turbulence. The chemical production of sulfate includes gas and aqueous-phase oxidation of sulfur dioxide by radicals, ozone, and hydrogen peroxide, which are calculated explicitly by the chemical mechanism described in section 3g. Dry deposition includes gravitational settling and impaction at the surface by turbulence. Wet deposition takes into account in- and 
(a) $\mathrm{AM} 3$

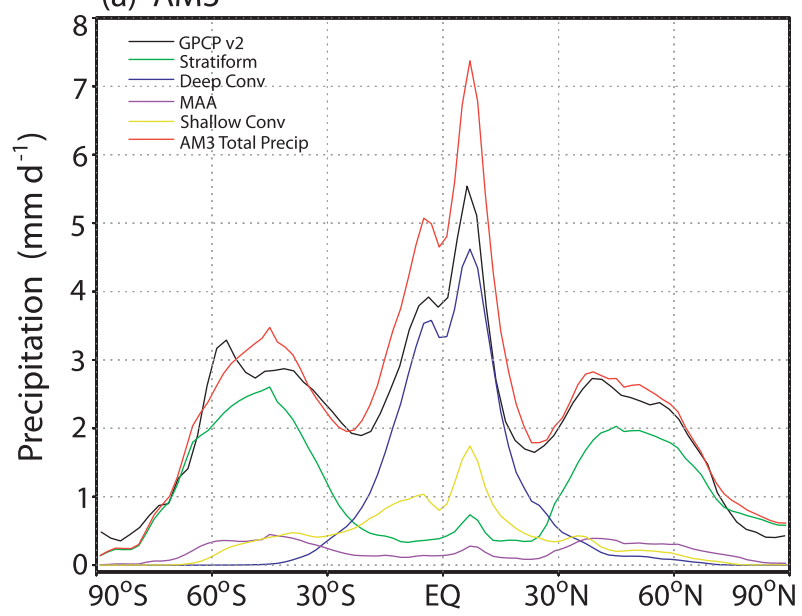

(b) $\mathrm{CM} 3$

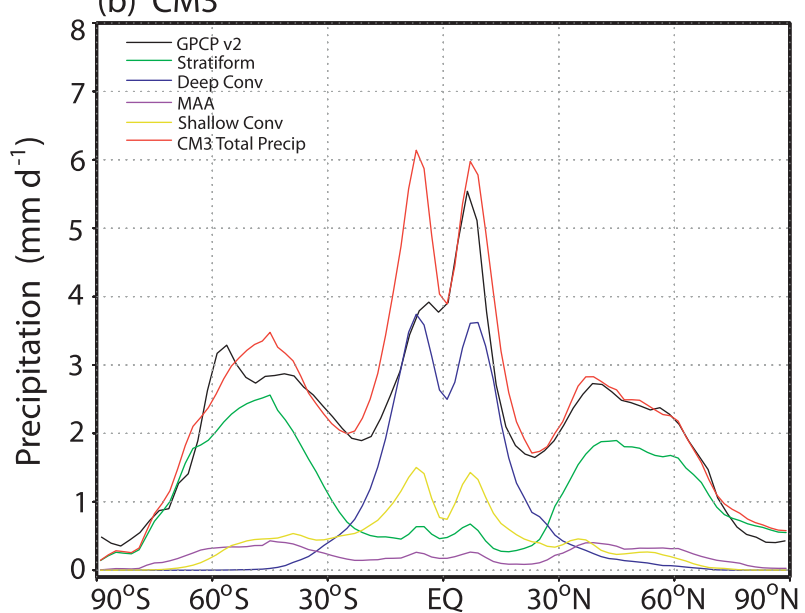

FIG. 2. Annual-mean, zonally averaged precipitation for (a) AM3 and (b) CM3.

below-cloud scavenging by large-scale and convective clouds.

Anthropogenic and biomass burning emissions of sulfur dioxide, black carbon, and organic carbon are from Lamarque et al. (2010). Dimethyl sulfide (DMS) emission is calculated using an empirical formula as a function of seawater DMS concentration and wind speed at $10 \mathrm{~m}$, as described by Chin et al. (2002).

Secondary organic aerosols are produced by terrestrial and oceanic sources. Terrestrial production includes natural and anthropogenic sources. The natural source includes oxidation of terpenes emitted from plants, which yields particulate organics (Dentener et al. 2006). The yield factor varies from 0.11 per molecule at latitudes lower than $20^{\circ}$ to 0.55 per molecule at the poles. The anthropogenic source follows Tie et al. (2005), where $10 \%$ of the butane oxidized by hydroxyl radicals becomes particulate organics. The oceanic source is the
O'Dowd et al. (2008) organic sea-spray source function. Anthropogenic and natural secondary organic aerosol production is 11.3 and $31.5 \mathrm{Tg} \mathrm{yr}^{-1}$, respectively.

Dust emission follows the parameterization by Ginoux et al. (2001) and is based on the preferential location of sources in topographic depressions. Sea salt particles are emitted from the ocean according to Monahan et al. (1986).

For volcanoes, time-invariant sulfur dioxide emissions are specified to be the total sulfur emissions recommended by AeroCom (Dentener et al. 2006) for continuous degassing and (time-averaged) explosive emissions, multiplied by a factor of 0.25 . These emissions are injected 500 to $1500 \mathrm{~m}$ above volcano tops for explosive emissions and over the upper third of volcanoes for continuously degassing volcanoes and are thus confined to the troposphere. The factor applied is justified by the need to scale the total sulfur emissions to include only sulfur dioxide emissions and to simulate realistic sulfur dioxide and sulfate abundances in otherwise clean regions with volcano sources, noting that considerable uncertainty exists in volcanic emissions. Owing to the absence of some chemical processes important for the formation of stratospheric volcanic aerosols, for example, related to carbonyl sulfide, and the absence of direct injection of volcanic aerosols into the stratosphere, a stratospheric signature for volcanoes is imposed through the specification of a time series of spatial distributions of optical properties, as noted in section $3 \mathrm{a}$.

Following Cooke et al. (1999), we assume that $80 \%$ of black carbon and $50 \%$ of organics emitted are hydrophobic, the rest being hydrophilic. Hydrophobic black carbon and organic aerosols undergo aging processes to become hydrophilic with $e$-folding times of 1.44 and 2.88 days, respectively. Secondary organic aerosols are treated as hydrophilic.

Chemical processes related to aerosol formation are discussed in section 3g. Aerosols are removed by dry deposition at the surface and scavenging in stratiform and convective clouds. Dry deposition velocities for aerosols are calculated interactively using a wind-driven resistance method in which the surface resistance is calculated as an empirical parameter (reflecting surface collection efficiency) divided by the friction velocity (Gallagher et al. 2002).

Cloud scavenging of aerosol species is calculated following Giorgi and Chameides (1985). The fractional removal rate is equal to its in-condensate fraction multiplied by the fractional removal rate of condensate by precipitation. For hydrophilic aerosols, an incondensate fraction (ranging from 0.07 for dust to 0.3 for sulfate in large-scale clouds, and from 0.12 for dust to 0.4 
for sulfate in convective clouds) is prescribed. These fractions qualitatively correspond to the relative solubilities and cloud drop nucleation properties of the aerosols, but the quantitative values are selected (globally) to provide a reasonable simulation of the global mean and regional patterns of aerosol optical depth (AOD). Below-cloud aerosol washout, for large-scale precipitation only, is parameterized as described by $\mathrm{Li}$ et al. (2008).

Interactive simulation of aerosols from emissions in CM3 is a major change in approach from CM2.1 (Delworth et al. 2006) in which aerosol concentrations were specified. AM3 uses different emissions inventories and optical properties than AM2. AM3 also includes internal mixing and couples wet deposition to cloud microphysics. A detailed evaluation of aerosol properties is beyond the scope of this paper. Here, two fundamental CM3 aerosol properties, aerosol optical depth and coalbedo (ratio of absorption optical depth to total optical depth), are compared with AERONET observations to show improved correlation relative to CM2.1. As analyzed in detail by Ginoux et al. (2006), the CM2.1 aerosol distribution tended to overestimate AOD in polluted regions, while underestimating biomass-burning AOD by a factor of 2 or more, relative to annual-mean AOD measured by AERONET sun photometers (Holben et al. 1998) (Figs. 3a and 3b). Ginoux et al. also indicate that sea-salt mass was largely underestimated but compensated in marine environments by excessive sulfate scattering. The best represented environment was in dusty regions. Figures $3 \mathrm{c}$ and $3 \mathrm{~d}$ show a reduction in these biases, particularly in biomass burning regions, but also in polluted regions. Note that the model results are averaged from 1981 to 2000, while most AERONET sun photometers began to operate in the mid-1990s or early twenty-first century. Since sulfur emission has decreased since the mid-1990s, simulated AOD values are likely higher than observed. The improved AOD simulation in AM3 is primarily due to changes in emissions and the treatment of optical properties. The treatments of chemistry, transport, and deposition are similar in AM2 and AM3, but differing large-scale and subgrid transports produce some AOD changes due to these also. Coalbedo measures aerosol absorption, and the model absorption has largely decreased from CM2.1 to CM3, agreeing much better with AERONET to generally within a factor of 2 at most stations (Fig. 4). This major change, which is particularly evident over regions of biomass burning, is due to several factors but primarily a decrease of black carbon emission. The decrease in black carbon emission, from $11 \mathrm{Tg} \mathrm{yr}^{-1}$ in AM2 (Horowitz 2006) to $8.2 \mathrm{Tg} \mathrm{yr}^{-1}$ in AM3, is partly compensated by increased absorption due to internal mixing of sulfate and black carbon. Unlike the direct measurement of AOD by sun photometers, coalbedo is retrieved by an inversion of Almucantar data (Dubovik and King 2000), and, to limit error of the retrieved values, only data with AOD greater than 0.45 are inverted. Thus, AERONET coalbedo is representative of heavily polluted, but not pristine, environments. Another bias to consider is that AERONET values are at $440 \mathrm{~nm}$ (blue), while the simulated aerosol properties are only archived at $550 \mathrm{~nm}$ (green). The subsequent bias will depend on the spectral variation of aerosol absorption. In biomass burning, smoke absorbs more in the green than the blue part of the solar spectrum, so the model coalbedo at $550 \mathrm{~nm}$ should be higher than at $440 \mathrm{~nm}$. In dusty environments, the opposite should be true. These biases may partially explain the persisting discrepancies in Figs. $4 \mathrm{c}$ and $4 \mathrm{~d}$ for CM3.

Clear-sky downward shortwave radiation in CM3 is generally larger in CM3 than CM2.1 and closer to observations from the Baseline Surface Radiation Network (BSRN; http://gewex-rfa.larc.nasa.gov) (Fig. 5). The increases in clear-sky downward shortwave radiation are due to reduced aerosol direct effects in CM3. Improved agreement of CM3 simulations of downward clear-sky surface shortwave radiation, optical depths, and coalbedo with BSRN and AERONET provides strong evidence that the direct effects of aerosols are more realistically simulated in CM3.

Aerosol activation into cloud droplets follows the parameterization detailed in Ming et al. (2006). Sulfate and sea salt aerosols are treated as pure ammonium sulfate and sodium chloride, respectively, in terms of cloud condensation nuclei (CCN) efficiency, while organic aerosol is partially soluble (Ming and Russell 2004). Black carbon is assumed to be insoluble and externally mixed with soluble species. Note that sulfate and black carbon are treated as an internal mixture for radiation calculation. The assumed size distribution of organic aerosol has two lognormal modes, which are characterized by the number concentrations $(N)$, median diameters $\left(D_{p}\right)$, and standard deviations $(\sigma)$. The specific parameters for organic aerosol are $N_{1}: N_{2}=17: 3$, $D_{p 1}=0.01 \mu \mathrm{m}, \sigma_{1}=1.6, D_{p 2}=0.15 \mu \mathrm{m}$, and $\sigma_{2}=2$. (The subscripts denote different modes.) Sea salt has one more mode to account for giant CCN $\left(N_{1}: N_{2}: N_{3}=\right.$ 340:60:0.75, $D_{p 1}=0.01 \mu \mathrm{m}, \sigma_{1}=1.6, D_{p 2}=0.15 \mu \mathrm{m}$, $\sigma_{2}=2, D_{p 3}=0.62 \mu \mathrm{m}$, and $\left.\sigma_{3}=2.7\right)$. The size distributions of organic and sea salt aerosols remain unchanged regardless of ambient conditions. Sulfate aerosol is assumed to have the same size distribution as organic aerosol (called distribution 1) if its concentration is above $0.3 \mu \mathrm{g} \mathrm{m}^{-3}$. In this case, most of the sulfate mass is in the accumulation mode $(0.1-1 \mu \mathrm{m})$. Otherwise, it is 
(a)

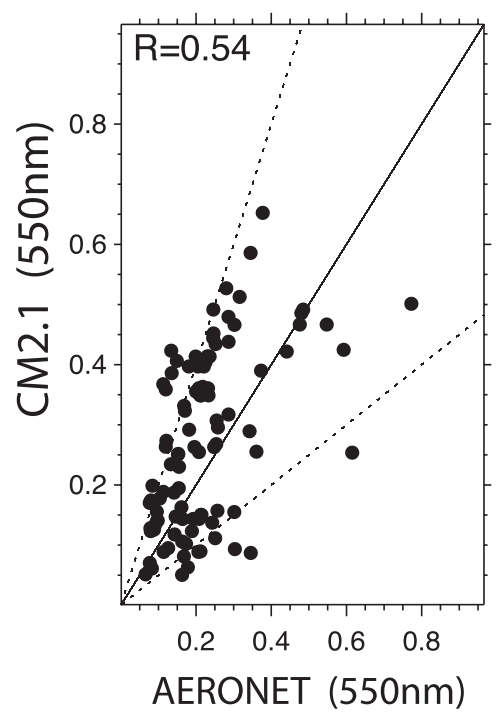

(c)

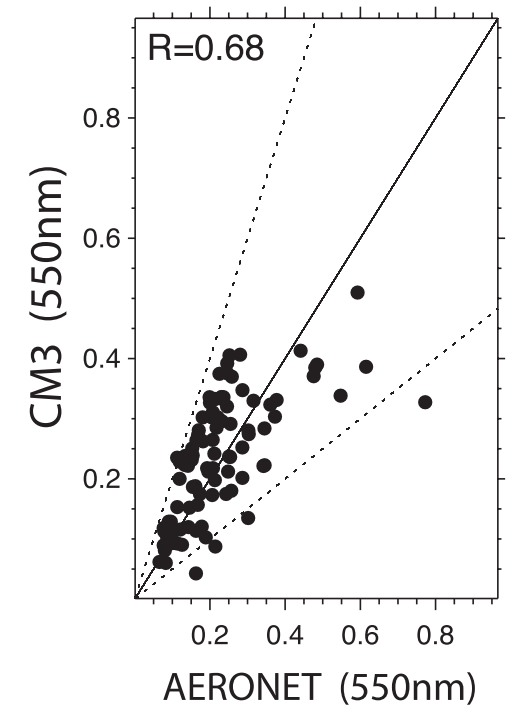

(b) Relative Difference $\frac{C M 2.1-\text { AERONET }}{\text { AERONET }}$
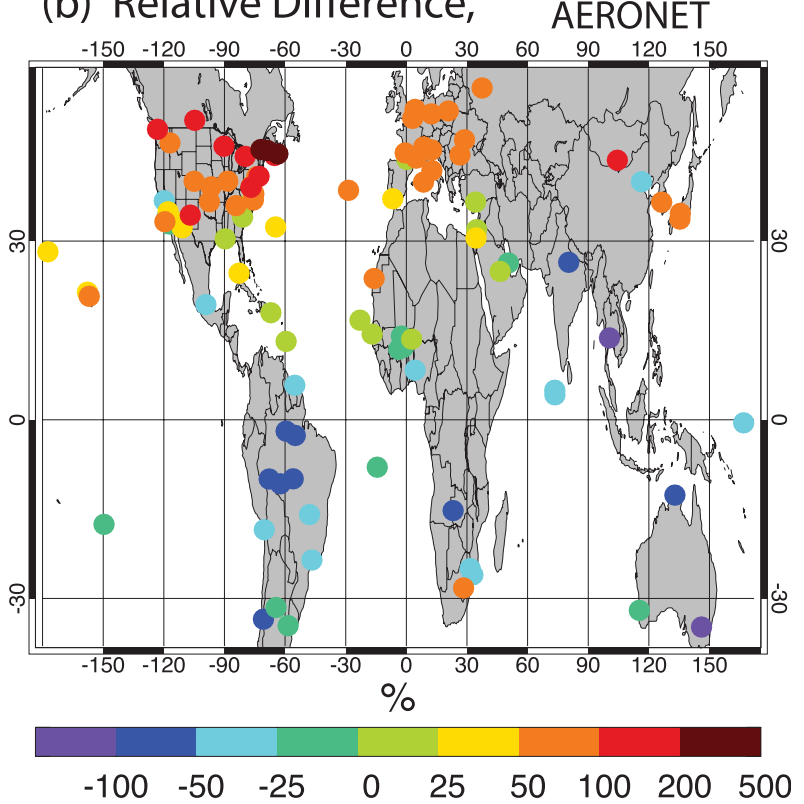

(d) Relative Difference, CM3-AERONET
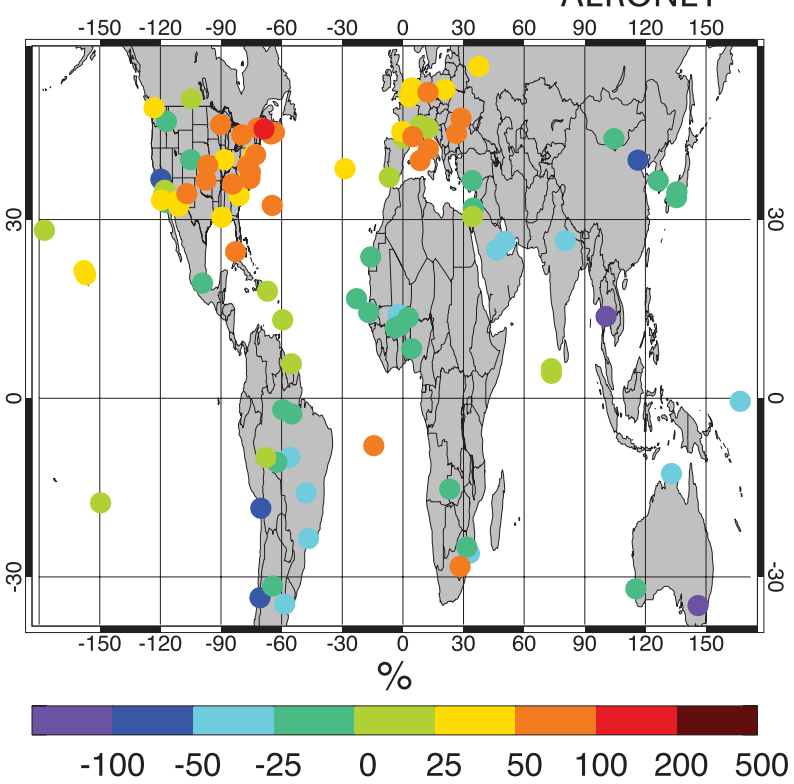

FIG. 3. Climatological aerosol optical depths (550 nm) from AERONET and (a),(b) CM2.1 and (c),(d) CM3. Dashed lines in (a) and (c) denote slopes of 0.5 and 2.

partitioned between distribution 1 and distribution 2, for which $N_{1}: N_{2}=17: 3, D_{p 1}=0.01 \mu \mathrm{m}, \sigma_{1}=1.6, D_{p 2}=$ $0.03 \mu \mathrm{m}$, and $\sigma_{2}=2$, depending on the abundance of primary aerosols (i.e., organics, sea salt, black carbon, and dust). The fraction of the sulfate mass in distribution 1 is 0 when the concentration of primary aerosols is less than $0.5 \mu \mathrm{g} \mathrm{m}^{-3}$ and increases linearly to 1 when it exceeds $1.0 \mu \mathrm{g} \mathrm{m}^{-3}$. Note that a considerable fraction of the mass in distribution 2 is in the nucleation mode (less than $0.1 \mu \mathrm{m}$ ). This choice is based upon the consideration that gas-to-particle conversion in polluted conditions occurs mainly through condensation onto preexisting particles, as opposed to nucleation.

Updraft velocities at cloud base and at the time of cloud formation are used to drive aerosol activation within shallow cumulus and stratiform clouds, respectively. Vertical 
(a)

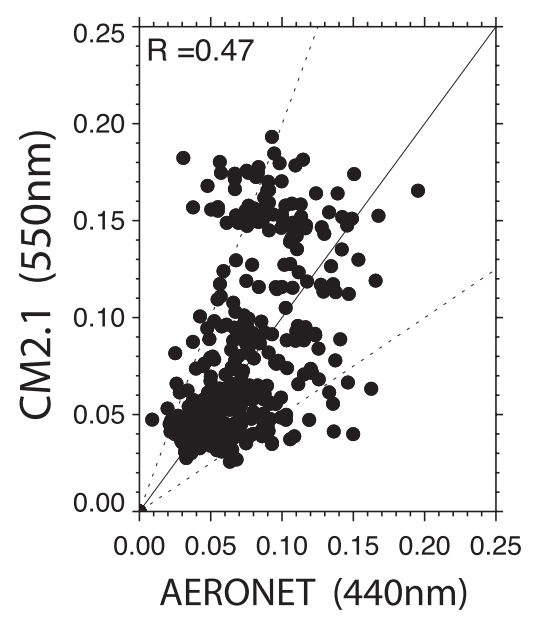

(c)

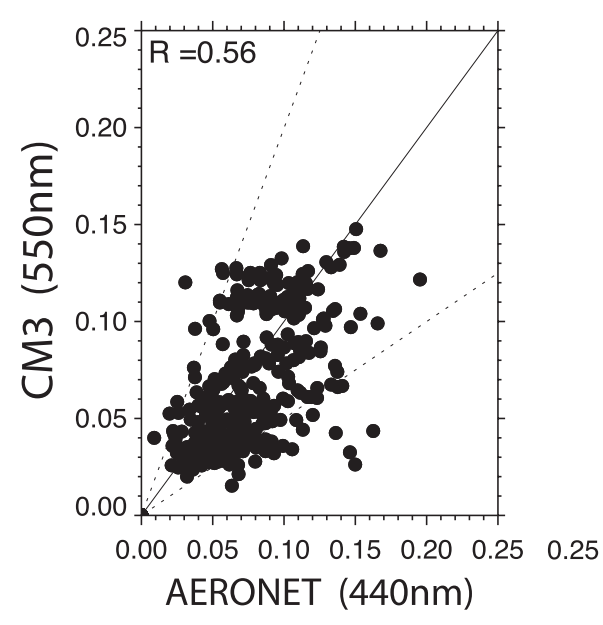

CM2.1 - AERONET

(b) Relative Difference, AERONET

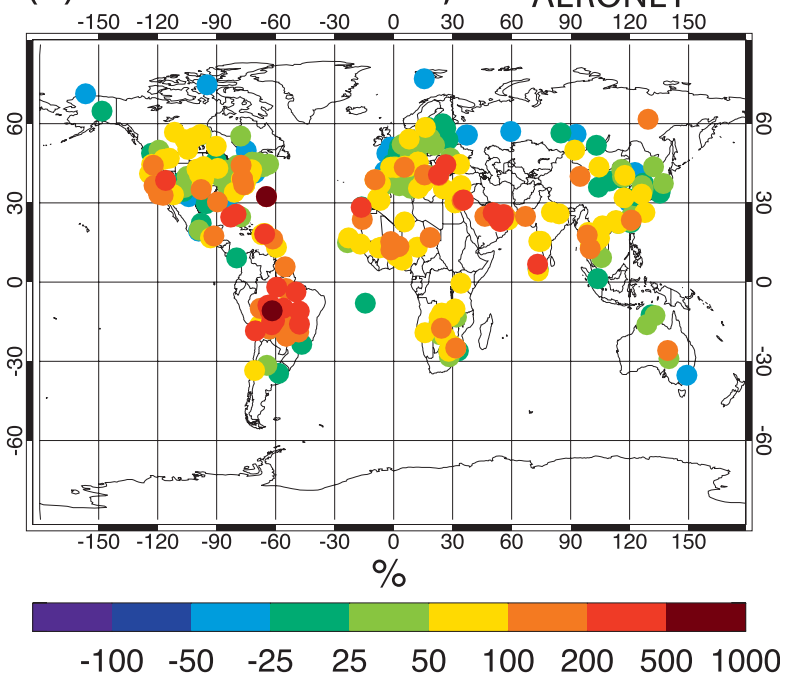

(d) Relative Difference, CM3 - AERONET

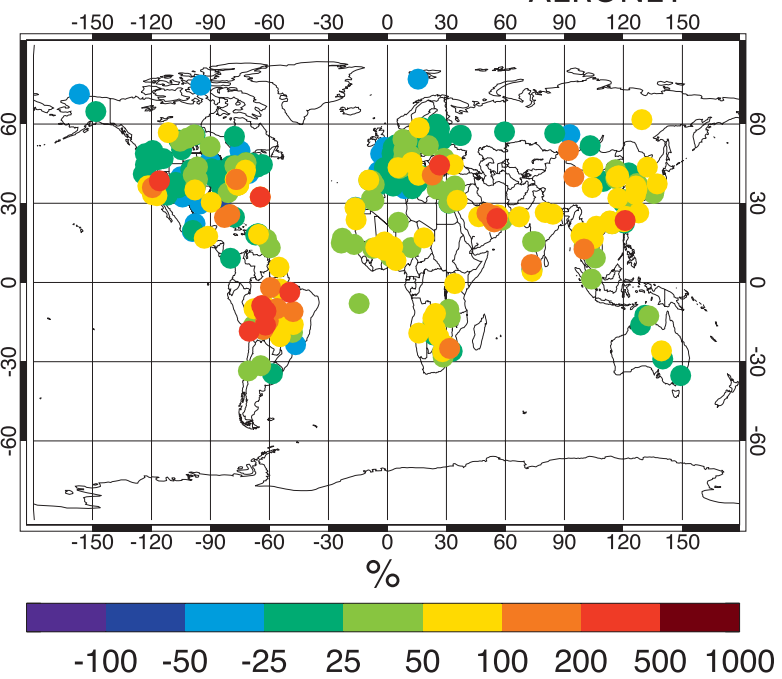

FIG. 4. Climatological aerosol coalbedos from AERONET (440 nm) and (a),(b) CM2.1 and (c),(d) CM3 (550 nm). Dashed lines in (a) and (c) denote slopes of 0.5 and 2.

velocities for shallow cumulus are provided directly by the Bretherton et al. (2004) shallow cumulus parameterization. The procedure for generating the probability distribution functions for updraft velocities in stratiform clouds is described in section 3d. Due to the absence of ice nucleation and limited treatment of microphysics generally in deep convection (in which substantial vertical accelerations can occur well above cloud base, leading to activation above cloud base), aerosol activation is not treated in deep convection. The consequences of this omission are not clear, and the matter is a high priority for future research.
A major motivation for including aerosol activation in AM3 is to enable simulation of cloud droplet sizes, which in turn partially determine the radiative and macrophysical properties of clouds, that is, aerosol indirect effects. Droplet sizes have been evaluated using a simple simulator for the Moderate Resolution Imaging Spectroradiometer (MODIS; King et al. 2003) satellite. For every subgrid column generated with the stochastic cloud scheme of Pincus et al. (2005) and Pincus et al. (2006) (cf. section 3a above), the radii for these liquid cloud layers in the top two units of cloud optical depth are averaged to produce a MODIS-like cloud-top radius. 
(a)

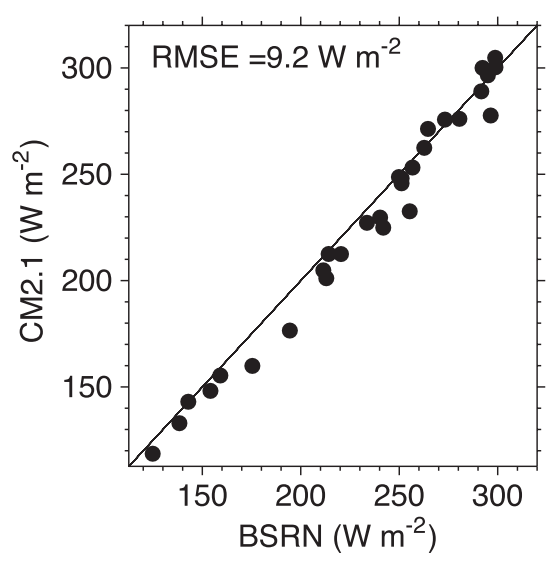

(c)

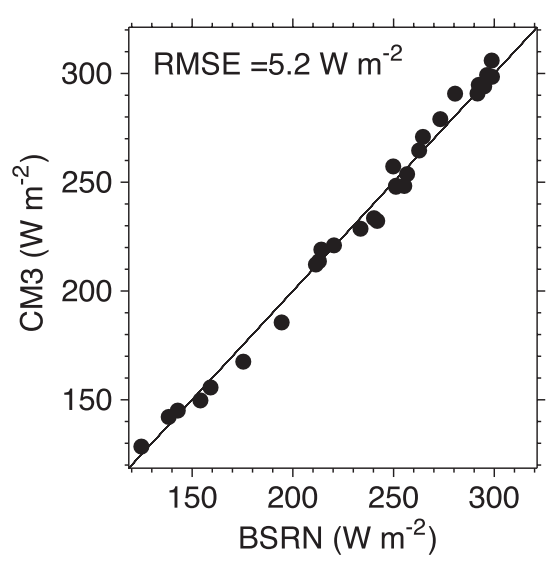

(b) Difference, CM2.1-BSRN

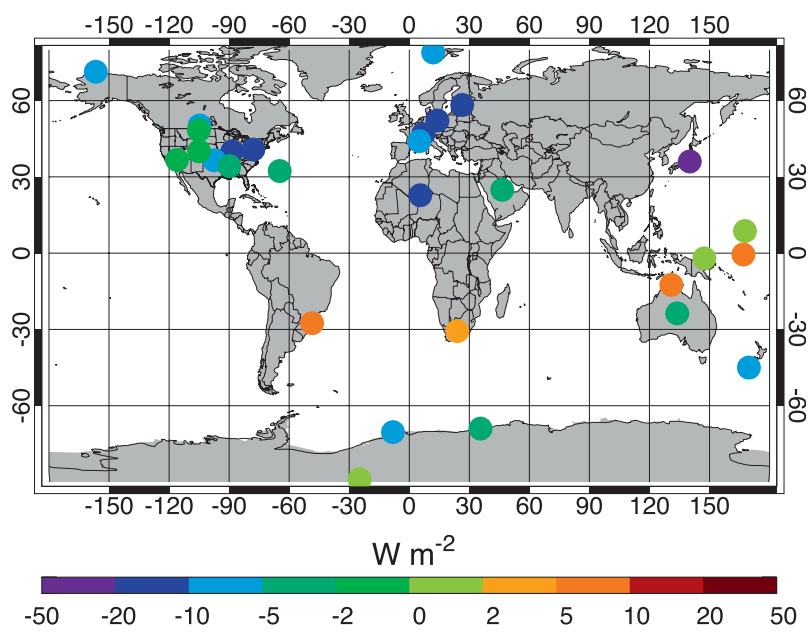

(d) Difference, CM3-BSRN

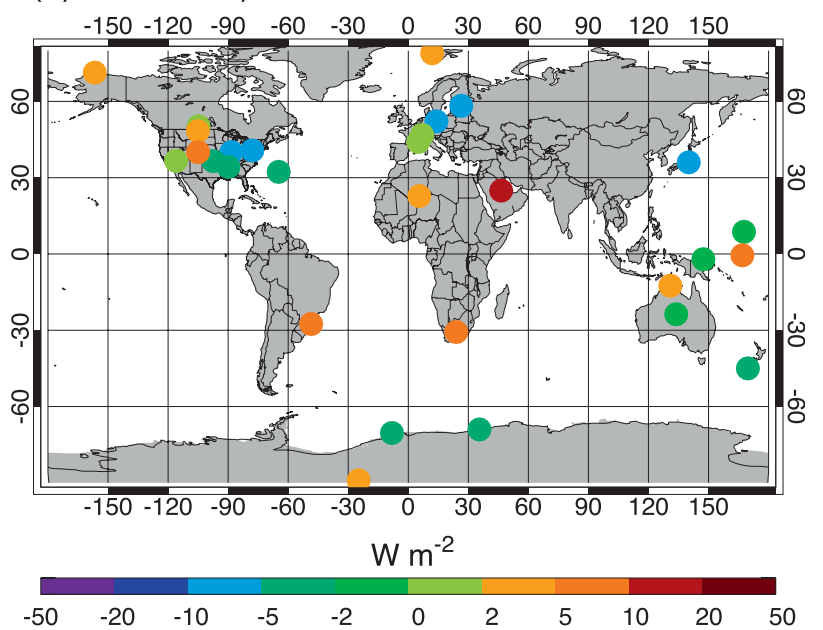

FIG. 5. Surface clear-sky downward shortwave fluxes from BSRN and (a) CM2.1 and (c) CM3, and differences in these fluxes for (b) CM2.1 minus BSRN and (d) CM3 minus BSRN. Model fluxes are obtained from the clear-sky radiative transfer code at all grid points and times (regardless of cloud characteristics), providing consistent sampling with respect to seasonal and diurnal cycles in CM2.1 and CM3.

All cloudy subgrid columns are given equal weight in calculating the grid-mean radius.

Many general patterns from MODIS (collection 5) are captured in AM3, including increases in droplet sizes in the oceans off the east coasts of most continents and the January-to-July decrease in droplet sizes over subtropical South America and Africa (Fig. 6). The amplitudes of the changes are generally smaller in AM3 than in MODIS and the locations of maxima and minima differ between AM3 and MODIS, however. Satellite retrievals are themselves uncertain, and MODIS drop sizes are much larger than estimates from other retrievals (e.g., Han et al. 1994).

\section{g. Tropospheric and stratospheric chemistry}

In AM3, the chemistry models of Horowitz et al. (2003) for the troposphere and Austin and Wilson (2006) for the stratosphere are merged. The chemical system is solved using a fully implicit Euler backward method with Newton-Raphson iteration, as in Horowitz et al. (2003). Merging the two models consisted mainly of augmenting the tropospheric model with species (including halogens and atomic hydrogen) and reactions, primarily gas-phase halogen reactions, stratospheric and mesospheric photolysis reactions, and heterogeneous reactions on stratospheric aerosols. Reaction rates follow 

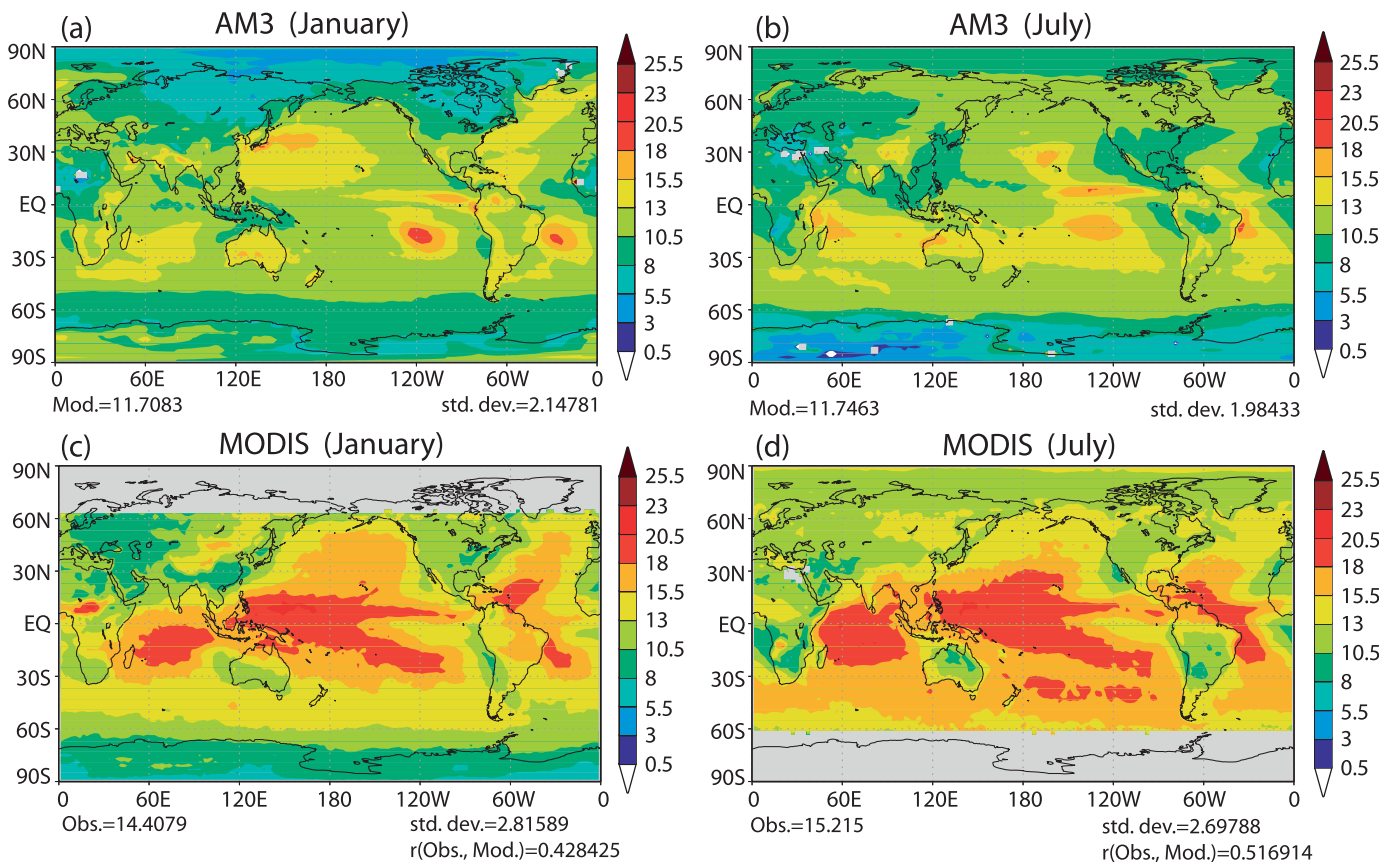

FIG. 6. Cloud-drop radius ( $\mu \mathrm{m})$ (a),(b) from MODIS simulator in AM3 and (c),(d) from MODIS for (a),(c) January and (b),(d) July.

recommendations from Sander et al. (2006). The oxidation of sulfur dioxide and dimethyl sulfide to form sulfate aerosol is fully coupled with the gas-phase chemistry. Clear-sky photolysis frequencies are calculated using a multivariate interpolation table derived from the tropospheric ultraviolet-visible radiation model (Madronich and Flocke 1998) with an adjustment applied for the effects of large-scale clouds, as described by Brasseur et al. (1998).

Monthly mean dry-deposition velocities for gas-phase species [except for ozone and peroxyacetyl nitrate (PAN)] are from Horowitz et al. (2003) and were calculated offline using resistance in series (Wesely 1989; Hess et al. 2000). Deposition velocities for ozone were taken from Bey et al. (2001) and those for PAN from a Model for Ozone and Related Chemical Tracers, version 4 (MOZART-4) simulation in which it was calculated interactively to reflect the updates described by Emmons et al. (2010).

Cloud scavenging of gas-phase species is treated as for aerosols (section 3f), except that the in-condensate fraction is determined by Henry's law equilibrium. Below-cloud washout is calculated only for large-scale precipitation, is based on Henry's law, as in Brasseur et al. (1998), and is assumed to operate over the full extent of the below-cloud grid cells.

Calculating the stratospheric sources of reactive chlorine and bromine directly by transporting and photolyzing source gases (CFCs and halons) is computationally expensive and sensitive to any circulation biases in the model.
Thus, we parameterize the source of reactive chlorine and bromine as a function of tropospheric concentrations of source gases (lagged by the stratospheric "age of air"), as described in appendix A of Austin and Wilson (2010). The parameterization uses observed source gas distributions to estimate, essentially, the fractional rate at which source gases entering the stratosphere are photolyzed and converted into reactive halogen species along their transport path through the stratosphere. Also as described in Austin and Wilson, heterogeneous reactions are included on ice and nitric acid trihydrate polar stratospheric clouds (PSCs) and in liquid ternary solution (LTS) aerosols. The PSCs are taken to be in thermodynamic equilibrium with the local conditions and calculated as in Hanson and Mauersberger (1988). The reaction rates in LTS are treated as in Carslaw et al. (1995). Mass accommodation coefficients and reaction probabilities are taken from Sander et al. (2006).

Compared to the observed climatology developed by Atmospheric Chemistry and Climate (AC\&C)/ Stratospheric Processes and their Role in Climate (SPARC) for CMIP5, following Randel and Wu (2007), general features of the annual-mean, zonally averaged ozone for the period 1980-99 are well reproduced (Fig. 7). The tropical peak in ozone mixing ratios is correctly simulated to occur near $10 \mathrm{hPa}$, but is overestimated by more than $10 \%$. Ozone at high latitudes is underestimated compared with the observations, likely resulting from a deficiency in model transport. The seasonal variation of total column ozone (Fig. 8) is very 
(a) $\mathrm{AM} 3$

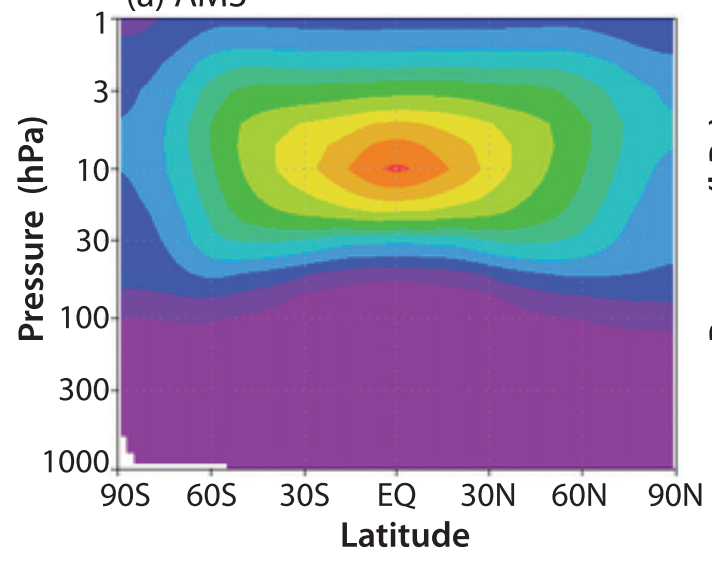

(b) CMIP5

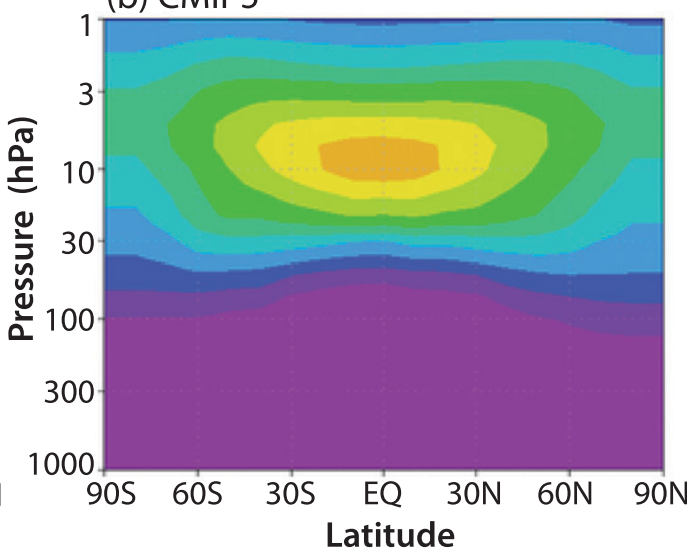

$\begin{array}{llllllllllll}1 & 2 & 3 & 4 & 5 & 6 & 7 & 8 & 9 & 10 & 11 & 12\end{array}$

FIG. 7. Annual-mean, zonally averaged ozone volume mixing ratio (ppmv) from (a) AM3 and (b) AC\&C/SPARC observational climatology for CMIP5 (http://www.pa.op.dlr.de/CCMVal/AC\&CSPARC_O3Database_CMIP5. html).

similar to values retrieved by the Total Ozone Mapping Spectrometer (TOMS) (Stolarski and Frith 2006) for the decades of the 1980s and 1990s. In the 1980s, before significant ozone destruction, the model shows low tropical ozone, consistent with observations throughout the year. In middle and high latitudes, the annual variation is well reproduced, but the column ozone amounts are biased low in high northern latitudes, reflecting the bias shown in Fig. 7. In the Southern Hemisphere, the peak column amounts in austral spring near $60^{\circ} \mathrm{S}$ are simulated to be larger than observed. Similar features are also present in the 1990s. Note that the excessive column ozone at $60^{\circ} \mathrm{S}$ (with respect to TOMS) occurs despite the underestimate of peak ozone mixing ratios near $5 \mathrm{hPa}$ at this latitude (with respect to the AC\&C/ SPARC climatology). This apparent discrepancy results from overestimate of ozone by AM3 compared with AC\&C/SPARC in the lower stratosphere (30-100 hPa), where most of the ozone column resides. The simulated ozone hole is deeper than observed and lasts longer into (austral) summer, although it is smaller in physical area. In the annual mean, the biases are generally small (Fig. $8 \mathrm{e})$, under $5 \%$, but are larger in the Southern Hemisphere and dominated by the spring period indicated above.

Chemistry was not calculated online in AM2. Instead, decadally varying monthly mean tropospheric ozone concentrations (and aerosol concentrations; see section 3f) were prescribed in $\mathrm{AM} 2$ on the basis of calculations using the MOZART chemical transport model driven with present-day climatological meteorology, as described by Horowitz (2006). MOZART was configured with the gas-phase chemical mechanism of Horowitz et al. (2003), the sulfate and carbonaceous aerosol mechanism of Tie et al. (2005), and the mineral dust scheme of Ginoux et al. (2001). Stratospheric concentrations of ozone in MOZART were constrained by relaxation to present-day climatological values [as described by Horowitz et al. (2003)]. Stratospheric ozone concentrations in AM2 were prescribed following Randel and Wu (1999).

\section{Basic simulation characteristics}

\section{a. Boundary conditions and integrations}

AM3 and the land model were integrated with prescribed sea surface temperatures, sea ice coverage, and sea ice albedo to demonstrate their behavior with realistic boundary conditions. These integrations will be contrasted in this section with observations and with simulations in which AM3 served as the atmospheric component of CM3.

Observed sea surface temperatures and sea ice for the uncoupled integrations are from Rayner et al. (2003). Except as noted below, the period of integration is 1980 to 2000, with averages taken from 1981 to 2000. Initial conditions for the atmospheric model are drawn from the AM3 developmental integrations.

For the coupled integrations, CM3 was spun up for several centuries with 1860 trace gas concentrations and emissions, as described in sections 3a and 3f. During the 1860 spinup, solar irradiance was held constant at 1860 values (no solar cycle). Following the spinup, 


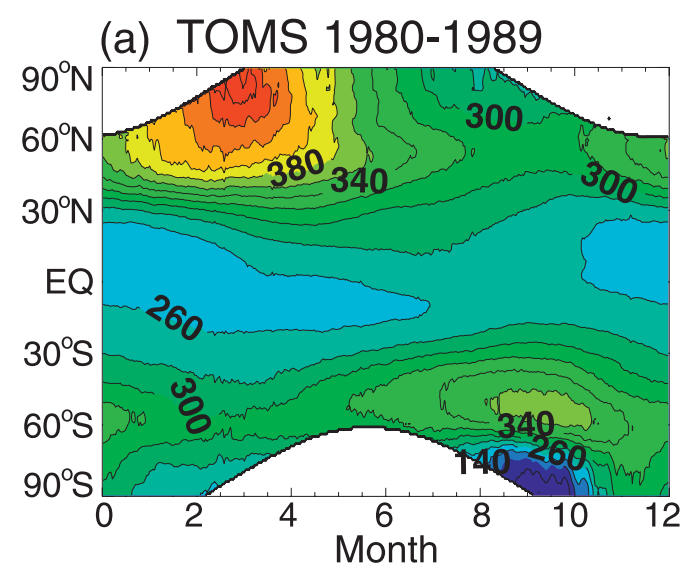

(c) TOMS 1990-1999

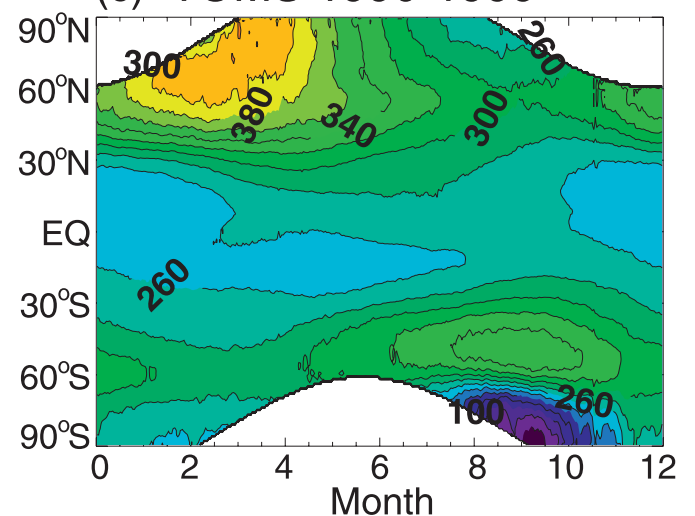

(b) AM3 1980-1989

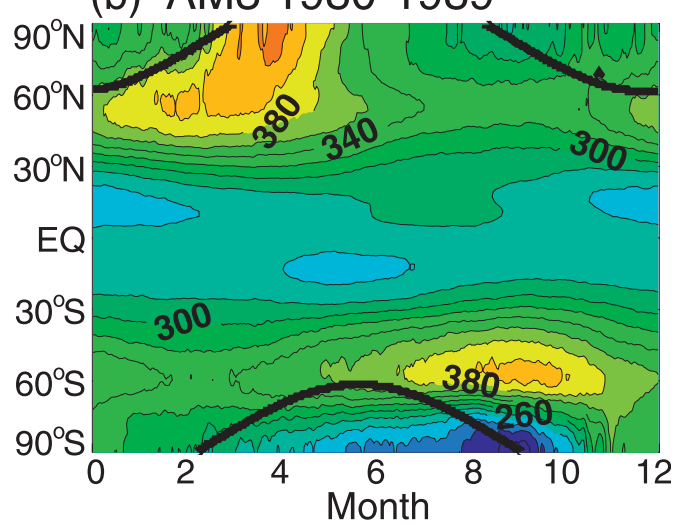

(d) AM3 1990-1999

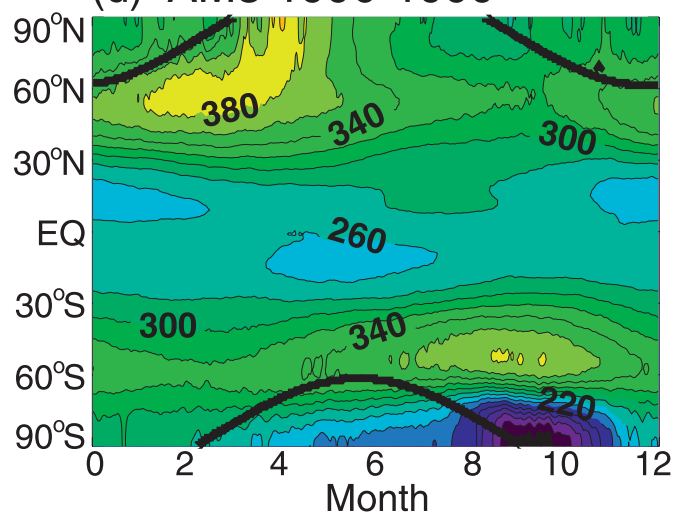

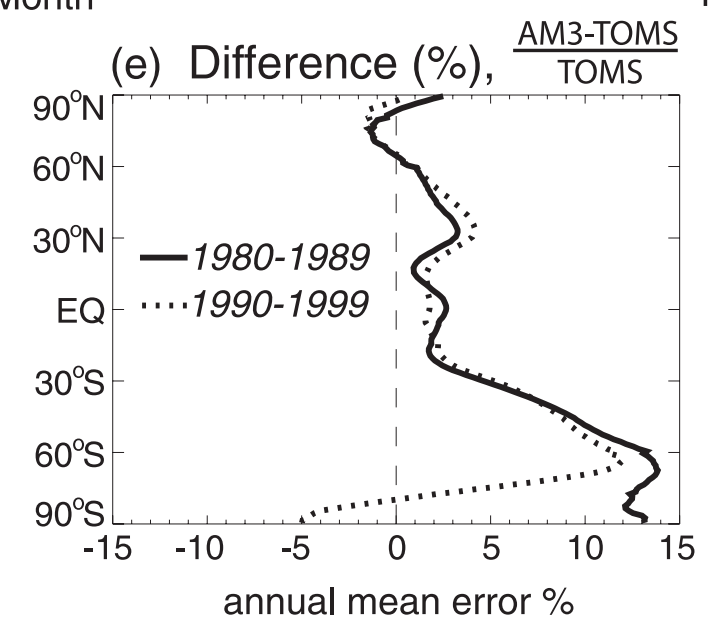

FIG. 8. Vertically integrated, zonally averaged ozone (Dobson units) for (a),(b) 1980-89 and (c),(d) 1990-99 from (a),(c) TOMS and (b),(d) AM3. (e) Annual-mean difference between AM3 and TOMS vertically integrated, zonally averaged ozone.

time-varying trace gas concentrations and emissions were imposed over the period 1860-2005. During the 1860-2005 simulation, solar irradiance varied following the observational time series recommended by CMIP5, as described by Fröhlich and Lean (2004). (As mentioned in section $3 \mathrm{a}$, the solar irradiance has been scaled uniformly to correspond to the TIM scale, as recommended by CMIP5.) Anthropogenic aerosols (through both direct and indirect effects) and trace gases force the climate between 1860 and 2000. The CM3 global-mean temperature (for a five-member ensemble) increases by $0.32^{\circ} \mathrm{C}$ from the $1881-1920$ period to the $1981-2000$ 
(a)

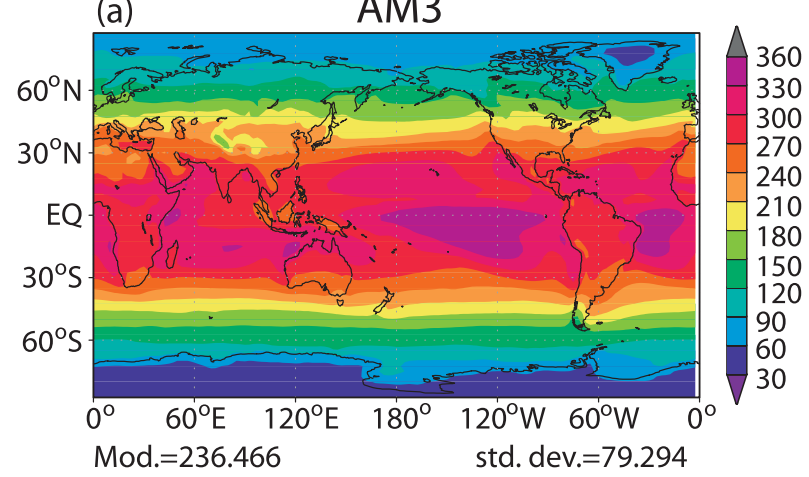

(b)

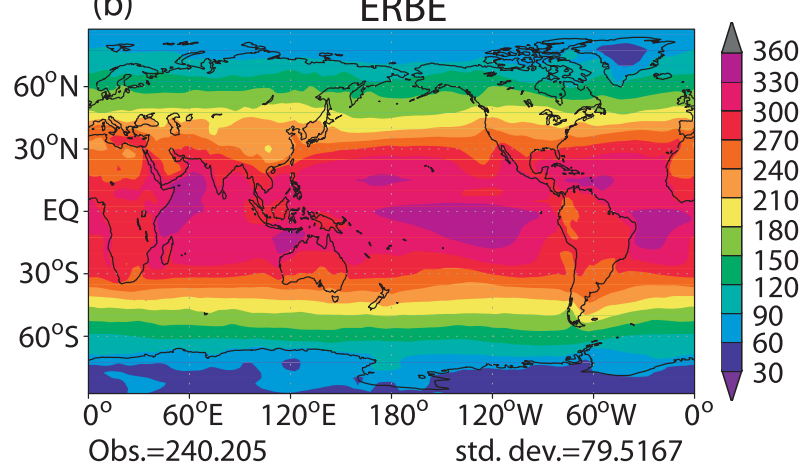

(c)

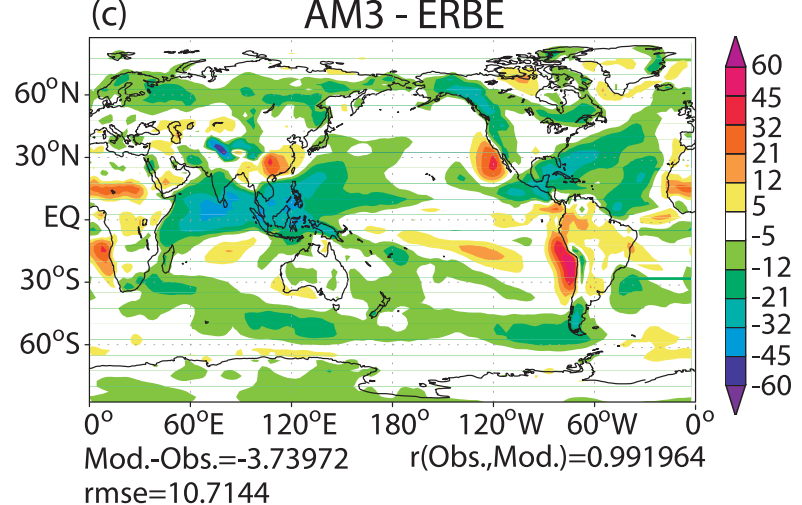

$=10.7144$

(d)

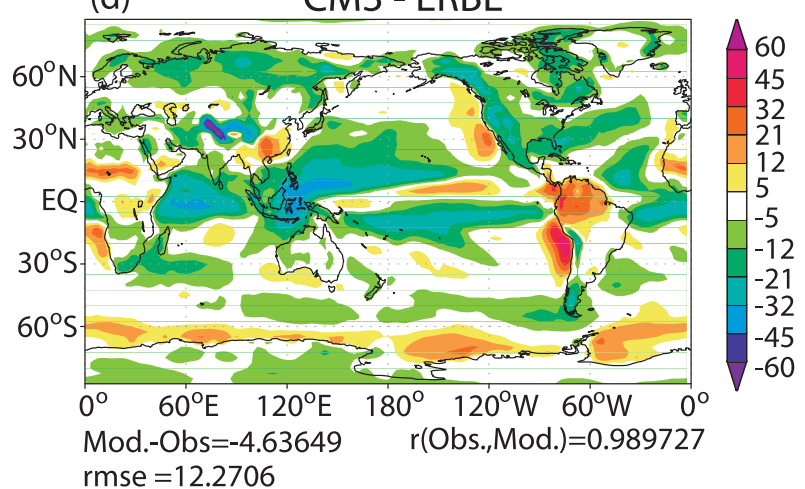

FIG. 9. Annual-mean shortwave absorbed radiation $\left(\mathrm{W} \mathrm{m}^{-2}\right)$ for (a) AM3, (b) ERBE, (c) AM3 minus ERBE, and (d) CM3 minus ERBE. period. The corresponding increases in the Climate Research Unit (CRU) observations (Brohan et al. 2006), Goddard Institute for Space Studies (GISS) observations (http://data.giss.nasa.gov/gistemp/tabledata/ GLB.Ts + dSST.txt), and a five-member CM2.1 ensemble (Knutson et al. 2006) are $0.56^{\circ}, 0.52^{\circ}$, and $0.66^{\circ} \mathrm{C}$, respectively. Observed warming is intermediate between the CM2.1 and CM3 warming. In the following sections, CM3 analyses are restricted to 1981-2000 averages. Considerable interensemble variability is likely at higher time resolution.

\section{b. Radiation and surface fluxes}

Annual-mean shortwave absorption by the earthatmosphere system in AM3 and the Earth Radiation Budget Experiment (ERBE) (Harrison et al. 1990) (Fig. 9) agree within $5 \mathrm{~W} \mathrm{~m}^{-2}$ over most of North America, the central Pacific Ocean, and southern Europe. AM3 exhibits negative biases in the tropical Indian and western Pacific Oceans, where excessive cloudiness and precipitation occur. Positive biases characterize the oceans off the subtropical west coasts of Africa, South America, and North America where marine stratocumulus is inadequate. Problematic marine stratocumulus persists from AM2 (Anderson et al. 2004), perhaps not surprisingly, given that the parameterizations for boundary layers and cloud macrophysics have not been changed in ways expected to remedy this deficiency. The marine stratocumulus biases are slightly smaller in the $\mathrm{CM} 3$ integrations than the AM3 integrations, suggesting a response to a small change in SSTs. Simultaneously, negative biases in the tropical oceans, consistent with a double ITCZ, emerge in the CM3 integration. A positive bias over the Amazon, consistent with insufficient convection, is considerably more apparent in the CM3 integration than in the AM3 integration. Positive biases exceeding $12 \mathrm{~W} \mathrm{~m}^{-2}$ between about $60^{\circ} \mathrm{S}$ and Antarctica are evident in CM3 but not AM3. The behavior of the corresponding fields for outgoing longwave radiation (OLR) is consistent with the shortwave changes (Fig. 10). In particular, the AM3 OLR exhibits negative biases in the tropical Indian Ocean and west Pacific where excessive high cloudiness occurs in association with deep convection (Fig. 10c). The double ITCZ in CM3 is evident in the splitting of the negative tropical OLR bias in the Pacific Ocean, separated by a zone of positive bias (Fig. 10d). The positive OLR bias over the Amazon in CM3 results from insufficient high cloudiness and convection (Fig. 10d).

To present a statistical summary of the radiation balances in AM3 and CM3, Taylor diagrams (Gates et al. 1999; Taylor 2001) (Fig. 11) are constructed using ERBE observations from 1985-89 (Harrison et al. 1990) 
(a)

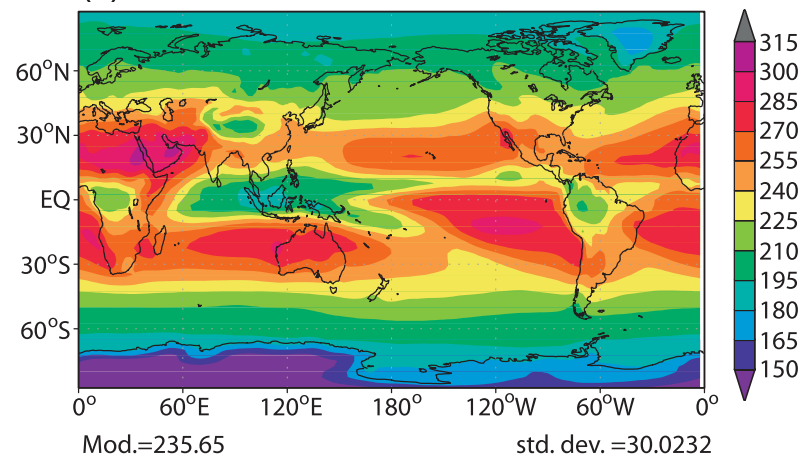

(b)

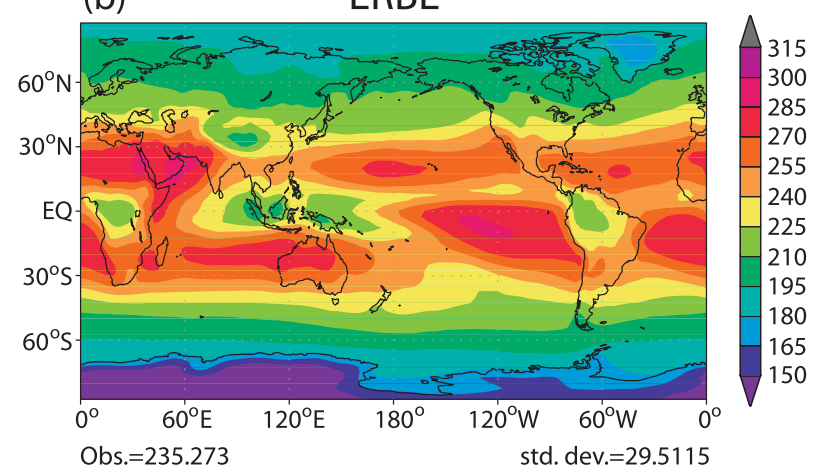

(c)

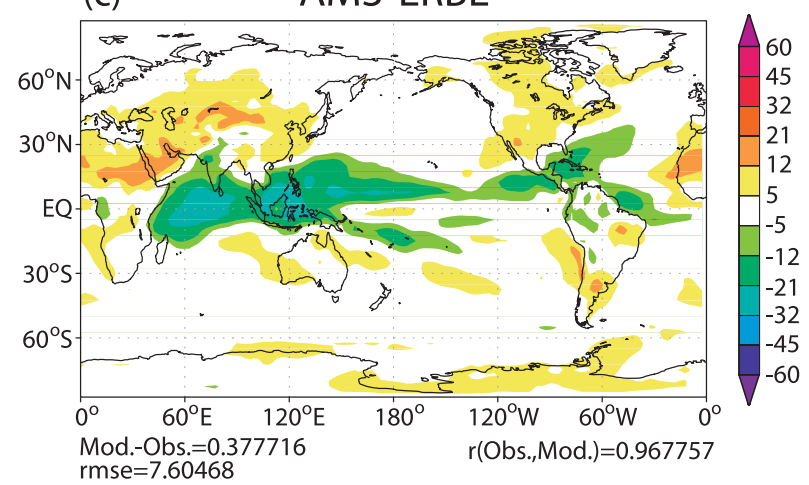

(d)

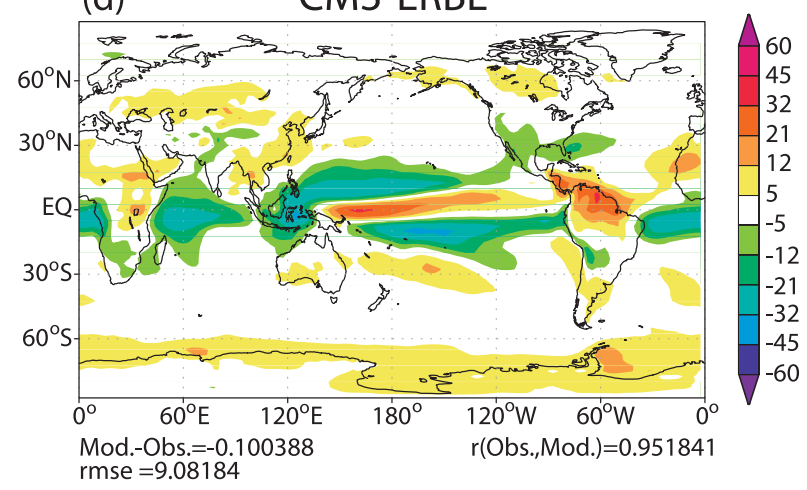

FIG. 10. As in Fig. 9 but for annual-mean outgoing longwave radiation for (a) AM3, (b) ERBE, (c) AM3 minus ERBE, and (d) CM3 minus ERBE. and observations from the Clouds and the Earth's Radiant Energy System (CERES) satellites from 2000-05. The CERES observations are analyzed in several ways: CERES-ES4-ERBE-like, CERES-SRB-GEO, CERESSRB-nonGEO (Wielicki et al. 1996), and CERESEnergy Balanced and Filled (EBAF) (Loeb et al. 2009). (Observations are available online at http://eosweb.larc. nasa.gov/PRODOCS/ceres/table_ceres.html). Shortwave and net radiation have similar root-mean-square (rms) errors and correlation relative to observations for both AM3 and CM3. ERBE and CERES observations differ by about as much as the modeled results do from the CERES results, and the various CERES analyses differ little among themselves. AM3 and CM3 OLR rms differences from ERBE are two to three times larger than those of shortwave and net radiation. Note that the rms differences in Fig. 11 are normalized by the standard deviation of the ERBE observations and that the ERBE shortwave standard deviation is also two to three times larger than that of the ERBE OLR. The spread among the CERES observations themselves is somewhat greater for shortwave and longwave cloud forcing (Figs. 11d,e) than for shortwave absorption and OLR, as are the differences between ERBE and CERES observations. AM3 and CM3 differ more between themselves than they did for OLR and shortwave absorption, consistent with the cloud differences between AM3 and CM3 evident in Figs. 9c,d and 10c,d, for example, in the ITCZ and regions of marine stratocumulus. Pincus et al. (2008) note that cloud forcing is a more difficult field for models to simulate than total fluxes, which are to an appreciable extent controlled by the geometry of solar insolation. In that light, it is noteworthy that shortwave cloud forcing in AM3 compares more favorably with ERBE and CERES than AM2 (Fig. 11d). Correlations and rms differences between both atmospheric models and observations are comparable for longwave cloud forcing, but AM3 has more spatial variability than observed, while AM2 has less.

AM3 and CM3 include the Cloud Feedback Model Intercomparison Project's Observation Simulator Package (COSP; http://cfmip.metoffice.com/). Among its components, the package includes simulators for the Cloud-Aerosol Lidar and Infrared Pathfinder Satellite Observations (CALIPSO) satellite lidar (Chepfer et al. 2008) and CloudSat radar (Bodas-Salcedo et al. 2008), which permit comparison of model cloud fields to the vertical structure of clouds provided by these new instruments. As an example, CALIPSO observations of cloud fraction for January 2007 (Chepfer et al. 2010) and the simulated cloud fractions from AM3 show broad qualitative agreement, while showing biases consistent with other fields sensitive to cloudiness (Fig. 12). For 

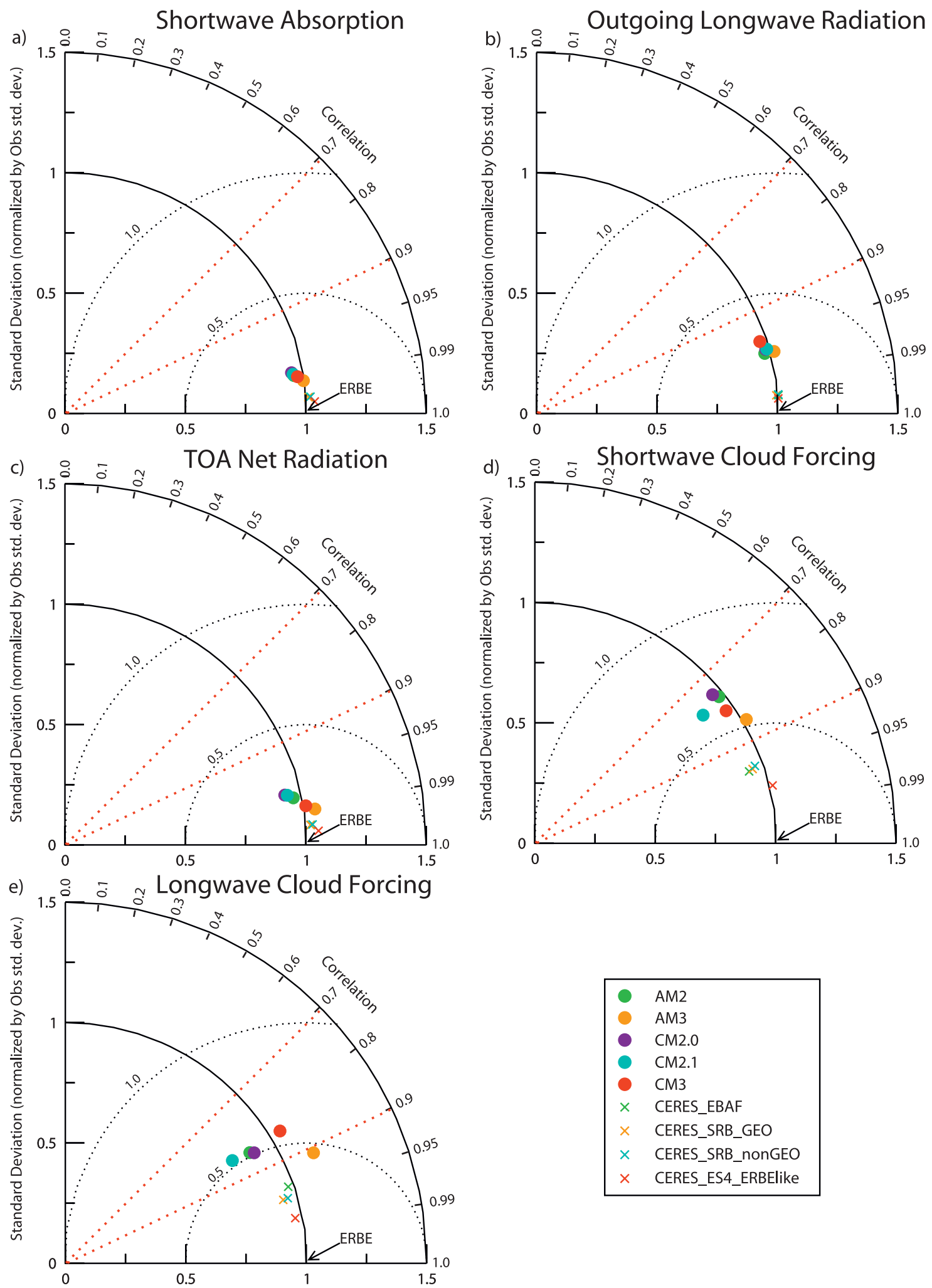

Dotted arcs: RMS error; Solid arcs: standard deviation (both normalized by obs standard deviation)

FIG. 11. Taylor diagrams for top-of-atmosphere (TOA) radiation balance. The rms errors, correlations, and standard deviations are based on global, annual means. 
(a) AM3 CALIPSO Simulator
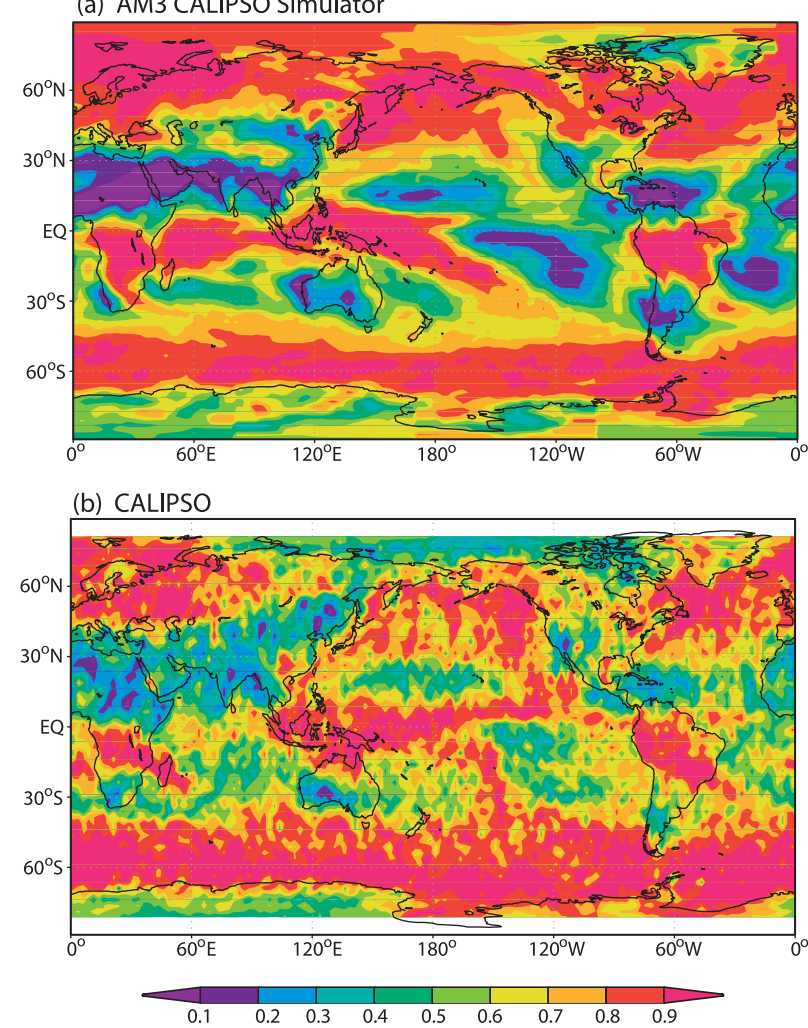

FIG. 12. January 2007 cloud fractions from (a) the AM3 CALIPSO simulator and (b) CALIPSO.

example, AM3 simulates smaller cloud fractions than CALIPSO observes off the west subtropical coasts of North America, South America, and Africa, consistent with positive ERBE shortwave biases in these regions (Figs. 9c,d). CALIPSO reveals excessive cloudiness in the AM3 Arctic, a region especially important for climate change. These errors are not evident in ERBE shortwave radiation (Fig. 9c). Unlike CALIPSO, ERBE shortwave radiation cannot separate cloud from clear sky with highly reflective surfaces in the Arctic.

For coupling AM3 with ocean models, the surface energy balance (including latent and sensible heat fluxes, in addition to radiative fluxes) is crucial and not related trivially to the top-of-atmosphere radiation balance. The implied ocean heat transport (OHT) is the heat transport implied in the ocean to balance surface fluxes. Although considerable uncertainty exists in diagnosing implied ocean heat transports from observations (e.g., Large and Yeager 2009; Griffies et al. 2009), agreement between these transports in uncoupled atmospheric models and observational estimates has been found to favor successful coupling with ocean models. The AM3 implied that OHT generally falls within or close to the observational estimates of Ganachaud and Wunsch
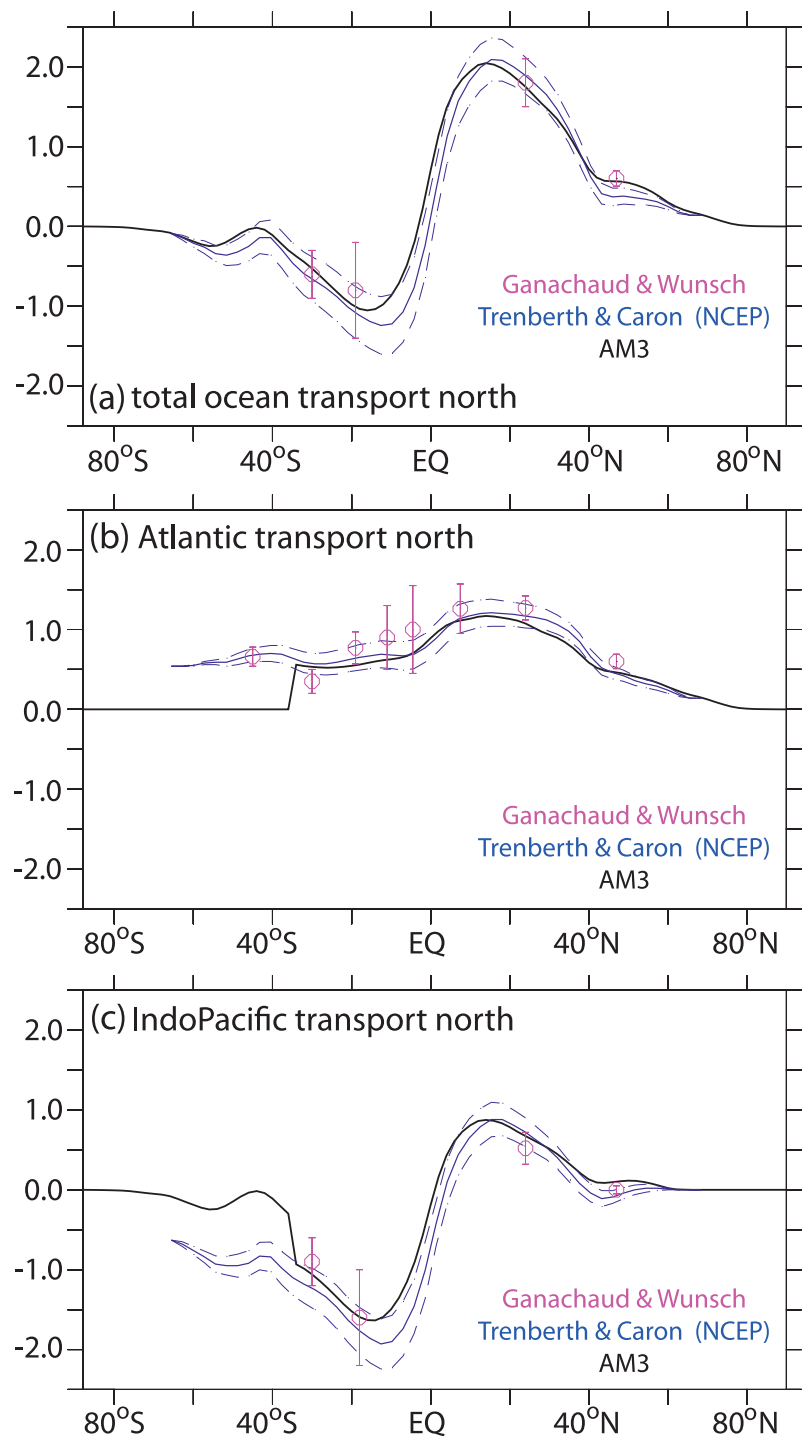

FIG. 13. Implied ocean heat transport (PW), AM3 (1981-2000) vs observation, for (a) total ocean, (b) Atlantic Ocean, and (c) Indo-Pacific Ocean. Dashed lines and vertical bars indicate range of one standard error above and below the Trenberth and Caron (2001) and Ganachaud and Wunsch (2003) estimates, respectively.

(2003) and Trenberth and Caron (2001), except for the Indo-Pacific Ocean south of $30^{\circ} \mathrm{S}$ (Fig. 13).

\section{c. Dynamics}

The AM3 midlatitude westerly jets in the troposphere are about $10 \%$ stronger than in the ERA-40 reanalysis (Uppala et al. 2005) (Fig. 14). A small area of weak, spurious westerlies appears in the equatorial stratosphere around $10 \mathrm{hPa}$, and stratospheric westerlies at polar latitudes can be over $50 \%$ stronger than in the $40-\mathrm{yr}$ European Centre for Medium-Range Weather Forecasts Re-Analysis (ERA-40). In the troposphere, westerly 

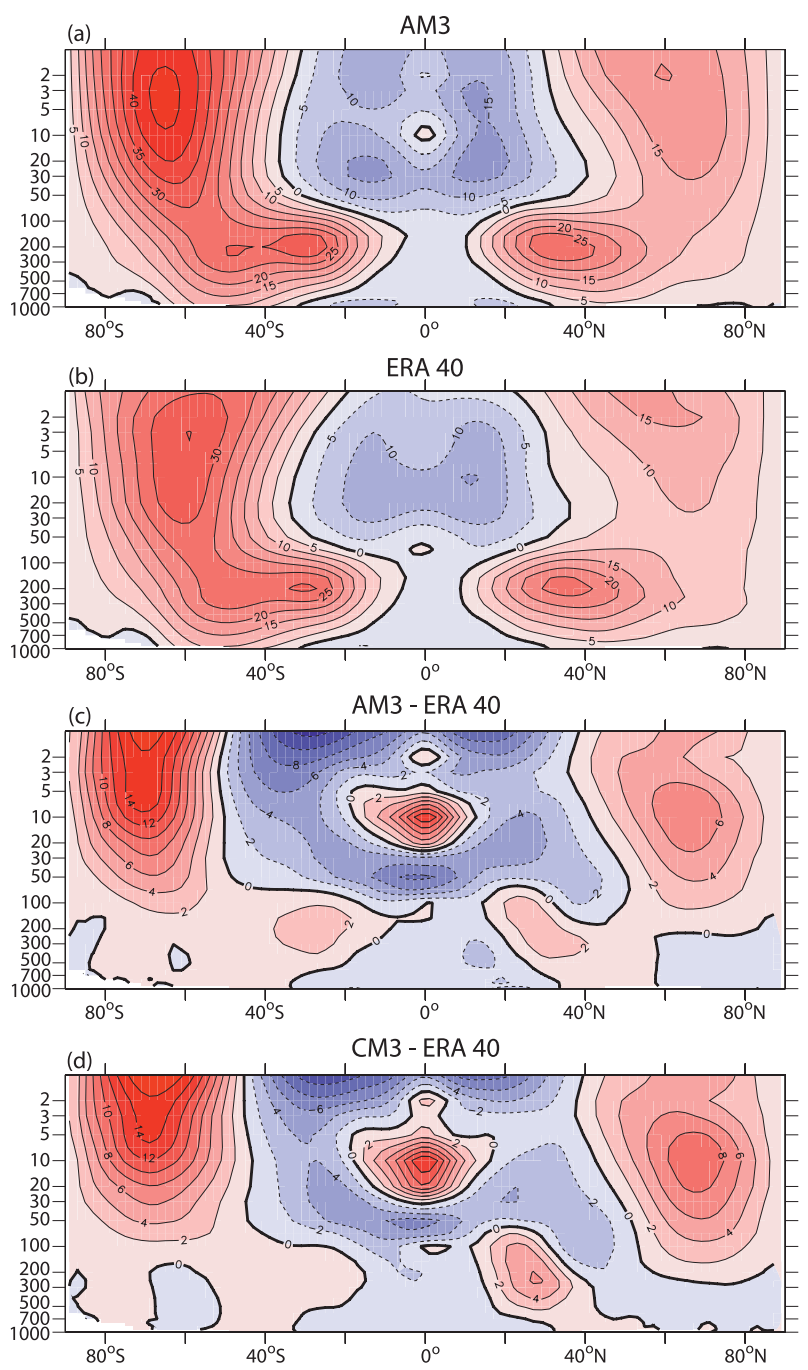

FIG. 14. Annual-mean, zonally averaged zonal wind $\left(\mathrm{m} \mathrm{s}^{-1}\right)$ for (a) AM3, (b) ERA-40, (c) AM3 minus ERA-40, and (d) CM3 minus ERA-40.

biases are smaller in CM3 than AM3 in the Southern Hemisphere but larger in the Northern Hemisphere.

Wind stresses in uncoupled models, along with implied OHT, are important to successful coupling. Wind stresses over the Atlantic and Pacific Oceans for AM3 and $\mathrm{CM} 3$ are generally within or close to the observational estimates from the Comprehensive Ocean-Atmosphere Datasets (COADS) (da Silva et al. 1994; Woodruff et al. 1987), ECMWF reanalysis (Gibson et al. 1997), and the European Remote Sensing Satellite (ERS) scatterometer (CERSAT-IFREMER 2002) (Fig. 15). The largest AM3 Pacific departures from observations are in the Southern Hemisphere, where CM3 stresses agree better with observations. The largest Atlantic departures for $\mathrm{CM} 3$ are in the Northern Hemisphere, where AM3 agrees better with observations.
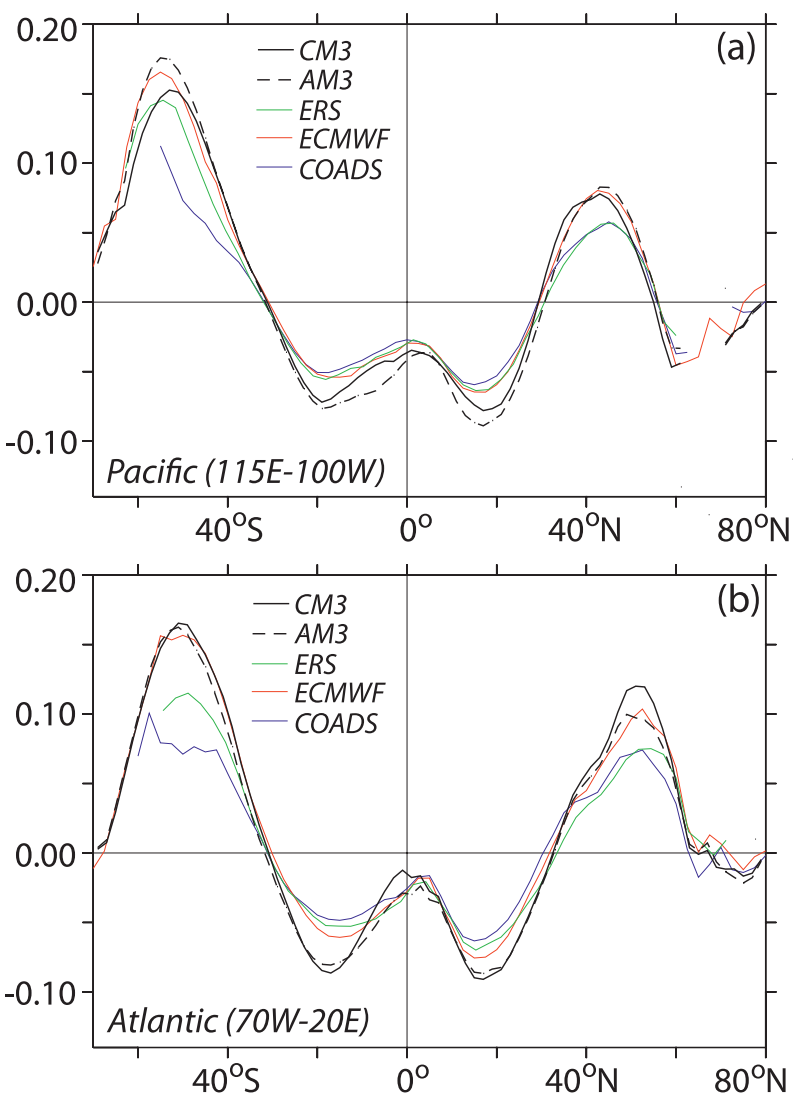

FIG. 15. Annual-mean wind stress $\left(\mathrm{N} \mathrm{m}^{-2}\right)$ for the (a) Pacific and (b) Atlantic Oceans.

In AM3, Northern Hemisphere December-February (DJF) sea level pressures (SLPs) are biased high over most of the middle latitudes with a mixed difference pattern in the Arctic, compared to the National Centers for Environmental Prediction-National Center for Atmospheric Research (NCEP-NCAR) reanalysis (Kalnay et al. 1996) (Fig. 16). CM3 differences over the Atlantic are similar in pattern to AM3 but larger in magnitude, but a negative bias characterizes the Pacific. The maximum positive bias in the Arctic is less than half as large as in AM2 (cf. Fig. 6 in Anderson et al. 2004).

The magnitudes of the errors in the DJF stationary waves (time mean departures of the 500-hPa geopotential height from its zonal mean) are noticeably larger in CM3 than AM3 (Fig. 17). The amplitudes of the waves are larger over Europe, East Asia, and northeast North America in $\mathrm{CM} 3$, and the waves are shifted slightly eastward over North America in CM3, relative to AM3. In the Southern Hemisphere, the magnitudes of the departures from the zonal mean are generally larger in AM3.

A measure of the AM3 skill in simulating a key aspect of the El Niño-Southern Oscillation is its modeled relationship between tropical SST and the 
DJF Northern Hemisphere Sea-Level Pressure minus $1013.25 \mathrm{hPa}(\mathrm{hPa})$

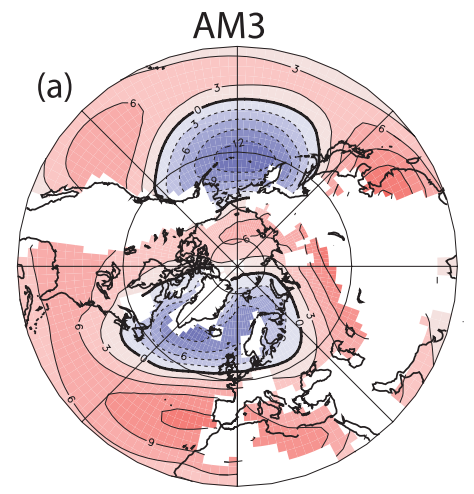

NCEP Re-analysis

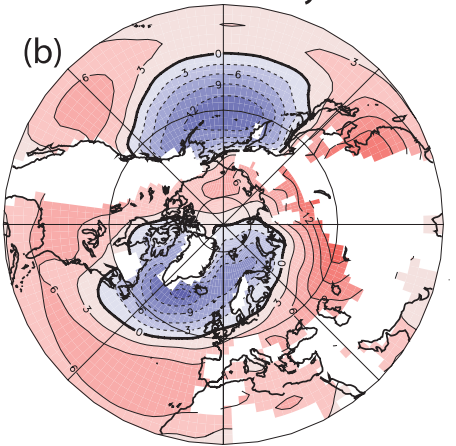

AM3 - NCEP Re-analysis

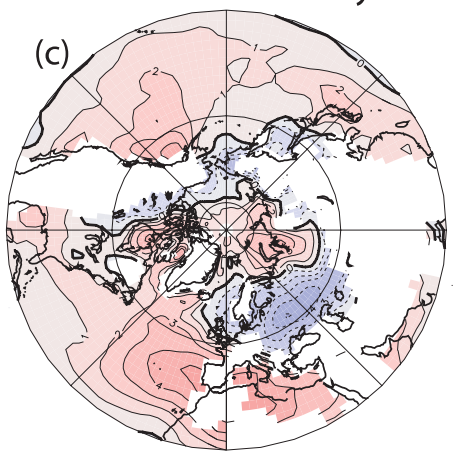

CM3 - NCEP Re-analysis

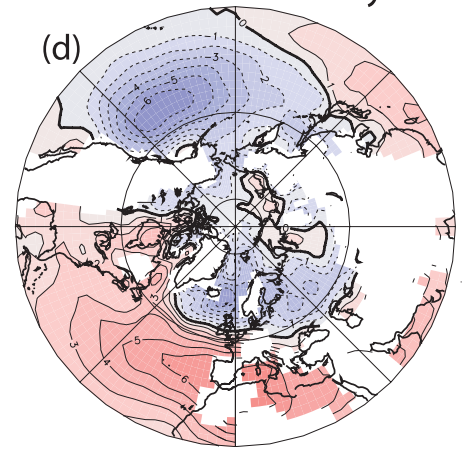

Southern Hemisphere Sea-Level Pressure - $1013.25 \mathrm{hPa}(\mathrm{hPa})$

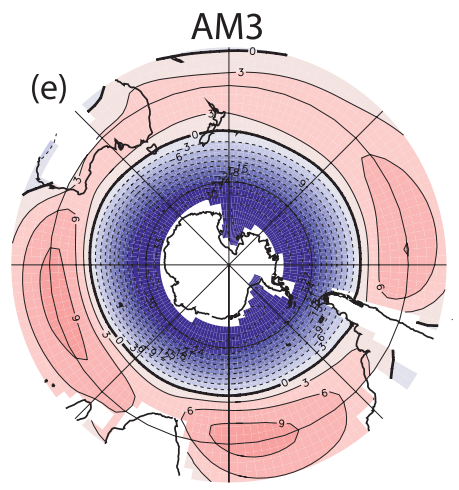

NCEP Re-analysis

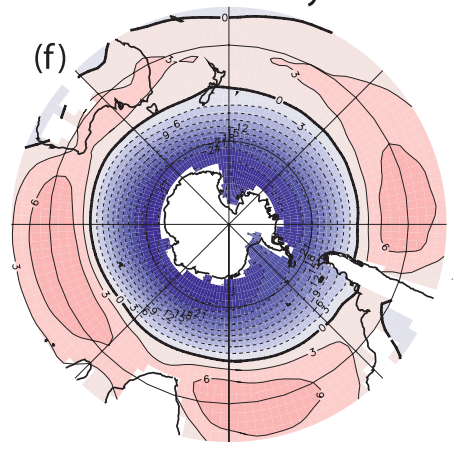

AM3 - NCEP Re-analysis

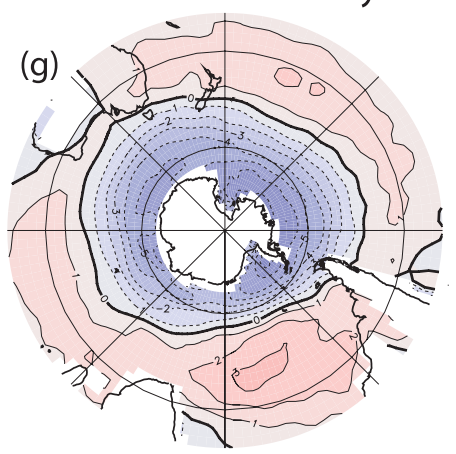

CM3 - NCEP Re-analysis

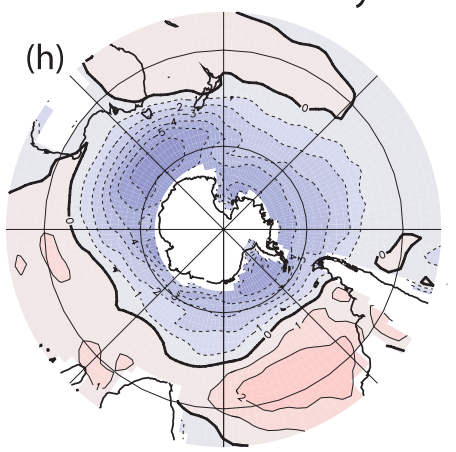

FIG. 16. Northern Hemisphere DJF sea level pressure minus $1013.25 \mathrm{hPa}$ for (a) AM3, (b) NCEP reanalysis, (c) AM3 minus NCEP reanalysis, and (d) CM3 minus NCEP reanalysis; contour intervals are (a),(b) $3 \mathrm{hPa}$ and (c),(d) $1 \mathrm{hPa}$. Areas with mean surface pressures less than $950 \mathrm{hPa}$ are masked. (e)-(h) Same as (a)-(d) but for Southern Hemisphere. 

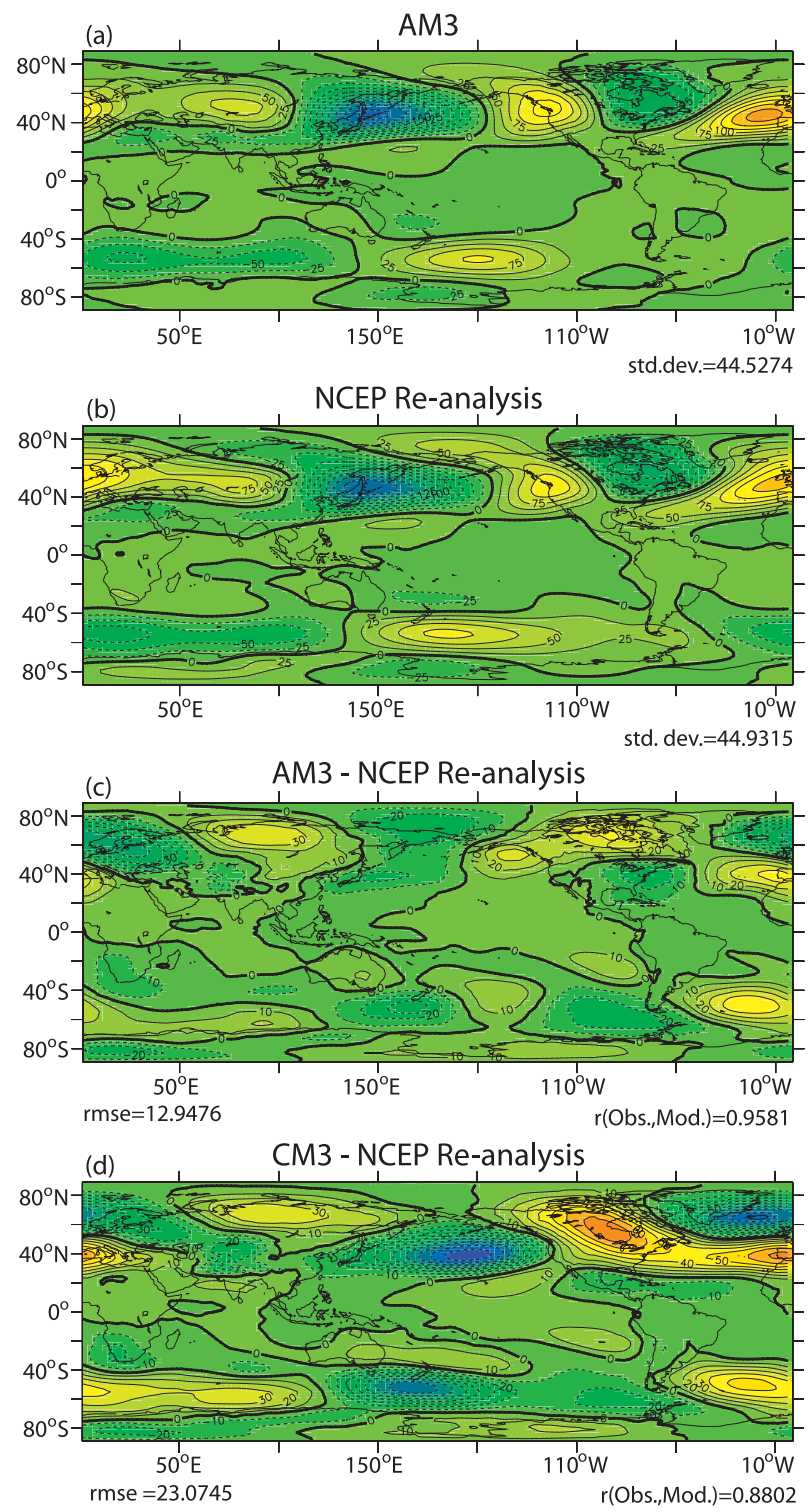

FIG. 17. DJF departure from zonally averaged 500-hPa geopotential height (m) for (a) AM3, (b) NCEP reanalysis, (c) AM3 minus NCEP reanalysis, and (d) CM3 minus NCEP reanalysis.

global precipitation pattern. This pattern can be depicted as the product of the standard deviation of the Niño3 index and regression coefficients between the Niño-3 index and precipitation. This pattern corresponds to AM3's precipitation response to a temperature anomaly of one standard deviation in the Niño-3 region. (The Niño-3 index is the average SST anomaly over the region $5^{\circ} \mathrm{S}-5^{\circ} \mathrm{N}, 150^{\circ}-90^{\circ} \mathrm{W}$.) Although the patterns in both AM3 and CM3 appear to be more zonal than those based on the GPCP analysis (Huffman et al. 1997), broad features of the observed pattern are simulated (Fig. 18). The magnitude of the anomalies is largest in AM3
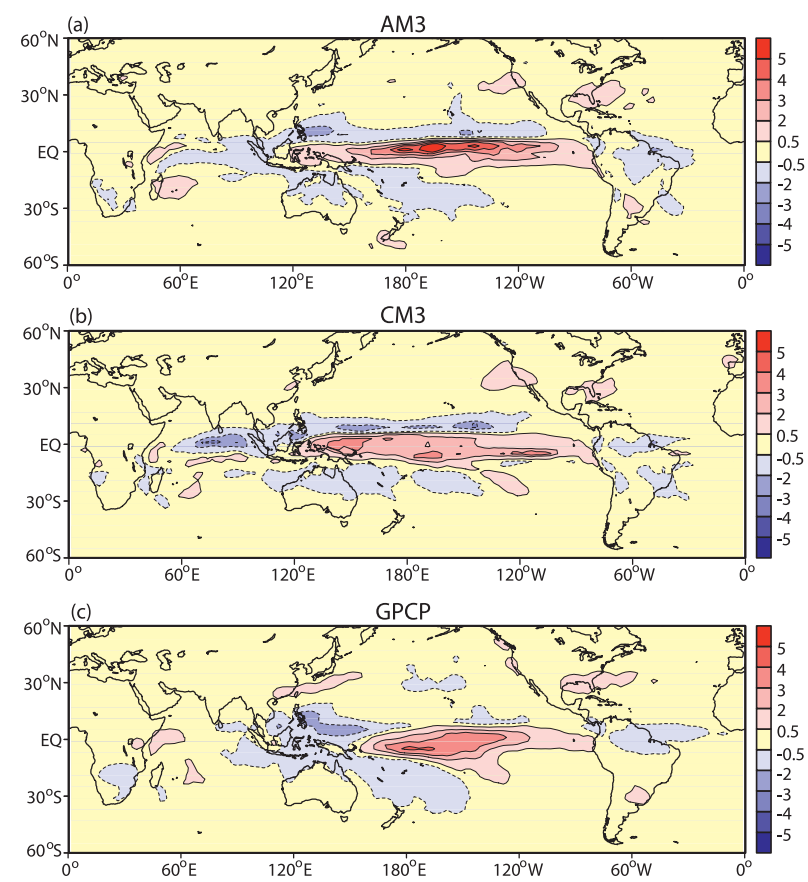

FIG. 18. DJF product of the standard deviation of the Niño-3 index and regression coefficient between precipitation and Niño-3 index $\left(\mathrm{mm} \mathrm{day}^{-1}\right.$ ) for (a) AM3, (b) CM3, and (c) GPCP.

and smallest in CM3, with GPCP being intermediate. The maxima in AM3 are clustered more closely together than in CM3. GPCP does not exhibit multiple maxima.

The AM3 skill in simulating temperature and pressure patterns associated with the Northern Hemisphere annular mode (NAM), also referred to as the Arctic Oscillation, can be similarly assessed. These patterns can be depicted as the product of the standard deviation of the NAM index and the regression coefficients between the NAM index and the field of interest. (The NAM index is the first principal component of April-November monthly SLP north of $20^{\circ} \mathrm{N}$.) The basic structures of temperature and pressure anomalies are similar in AM3 and observations with magnitudes of AM3 pressure anomalies larger than observed over the North Pacific (Fig. 19). The magnitudes of temperature anomalies in AM3 are larger than observed at high latitudes and over the North Pacific.

The frequencies of simulated tropical cyclones in AM3 and CM3 have been diagnosed using the method of Vitart et al. (1997). Observed frequencies are available from the U.S. National Hurricane Center (http://www.nhc.noaa. gov/pastall.shtml\#hurdat) for the Atlantic and from the U.S. Navy (http://www.usno.navy.mil/NOOC/nmfc-ph/ RSS/jtwc/best_tracks) for other basins. The model simulation captures some features of the observed distribution, but has a very strong low bias (Fig. 20) and has much 
(a) AM3

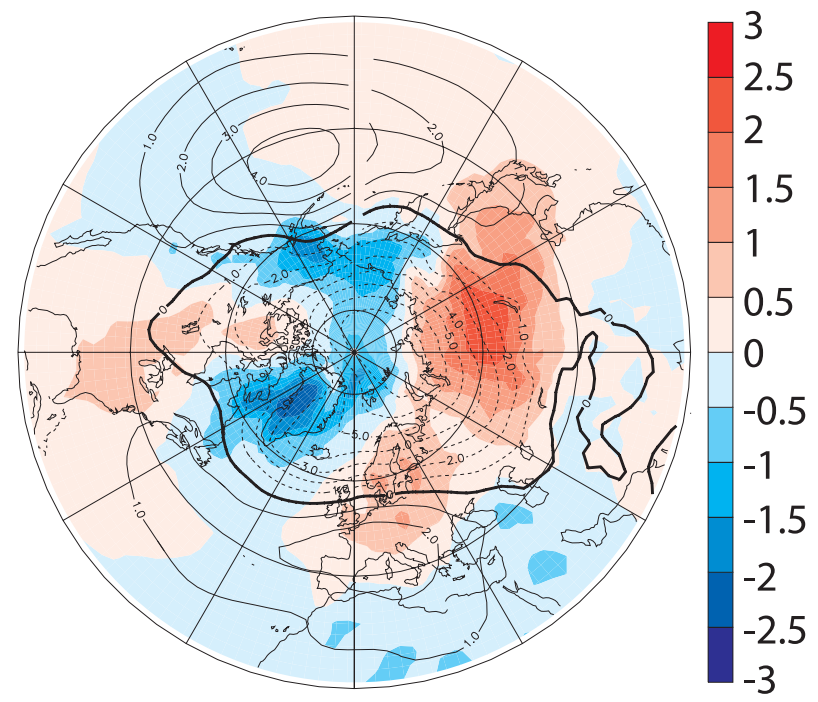

\section{(b) Observations}

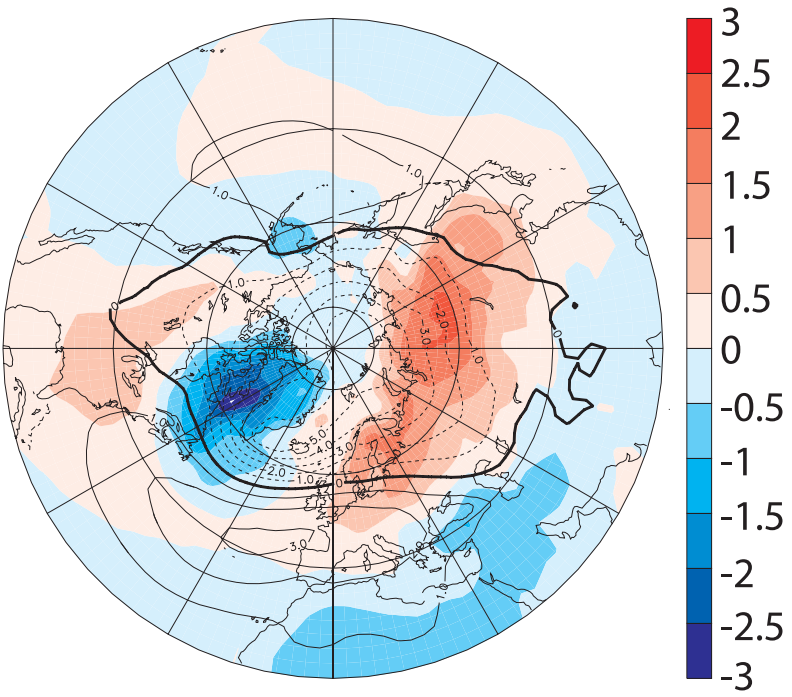

FIG. 19. Product of the standard deviation of the NAM index and regression coefficients between the NAM index and SLP (contours, $\mathrm{hPa}$ ) and 2-m temperature (shading, ${ }^{\circ} \mathrm{C}$ ) for (a) AM3 and (b) NCEP reanalysis.

poorer tropical cyclone simulation overall than has been achieved using higher-resolution atmospheric models developed more specifically for this purpose (e.g., Zhao et al. 2009; Bender et al. 2010).

The AM3 tropical $\left(15^{\circ} \mathrm{S}\right.$ to $\left.15^{\circ} \mathrm{N}\right)$ wave spectrum has been evaluated in the format of Wheeler and Kiladis (1999). AM3 is essentially without Kelvin waves or a Madden-Julian oscillation (MJO) in contrast to the analysis based on OLR observations (Liebmann and
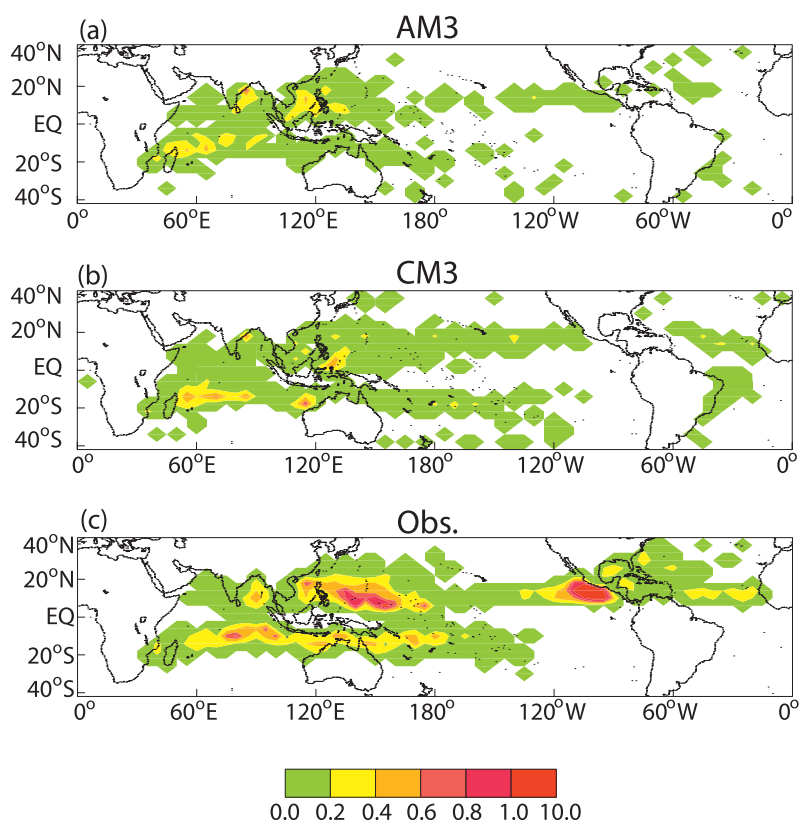

FIG. 20. Tropical cyclone frequency (per year) for (a) AM3, (b) CM3, and (c) U.S. National Hurricane Center and Navy observations.

Smith 1996) (Figs. 21a,c). The simulated tropical wave spectrum is very sensitive to the closure and trigger used for the deep-cumulus parameterization (Lin et al. 2006). In experimental integrations with AM3, the CAPE relaxation closure, described in section $3 \mathrm{e}$, was replaced by the Zhang (2002) closure and a trigger requiring timeintegrated low-level lifting sufficient to move a parcel from the boundary layer to the level of free convection [cf. Eqs. (6) and (7) in Donner et al. 2001]. Zhang's closure balances changes in CAPE by convection with changes in CAPE by nonconvective processes above the PBL, that is, CAPE changes arising only from changes in the environment of a cumulus parcel. Effectively, Zhang's closure imposes a balance between the vertical integrals of large-scale advection of dry static energy and convective heating (Zhang 2009). Use of the Zhang (2002) closure with a lifting trigger produces a stronger Kelvin wave and MJO, although both remain weaker than observed (Fig. 21b). (These sensitivity experiments are 5-yr integrations using climatological 1981-2000 SSTs.) The closure and trigger for the cumulus parameterization impact many aspects of the simulated general circulation. For example, unlike the tropical wave spectrum, the annualmean precipitation is more realistic in AM3 with the CAPE relaxation closure. The promising simulation of the tropical wave spectrum (and evidence in its favor from field programs; e.g., Zhang 2002; Donner and Phillips 2003) suggests further research as to its impact on other aspects of ocean-atmosphere coupled simulations. 
(a)

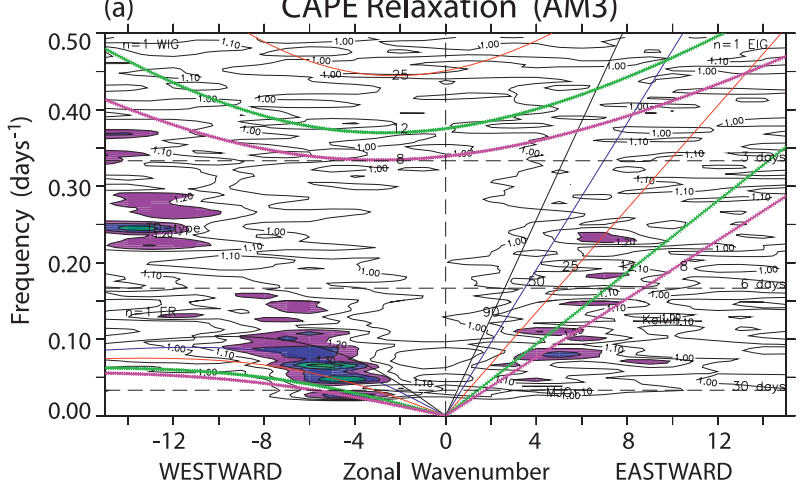

(b) Parcel-Environment Equilibrium

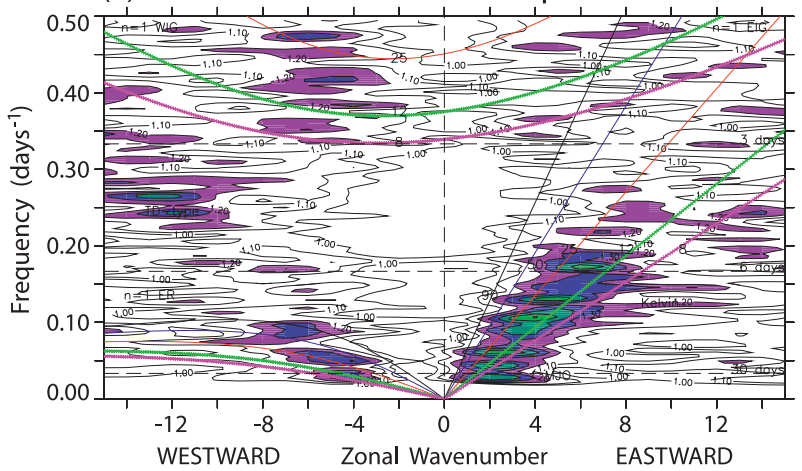

(c)

Obs.

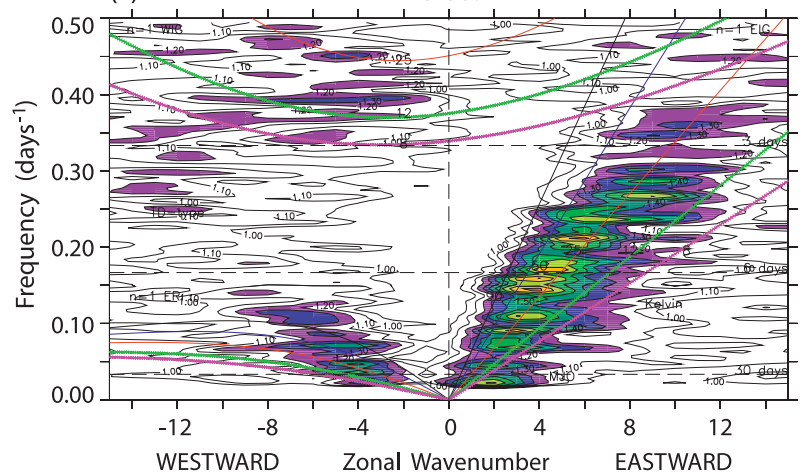

FIG. 21. Normalized tropical symmetric OLR wavenumberfrequency power spectrum for (a) AM3, (b) AM3 with CAPE relaxation closure for deep cumulus replaced by a closure in which CAPE tendencies in the environment of cumulus parcels are balanced by deep convection with low-level-lift trigger, and (c) OLR observations. Contour interval is 0.1 (shown for values 1.0 and greater) with colored shading of regions greater than 1.2 indicating power associated with MJO, Kelvin, and other tropical convective waves that are significantly above an approximately red-noise background power spectra. The colored lines represent various equatorial wave dispersion curves labeled for five different equivalent depths $(8,12,25,50$, and $90 \mathrm{~m})$.

However, the opposing effects of the differing closures and triggers on the realism of the mean circulation and the tropical wave spectrum suggest fundamental difficulties remain in treating convection.
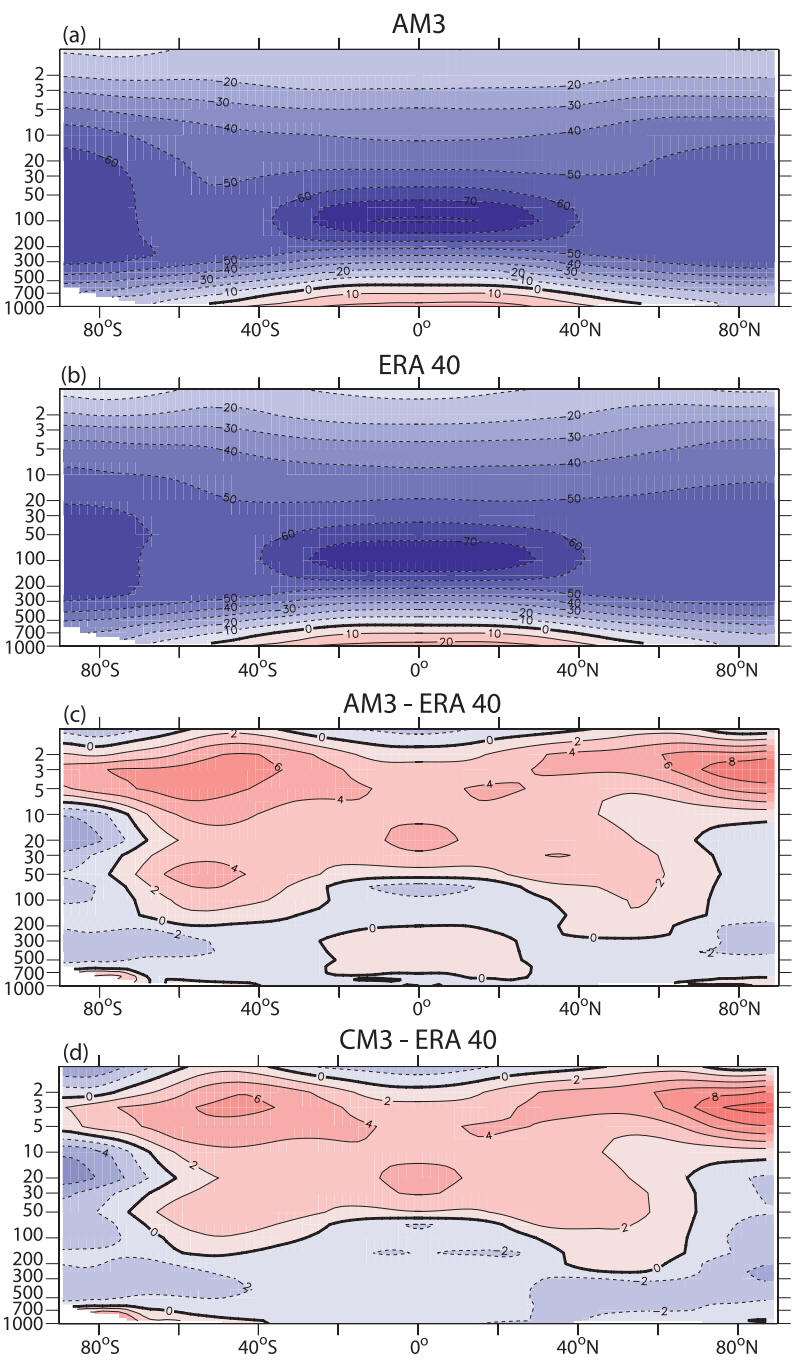

FIG. 22. Annual-mean, zonally averaged temperature $\left({ }^{\circ} \mathrm{C}\right)$ for (a) AM3, (b) ERA-40 reanalysis, (c) AM3 minus ERA-40, and (d) CM3 minus ERA-40.

\section{d. Thermodynamics and precipitation}

Tropospheric temperatures in AM3 and CM3 are generally within $2^{\circ} \mathrm{C}$ of ERA-40 reanalysis (Uppala et al. 2005) with CM3 slightly cooler than AM3 (Fig. 22). Except in polar regions at pressures greater than 5 to $10 \mathrm{hPa}, \mathrm{AM} 3$ and $\mathrm{CM} 3$ stratospheric temperatures are generally higher than those of ERA-40.

Compared to observed SST (see http://www-pcmdi.llnl. gov/projects/amip/ AMIP2EXPDSN/BCS_OBS/amip2_ bcs.htm), warm biases in CM3 are evident off the subtropical west coasts of North and South America and Africa (Fig. 23), consistent with low-cloud errors also apparent in absorbed shortwave radiation (Figs. 9c,d). Warm biases north of Antarctica are consistent with shortwave errors in $\mathrm{CM} 3$, which develop as a result of 
(a)

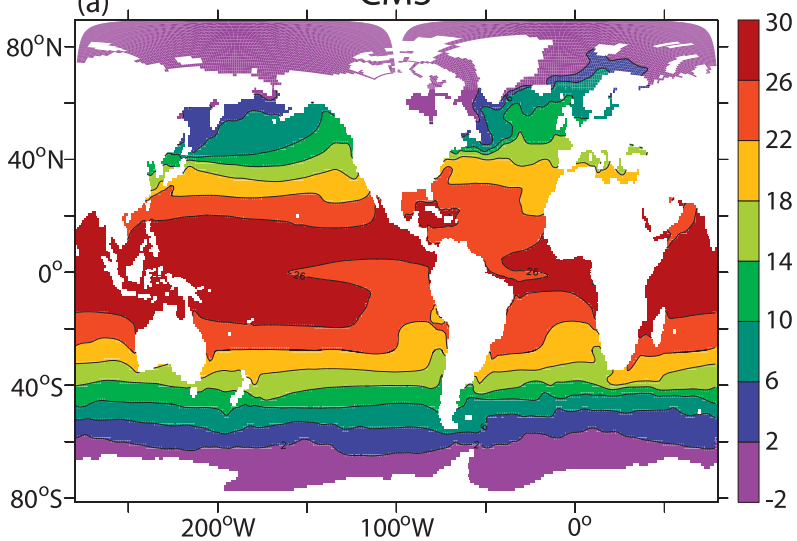

(b)

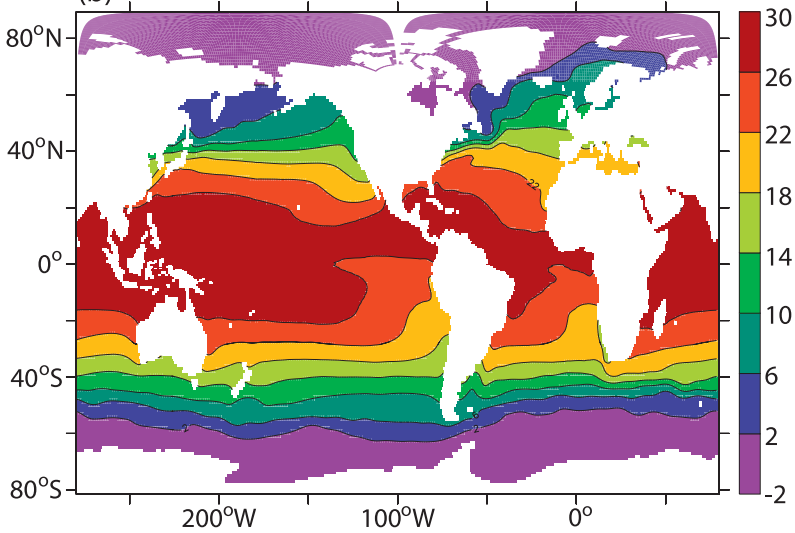

(c)

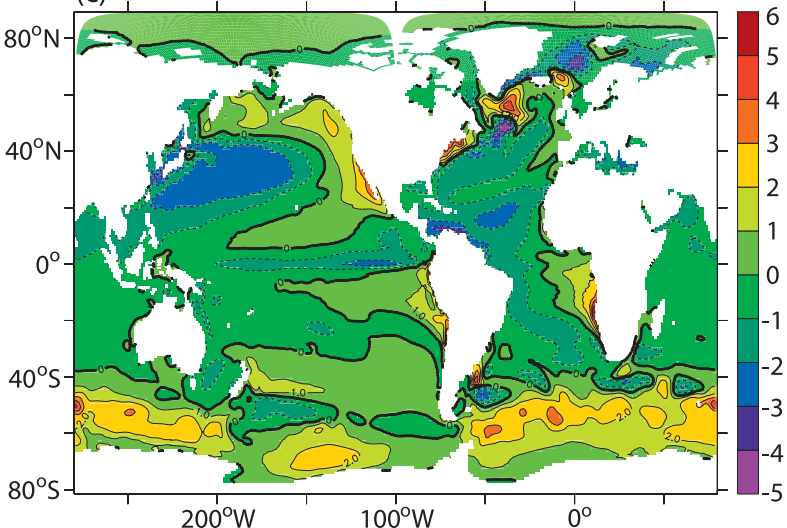

FIG. 23. Sea level temperature $\left({ }^{\circ} \mathrm{C}\right.$ ) for (a) $\mathrm{CM} 3$, (b) observations compiled at Lawrence Livermore National Laboratory (LLNL; http://www-pcmdi.llnl.gov/projects/amip/AMIP2EXPDSN/BCS OBS/amip2_bcs.htm), and (c) difference.

ocean-atmosphere coupling (Figs. 9c,d). A broad cold bias from $2^{\circ}$ to $3^{\circ} \mathrm{C}$ prevails over the middle latitudes of the west and central Pacific, and a complex error pattern of varying signs, associated with details of the Gulf Stream simulation, characterizes the North Atlantic.
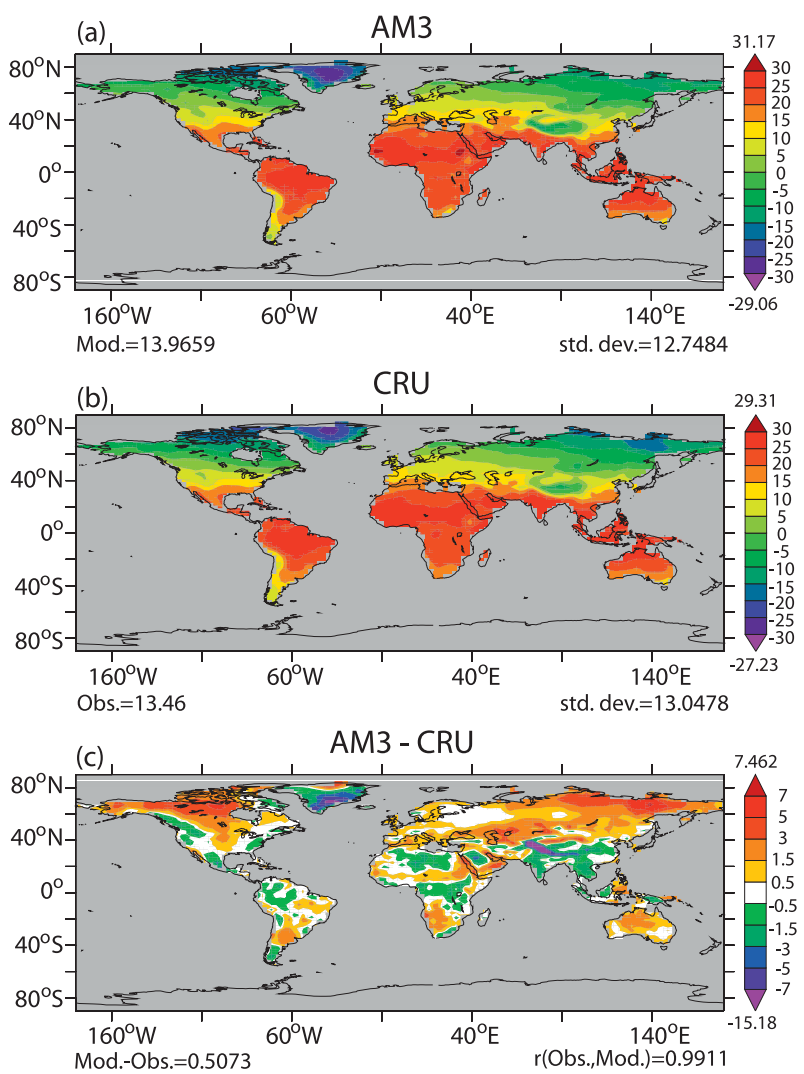

Mod. - Obs. $=0.5073$

rmse $=1.8155 \quad \mathrm{CM} 3-\mathrm{CRU}$

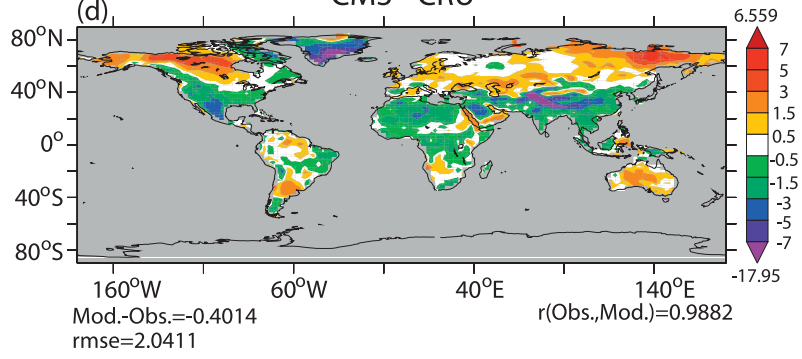

FIG. 24. Air temperature at 2-m height $\left({ }^{\circ} \mathrm{C}\right)$ for (a) AM3, (b) CRU, (c) AM3 minus CRU, and (d) CM3 minus CRU.

Both AM3 and CM3 capture general features of CRU temperature observations (Brohan et al. 2006) at $2 \mathrm{~m}$ over land areas (Fig. 24). A major warm bias, occurring mostly in northern winter, is evident in AM3 and CM3 at

TABLE 2. Global land, area average of standard deviation of 2-m temperature $\left({ }^{\circ} \mathrm{C}\right)$ from 1981 to 2000 .

\begin{tabular}{lccc}
\hline \hline Season & CRU2.0 & CM2.1 & CM3 \\
\hline Annual & 0.567 & 0.768 & 0.677 \\
Dec-Feb & 1.197 & 1.639 & 1.391 \\
Mar-May & 0.919 & 1.280 & 1.178 \\
Jun-Aug & 0.675 & 1.037 & 0.878 \\
Sep-Nov & 0.820 & 1.127 & 0.925 \\
\hline
\end{tabular}




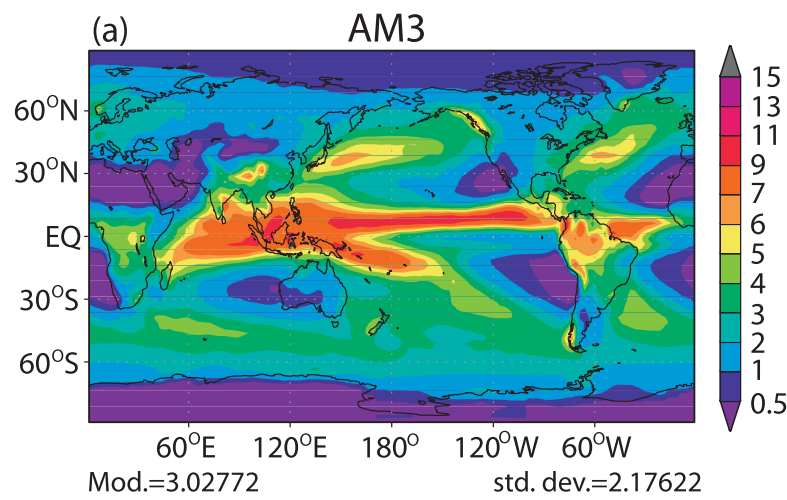

(b)
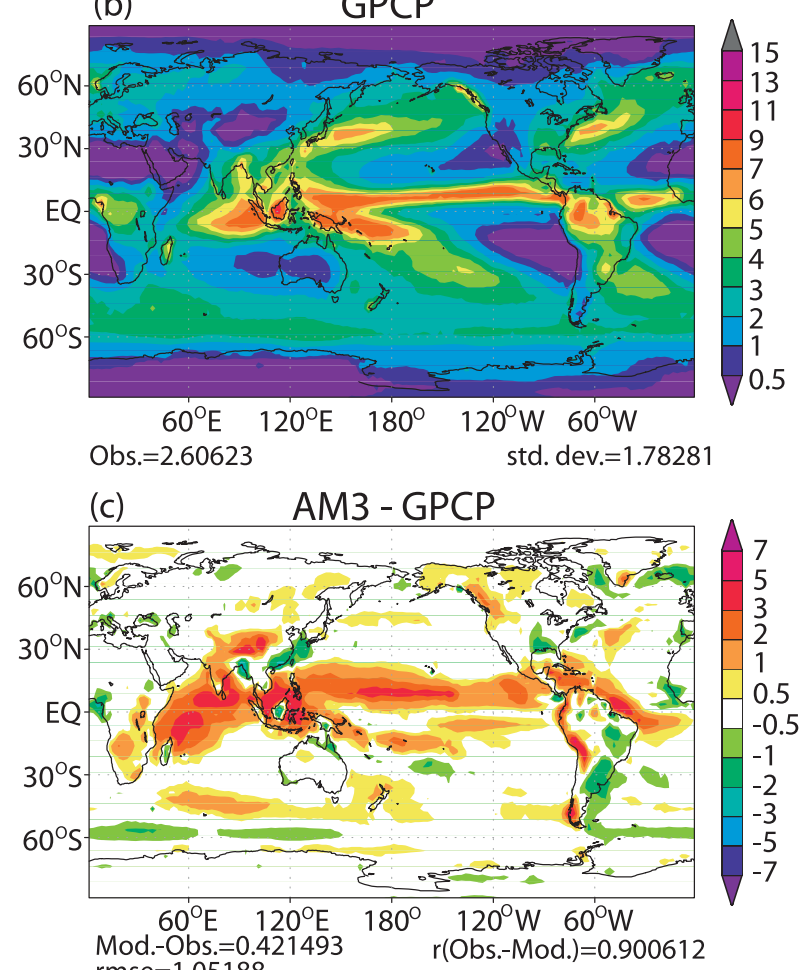
rmse $=1.05188$

(d) CM3 - GPCP

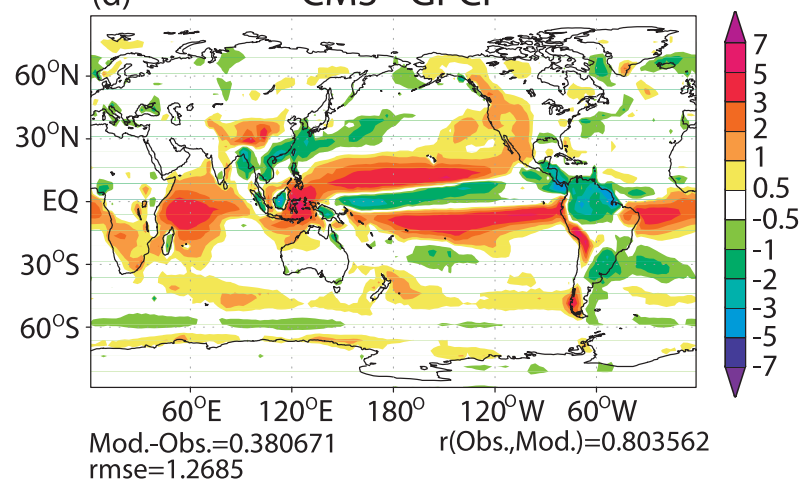

FIG. 25. Annual-mean precipitation $\left(\mathrm{mm} \mathrm{day}^{-1}\right)$ for (a) AM3, (b) GPCP v. 2, (c) AM3 minus GPCP v. 2, and (d) CM3 minus GPCP v. 2.

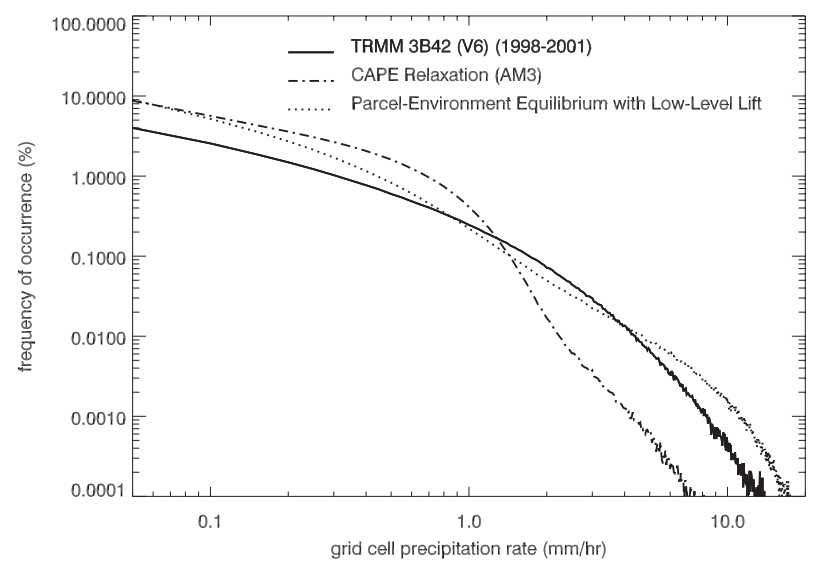

FIG. 26. Precipitation intensity distribution from TRMM, AM3, and AM3 with CAPE relaxation closure for deep cumulus replaced by a closure in which CAPE tendencies in the environment of cumulus parcels are balanced by deep convection with low-level lift trigger.

high and middle latitudes in the Northern Hemisphere. Eurasia, North America, and Africa are slightly cooler in CM3 than in AM3. Excessive variability of these temperatures compared to CRU observations is reduced in CM3 relative to CM2 (Table 2).

AM3 precipitation in tropical oceans is excessive compared with GPCP v2 observations (Adler et al. 2003), by as much as $3-5 \mathrm{~mm}^{-1 a y}{ }^{-1}$ (Fig. 25). Relative to AM2.1, the AM3 Amazon simulation has improved markedly (cf. Fig. 17 of Delworth et al. 2006) and reduced the summer dry bias in the southern Great Plains of North America. CM3 develops a double ITCZ, which is considerably less evident in AM3. A moist bias over the western United States and a dry bias over northern South America develop in CM3 but are not evident in AM3. A moist bias over southern Africa is stronger in CM3 than AM3. As for the tropical wave spectrum (Fig. 21), the distribution of precipitation intensity depends strongly on the closure and triggers for deep convection. As an example, the CAPE-relaxation closure used in AM3 fails to capture observed high-intensity precipitation events over tropical land areas (Fig. 26). The closure balancing convective changes in CAPE against changes in CAPE due to changes in the environment of cumulus parcels, in conjunction with a low-level lift trigger, does so. [The observed distribution of precipitation intensities is from the Tropical Rainfall Measuring Mission (TRMM) 3B42 (V6), Huffman et al. (2007)] (http://disc.sci.gsfc.nasa.gov/ precipitation). As noted in section $4 \mathrm{c}$, future research on alternatives to the CAPE relaxation closure is planned.

Annual, global-mean water vapor paths agree between AM3 and the National Aeronautics and Space Administration Water Vapor Project (NVAP) (http://eosweb. larc.nasa.gov/PRODOCS/nvap/table_nvap.html) to within 
(a)

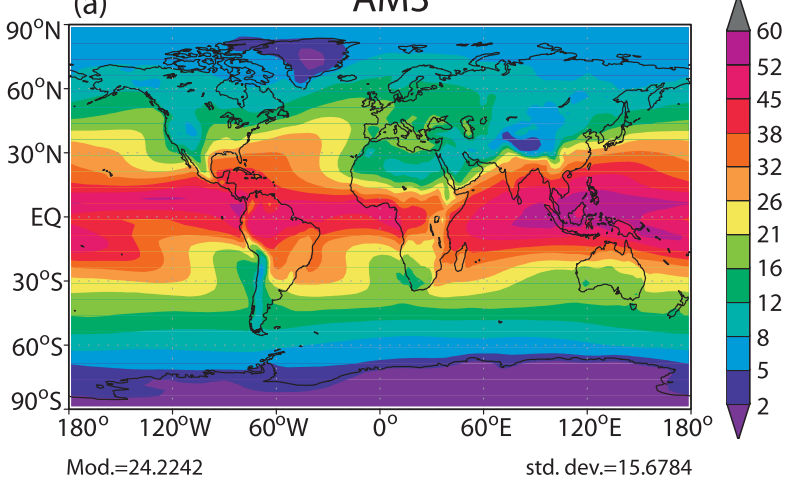

(b)

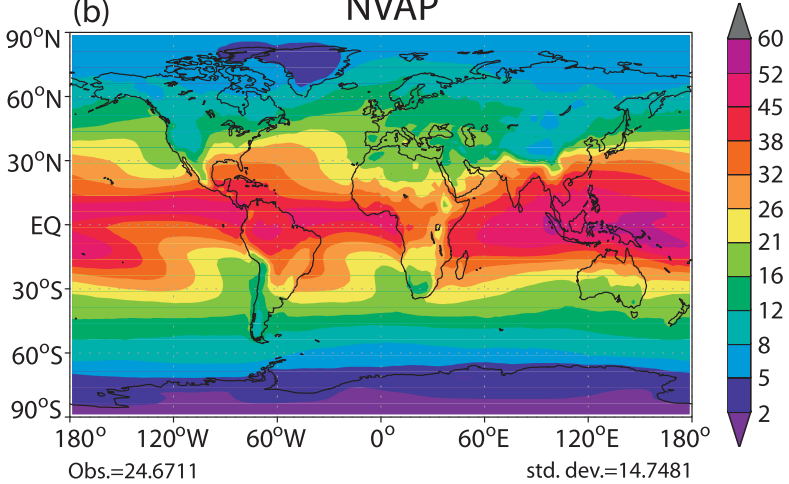

(c)

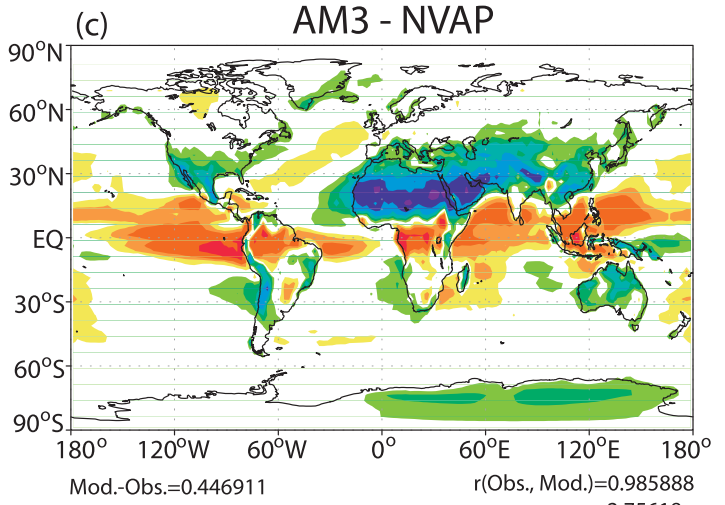

(d)

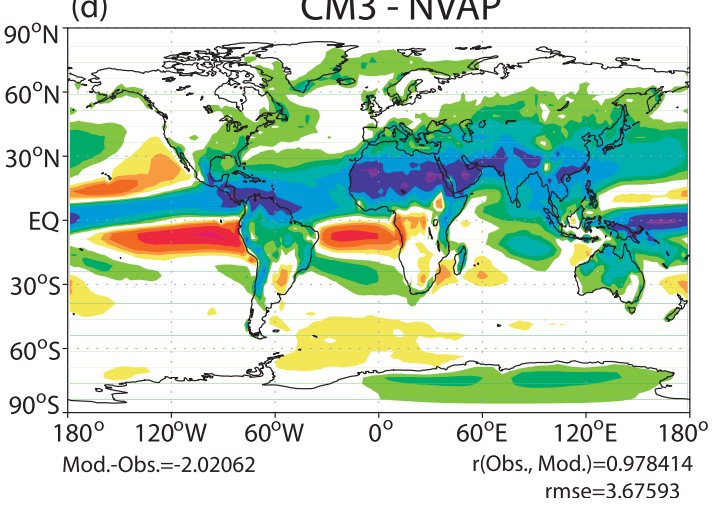

FIG. 27. Water vapor path $\left(\mathrm{kg} \mathrm{m}^{-2}\right)$ for (a) AM3, (b) NVAP, (c) AM3 minus NVAP, and (d) CM3 minus NVAP.
2\% (Fig. 27), an agreement achieved by larger, compensating regional errors. AM3 is too moist over most of the equatorial region, but too dry over much of the northern tropics and subtropics. The positive biases in water vapor path over equatorial oceans are consistent with positive precipitation biases (Fig. 25c). Although positive biases in water vapor path are also apparent over equatorial land areas, comparable positive precipitation biases over equatorial land are not (Fig. 25c). Globally CM3 is drier than AM3, consistent with cooler temperatures in the lower troposphere in $\mathrm{CM} 3$ than AM3 (Fig. 22). Although there are some exceptions (e.g., the southwest United States and adjoining Pacific), most regions in $\mathrm{CM} 3$ are drier than in AM3. Particularly evident is the reduced positive bias in $\mathrm{CM} 3$ over equatorial Africa and the change from a positive bias to a negative bias from AM3 to CM3 in the Amazon region. The Amazon differences between AM3 and CM3 are consistent with corresponding precipitation differences (Fig. 25).

\section{Conclusions}

AM3 and CM3 have been formulated to enable the study of several issues in climate and climate change that could be addressed in only limited ways with earlier GFDL coupled GCMs. These issues include cloudaerosol interactions in the climate system, tropospheric and stratospheric chemistry, and interactions between the troposphere and stratosphere, which have been identified as important in decadal variability (e.g., the Southern Hemisphere annular mode). AM3 has increased vertical resolution and extent in its stratosphere, relative to AM2.

Despite major changes in the dynamical core and parameterizations for cloud microphysics (physically based aerosol activation), cloud macrophysics (subgrid vertical velocities, used for aerosol activation), and deep and shallow cumulus convection, overall statistics characterizing key climate fields change only slightly relative to AM2 and CM2.1 (Fig. 28). AM3 compares favorably to models in the Atmospheric Model Intercomparison Program (AMIP) at the Project for Climate Model Diagnosis and Intercomparison (PCMDI) for phase 3 of the Climate Model Intercomparison Project (CMIP3) (Meehl et al. 2007) whose coupled simulations have performed well (Reichler and Kim 2008). Relative to AM2 and CM2.1, several notable improvements in AM3 and CM3 are not evident in Fig. 28, as discussed elsewhere. 1) AM3 has a smaller Amazon precipitation bias (important for future coupling with a carbon cycle model) and summer dry bias in the North American southern Great Plains. 2) The AM3 simulation of shortwave cloud forcing agrees better with ERBE and CERES observations 

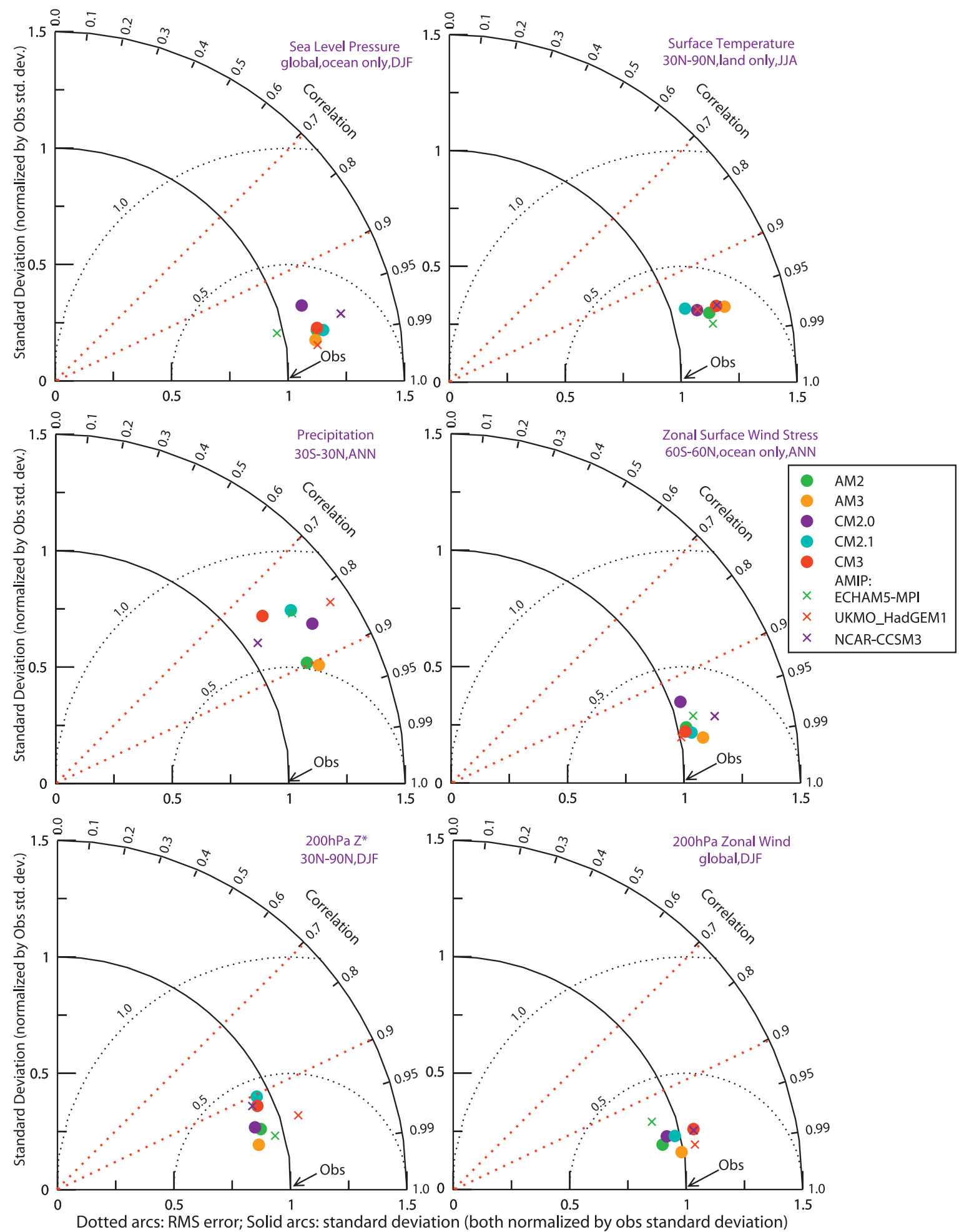

FIG. 28. Taylor diagrams for sea level pressure, surface temperature, precipitation, zonal surface wind stress, 200-hPa deviation of geopotential height from zonal mean, and 200-hPa zonal wind. Regions and periods for averages as indicated. The ECHAM5-Max Planck Institute (MPI), Met Office Hadley Centre Global Environmental Model version 1 (UKMO HadGEM1), and NCAR Community Climate System Model, version 3 (CCSM3) results are their latest AMIP submissions to the World Climate Research Program's CMIP3. Observations of sea level pressure, geopotential height, and winds are from NCEP reanalysis, precipitation from GPCP v2, surface temperature from CRU, and wind stress from ERA-40. 
than AM2's. 3) The simulation of Arctic SLP and sea ice in $\mathrm{CM} 3$ has improved relative to CM2.1 (Fig. A1). 4) Aerosol direct effects are more realistic in AM2, as evidenced by better agreement of clear-sky downward shortwave radiation with BSRN and optical depths and coalbedos with AERONET.

Comparatively assessing CM2 and CM3, it is important to consider more than just the improvements summarized in the preceding paragraph. Specifically, given the development goals for AM3 summarized in the introduction, important additional measures for $\mathrm{CM} 3$ are 1) the extent to which the realism of its physical processes (especially with respect to interactions between clouds and changing aerosols) has improved, 2) the extent to which anthropogenic agents of climate change are more realistically represented, and 3) the extent to which $\mathrm{CM} 3$ can simulate preindustrial to present-day climate transitions. CM2 lacked any mechanism to link changing aerosols to cloud microphysical and radiative properties, so, by measure 1), CM3 represents an overwhelming advance over CM2. As Figs. 3-5 and the discussion in section $3 \mathrm{f}$ show, aerosol optical depths, coalbedos, and effects on reducing downward surface shortwave radiation are more realistic in $\mathrm{CM} 3$ than CM2. Also, by measure 2), CM3 has improved relative to CM2. To the limited extent that they are analyzed here, preindustrial to present-day temperature changes, measure 3), are slightly less realistic in CM3 than CM2. The magnitude of CM3's difference from the observed change is about $0.1^{\circ} \mathrm{C}$ greater than CM2's for the change between 1980-2000 and 1881-1920. Future publications will explore the CM3 climate change over the twentieth century in considerably more detail. Based on measures 1) and 2), the physical mechanisms important for climate and climate change are more comprehensively treated in CM3 than CM2, but cooling associated with its treatment of cloud-aerosol interactions is somewhat excessive. In this regard, note that CM3 stratiform macrophysics uses very simple treatments of evaporation in clouds by entrainment. Negative feedbacks between entrainment and evaporation at higher liquid water contents, not treated in $\mathrm{CM} 3$, and aerosol concentrations have been hypothesized to limit cooling due to aerosolcloud interactions (e.g., Ackerman et al. 2004). Aerosol interactions with ice clouds, also hypothesized to limit cooling by aerosols (Lee et al. 2009), are also not treated in $\mathrm{CM} 3$.

AM3 simulates key observed features of the stratospheric ozone distribution and evolution of the stratospheric ozone hole. Opportunities for future research on interactions between the troposphere and stratosphere expand as a result of AM3's better-resolved stratosphere, relative to $\mathrm{AM} 2$.
High-priority future development should address ongoing biases in subtropical marine stratocumulus in both AM3 and CM3. The emergence of a double ITCZ and dry bias in the Amazon when AM3 is coupled to an ocean model is also an important deficiency. Improved simulation of the intensity of the precipitation distribution and tropical waves, especially the MJO, also deserves attention. Addressing biases in marine stratocumulus and improving treatments of cloud-aerosol interactions will require changing the behavior of stratiform macrophysics, most likely by a combination of changes in vertical resolution and formulation (Guo et al. 2010). The closure for the cumulus parameterization appears to be a promising target for increased realism of higher-frequency variability and precipitation intensity. The implementation of aerosol-cloud interactions in AM3 does not include deep convective clouds or ice clouds. Emphasis should be placed on improving the physical realism of convective microphysics and ice microphysics, with double-moment microphysics offering advantages of consistent treatment of ice and liquid particles. With respect to the stratosphere, improvements in the parameterization of gravity waves are required, and the absence of a quasi-biennial oscillation is a serious deficiency requiring attention.

Acknowledgments. We thank Jeff Varanyak for assisting with figure preparation. Reviews of an early draft by Tom Delworth and Gabriel Lau are appreciated.

We acknowledge the modeling groups, PCMDI, and the World Climate Research Program's (WCRP's) Working Group on Coupled Modelling for their roles in making available the WCRP CMIP3 multi-model dataset. Support of this dataset is provided by the Office of Science, U.S. Department of Energy.

The contribution of Stephen A. Klein to this work was funded through the Regional and Global Climate Modeling and Atmospheric System Research Programs of the Office of Science in the U.S. Department of Energy and was performed under the auspices of the U.S. Department of Energy by Lawrence Livermore National Laboratory under Contract DE-AC52-07NA27344. Robert Pincus was supported by the Office of Science, U.S. Department of Energy, under contract DE FG02-03ER63561. Yanluan Lin was supported by the Office of Biological and Environmental Research, U.S. Department of Energy, under Project DE AI02-07ER64477.

The TRMM and NVAP data were acquired as part of the activities of NASA's Science Mission Directorate and are archived and distributed by the Goddard Earth Sciences Data and Information Services Center.

We thank the AERONET principal investigators and their staffs for establishing and maintaining the 
AERONET sun photometer sites used in this investigation.

\section{APPENDIX A}

\section{CM3 Land, Ocean, and Sea Ice Models}

\section{a. Land model}

LM3, the land model coupled to AM3, is a new model for land water, energy, and carbon balance. In comparison to its predecessor [the Land Dynamics, or $\mathrm{LaD}$, model, Milly and Shmakin (2002)], LM3 includes a multilayer model of snowpack above the soil; a continuous vertical representation of soil water that spans both the unsaturated and saturated zones; a frozen soil-water phase; a parameterization of water table height, saturated-area fraction, and groundwater discharge to streams derived from standard groundwater-hydraulic assumptions and surface topographic information; finite-velocity horizontal transport of runoff via rivers to the ocean; lakes, lake ice, and lake-ice snow packs that exchange mass and energy with both the atmosphere and the rivers; and consistent, energy-conserving accounting of sensible heat content of water in all its phases. Carbon balance and the determination of vegetation structure, phenology, and function are accomplished as in the model LM3V (Shevliakova et al. 2009).

In stand-alone numerical experiments with observationbased atmospheric forcing, and in experiments coupled to AM2 and AM3, LM3 preserves the generally realistic water-balance partitioning of the $\mathrm{LaD}$ model, ameliorates some of the deficiencies of the LaD model previously identified, and provides qualitatively realistic estimates of physical variables that are not tracked by the LaD model.

\section{b. Ocean model}

The ocean model component of CM3 uses the Modular Ocean Model (MOM4p1) code (Griffies 2009), whereas the ocean component of CM2.1 used the MOM4.0 code (Griffies et al. 2004). The physical parameterizations for the $\mathrm{CM} 3$ ocean are the same as those used in CM2.1, as detailed in Griffies et al. (2005) and Gnanadesikan et al. (2006). In both CM2.1 and CM3, the ocean model resolution is $1^{\circ}$ in latitude and longitude, with refined meridional resolution equatorward of $30^{\circ}$ so that it reaches $13^{\circ}$ at the equator. There are 50 vertical levels in the ocean, with 22 levels of 10-m thickness (with a resting ocean) each in the top $220 \mathrm{~m}$. The single change made for CM3 concerns the numerical formulation of the vertical coordinate (Griffies et al. 2011). Tests with the (a)

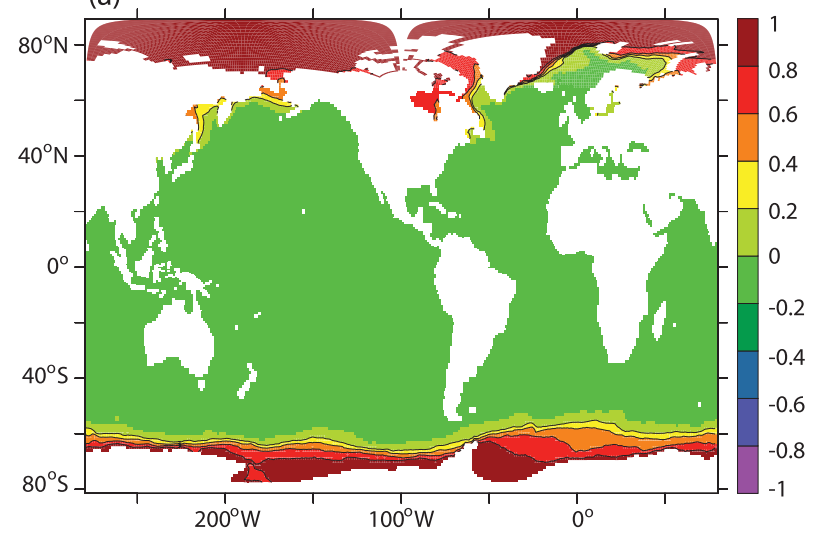

(b)

Obs.

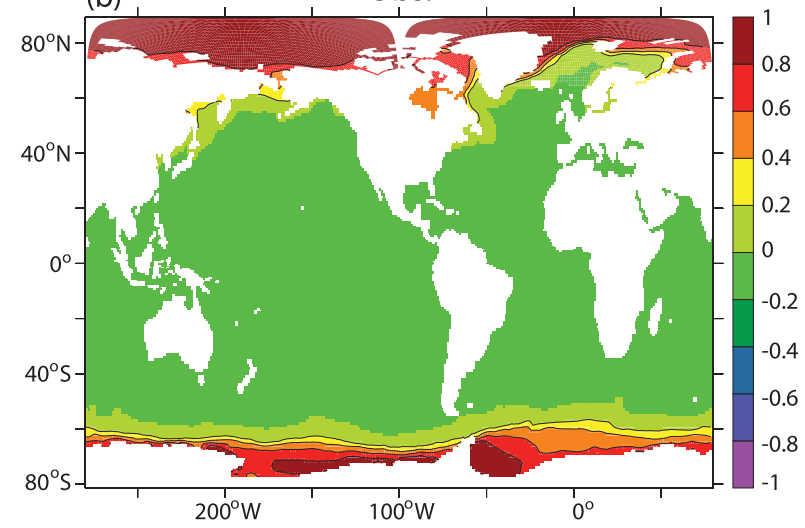

(c)

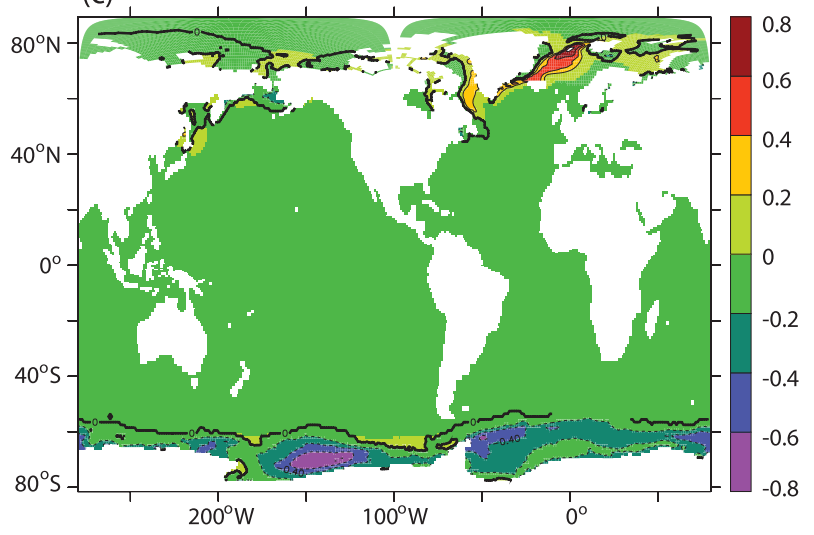

FIG. A1. Annual-mean sea ice extent for (a) CM3, (b) observations, and (c) difference. Sea ice extent is defined to be 1 if sea ice concentration is $15 \%$ or greater and 0 otherwise. Observed ice extent is computed from monthly ice concentrations following Hurrell et al. (2008). Values between 0 and 1 result from time averaging.

new vertical coordinate in CM2.1 showed trivial climate changes to the simulation as described, for example, in Delworth et al. (2006) and Gnanadesikan et al. (2006). Hence, for purposes of the present paper, 
the ocean component can be considered the same as that in CM2.1.

\section{c. Sea ice model}

The CM3 sea ice is identical to that in CM2.1 (Delworth et al. 2006; Winton 2000) except for some parameter resetting made possible by improved realism in the $\mathrm{CM} 3$ climate in regions of sea ice. The dry snow and ice albedos in $\mathrm{CM} 3$ are 0.85 and 0.68 , respectively. These albedos are more realistic (Perovich et al. 2002) than the corresponding values of 0.80 and 0.58 in $\mathrm{CM} 2.1$. The decrements to these values for melting are ramped linearly between a threshold skin temperature of $1^{\circ} \mathrm{C}$ below freezing in $\mathrm{CM} 3$ (compared to $10^{\circ} \mathrm{C}$ below freezing in $\mathrm{CM} 2.1$ ) and the freezing point.

Compared to observations (Hurrell et al. 2008) the CM3 sea ice extent is too far south in areas of the North Atlantic east of Greenland (Fig. A1). In general, the simulation of Northern Hemisphere sea ice has improved in CM3 relative to CM2.1, but Southern Hemisphere ice concentrations remain smaller than observed (cf. Fig. 9 in Griffies et al. 2011).

\section{APPENDIX B}

\section{Symbols and Units Used in Parameterizations and for the Interface Pressure}

\begin{tabular}{lll}
\hline \hline Symbol & & \multicolumn{1}{c}{ Description } \\
\hline$a_{k}$ & Constant used to calculate pressure at interface $k$ & Unit \\
$b_{k}$ & Constant used to calculate pressure at interface $k$ & Pa \\
$c_{0}$ & Lateral mixing constant for shallow cumulus & Dimensionless \\
$C_{A}$ & Vertically integrated lateral transfer of condensate from updraft cells & Dimensionless \\
& to mesoscale updrafts & $\mathrm{kg} \mathrm{m}^{-2} \mathrm{~s}^{-1}$ \\
$C_{\mathrm{mu}}$ & Vertically integrated condensation and deposition in mesoscale updrafts & $\mathrm{kg} \mathrm{m}^{-2} \mathrm{~s}^{-1}$ \\
$D$ & Rate of change of saturated cloud mass flux with pressure in detraining layers & $\mathrm{s} \mathrm{m}^{-1}$ \\
$E_{\mathrm{me}}$ & Vertically integrated condensate transfer from mesoscale updrafts to large-scale & $\mathrm{kg} \mathrm{m}^{-2} \mathrm{~s}^{-1}$ \\
$g$ & stratiform clouds & $\mathrm{m} \mathrm{s}^{-2}$ \\
$M$ & Gravity constant & $\mathrm{kg} \mathrm{m}^{-2} \mathrm{~s}^{-1}$ \\
$p$ & Mass flux & $\mathrm{Pa}^{-2} \mathrm{~s}^{-1}$ \\
$R_{m}$ & Pressure & $\mathrm{kg} \mathrm{m}^{-1}$ \\
$X$ & Precipitation rate from mesoscale updrafts & $\mathrm{kg}\left(\right.$ water) $\mathrm{kg}^{-1} ;$ dimensionless \\
$z$ & Mixing ratio for cloud liquid or ice; cloud fraction & $\mathrm{km}$ \\
$\gamma$ & Height & dimensionless \\
\hline
\end{tabular}

The following apply generally:

$(\cdots)_{\text {deep }}$ refers to deep convective systems, comprised of cells and mesoscale circulations.

$(\cdots)_{\text {meso }}$ refers to mesoscale updrafts.

$(\cdots)_{\text {shal }}$ refers to shallow cumulus.

$(\cdots)_{s}$ refers to lower boundary of atmospheric model.

$(\cdots) *$ refers to a property or process within a convective system.

$\overline{(\cdots)}$ refers to a large-scale average.

\section{REFERENCES}

Ackerman, A. S., M. P. Kirkpatrick, D. E. Stevens, and O. B. Toon, 2004: The impact of humidity above stratiform clouds on indirect aerosol forcing. Nature, 432, 1014-1017.

Adler, R. F., and Coauthors, 2003: The version-2 Global Precipitation Climatology Project (GPCP) monthly precipitation analysis (1979-present). J. Hydrometeor., 4, 1147-1167.

Alexander, M. J., and T. J. Dunkerton, 1999: A spectral parameterization of mean-flow forcing due to breaking gravity waves. J. Atmos. Sci., 56, 4167-4182.
— sphere: Observational constraints from the Upper Atmosphere Research Satellite and implications for parameterization in global models. J. Geophys. Res., 108, 4597, doi:10.1029/2003JD003373.

Anderson, J. L., and Coauthors, 2004: The new GFDL global atmosphere and land model AM2-LM2: Evaluation with prescribed SST simulations. J. Climate, 17, 4641-4673.

Austin, J., and R. J. Wilson, 2006: Ensemble simulations of the decline and recovery of stratospheric ozone. J. Geophys. Res., 111, D16314, doi:10.1029/2005JD006907.

$\longrightarrow$, and - 2010: Sensitivity of polar ozone to sea surface temperatures and halogen amounts. J. Geophys. Res., 115, D18303, doi:10.1029/2009JD013292.

Balkanski, Y., M. Schulz, T. Claquin, and S. Guibert, 2007: Reevaluation of mineral aerosol radiative forcings suggests a better agreement with satellite and AERONET data. Atmos. Chem. Phys., 7, 81-95.

Bender, M. A., T. R. Knutson, R. E. Tuleya, J. J. Sirutis, G. A. Vecchi, S. T. Garner, and I. M. Held, 2010: Modeled impact of anthropogenic warming on the frequency of intense Atlantic hurricanes. Science, 327, 454-458.

Bey, I., and Coauthors, 2001: Global modeling of tropospheric chemistry with assimilated meteorology: Model description and evaluation. J. Geophys. Res., 106, 23 073-23 095. 
Bodas-Salcedo, A., M. J. Webb, M. E. Brooks, M. A. Ringer, K. D. Williams, S. F. Milton, and D. R. Wilson, 2008: Evaluating cloud systems in the Met Office global forecast model using simulated CloudSat radar reflectivities. J. Geophys. Res., 113, D00A13, doi:10.1029/2007JD009620.

Bower, K. N., T. W. Choularton, J. Latham, J. Nelson, M. B. Baker, and J. Jensen, 1994: A parameterization of warm clouds for use in atmospheric general circulation models. J. Atmos. Sci., 51, 2722-2732.

Brasseur, G. P., D. A. Hauglustaine, S. Walters, R. J. Rasch, J.-F. Müller, C. Granier, and X. X. Tie, 1998: MOZART, a global chemical transport model for ozone and related chemical tracers: 1. Model description. J. Geophys. Res., 103, 28 26528289.

Bretherton, C. S., J. R. McCaa, and H. Grenier, 2004: A new parameterization for shallow cumulus convection and its application to marine subtropical cloud-topped boundary layers. Part I: Description and 1D results. Mon. Wea. Rev., 132, 864-882.

Brohan, P., J. J. Kennedy, I. Harris, S. F. B. Tett, and P. D. Jones, 2006: Uncertainty estimates in regional and global observed temperature changes: a new dataset from 1850. J. Geophys. Res., 111, D12106, doi:10.1029/2005JD006548.

Carslaw, K. S., B. P. Luo, and Th. Peter, 1995: An analytic expression for the composition of aqueous $\mathrm{HNO}_{3}-\mathrm{H}_{2} \mathrm{SO}_{4}$ stratospheric aerosols including gas phase removal of $\mathrm{HNO}_{3}$. Geophys. Res. Lett., 22, 1877-1880.

CERSAT-IFREMER, 2002: ERS-1, ERS-2, and NSCAT. Vol. 1, Mean wind fields (MWF product), user manual C2-MUT-W05-IF, 72 pp. [Available online at http://cersat.ifremer.fr/fr/ data/discovery/by_mission/ers_1_ers_2/mwf_ers (see bottom of page).]

Chepfer, H., S. Bony, D. Winker, M. Chiriaco, J.-L. Dufresne, and G. Séze, 2008: Use of CALIPSO lidar observations to evaluate cloudiness simulated by a climate model. Geophys. Res. Lett., 35, L15704, doi:10.1029/2008GL034207.

,,--- G. Cesana, J. L. Dufresne, P. Minnis, C. J. Stubenrauch, and S. Zeng, 2010: The GCM-oriented CALIPSO cloud product (CALIPSO-GOCCP). J. Geophys. Res., 115, D00H16, doi:10.1029/2009JD012251.

Chin, M., and Coauthors, 2002: Tropospheric aerosol optical thickness from the GOCART model and comparisons with satellite and sun photometer measurements. J. Atmos. Sci., 59, 461-483.

Cooke, W. F., C. Liousse, H. Cachier, and J. Feichter, 1999: Construction of a $1^{\circ} \times 1^{\circ}$ fossil fuel emission data set for carbonaceous aerosol and implementation and radiative impact in the ECHAM4 model. J. Geophys. Res., 104, 22 137-22 162.

da Silva, A., A. C. Young, and S. Levitus, 1994: Algorithms and Procedures. Vol. 1, Atlas of Surface Marine Data 1994, NOAA Atlas NESDIS 6, 83 pp.

Delworth, T. D., and Coauthors, 2006: GFDL's CM2 global coupled climate models. Part I: Formulation and simulation characteristics. J. Climate, 19, 643-674.

Dentener, F., and Coauthors, 2006: Emissions of primary aerosol and precursor gases in the years 2000 and 1750 prescribed data-sets for AeroCom. Atmos. Chem. Phys., 6, 4321-4344.

Donner, L. J., 1993: A cumulus parameterization including mass fluxes, vertical momentum dynamics, and mesoscale effects. J. Atmos. Sci., 50, 889-906.

- and V. T. Phillips, 2003: Boundary-layer control on convective available potential energy: Implications for cumulus parameterization. J. Geophys. Res., 108, 4701, doi:10.1029/ 2003JD003773.
, C. J. Seman, B. J. Soden, R. S. Hemler, J. C. Warren, J. Ström, and K.-N. Liou, 1997: Large-scale ice clouds in the GFDL SKYHI general circulation model. J. Geophys. Res., 102, $21745-21768$.

,-- , R. S. Hemler, and S. Fan, 2001: A cumulus parameterization including mass fluxes, convective vertical velocities, and mesoscale effects: Thermodynamic and hydrological aspects in a general circulation model. J. Climate, 14, 3444 3463.

Dubovik, O., and M. D. King, 2000: A flexible inversion algorithm for retrieval of aerosol optical properties from sun and sky radiance measurements. J. Geophys. Res., 105, $20673-$ 20696.

Emmons, L. K., and Coauthors, 2010: Description and evaluation of the Model for Ozone and Related Chemical Tracers, version 4 (MOZART-4). Geosci. Model Dev., 3, 43-67.

Freidenreich, S. M., and V. Ramaswamy, 1999: A new multipleband solar radiative parameterization for general circulation models. J. Geophys. Res., 104, 31 389-31 409.

Fröhlich, C., and J. Lean, 2004: Solar radiative output and its variability: Evidence and mechanisms. Astron. Astrophys. Rev., 12, 273-320, doi:10.1007/s00159-004-0024-1.

Fu, Q., 1996: An accurate parameterization of the solar radiative properties of cirrus clouds for climate models. J. Climate, $\mathbf{9}$, 2058-2082.

— , and K. N. Liou, 1993: Parameterization of the radiative properties of cirrus clouds. J. Atmos. Sci., 50, 2008-2025.

_, P. Yang, and W. B. Sun, 1998: An accurate parameterization of the infrared radiative properties of cirrus clouds for climate models. J. Climate, 11, 2223-2237.

Gallagher, M. W., E. Nemitz, J. R. Dorsey, D. Fowler, M. A. Sutton, M. Flynn, and J. Duyzer, 2002: Measurements and parameterizations of small aerosol deposition velocities to grassland, arable crops, and forest: Influence of surface roughness length on deposition. J. Geophys. Res., 107, 4154, doi:10.1029/2001JD000817.

Ganachaud, A., and C. Wunsch, 2003: Large-scale ocean heat and freshwater transports during the World Ocean Circulation Experiment. J. Climate, 16, 696-705.

Gates, W. L., and Coauthors, 1999: An overview of the results of the Atmospheric Model Inter-Comparison Project (AMIP I). Bull. Amer. Meteor. Soc., 80, 29-55.

Ghan, S. J., L. R. Leung, R. C. Easter, and H. Abdul-Razzak, 1997: Prediction of cloud droplet number in a general circulation model. J. Geophys. Res., 102, 21 777-21 794.

Gibson, J. K., P. Kallberg, S. Uppala, A. Hernandez, A. Nomura, and E. Serrano, 1997: ERA description. Vol. 1, ECMWF ReAnalysis Project Rep. Series, European Centre for MediumRange Weather Forecasts, 66 pp. [Available online at http:// www.ecmwf.int/publications/library/do/references/list/191.]

Ginoux, P., M. Chin, I. Tegen, J. M. Prospero, B. Holben, O. Dubovik, and S.-J. Lin, 2001: Sources and distributions of dust aerosols simulated with the GOCART model. J. Geophys. Res., 106, 22 255-22 274

— L. W. Horowitz, V. Ramaswamy, I. V. Geogdzhayev, B. N. Holben, G. Stenchikov, and X. Tie, 2006: Evaluation of aerosol distribution and optical depth in the Geophysical Fluid Dynamics Laboratory coupled model CM2.1 for present climate. J. Geophys. Res., 111, D22210, doi:10.1029/2005JD006707.

Giorgetta, M. A., E. Manzini, R. Roeckner, M. Esch, and L. Bengtsson, 2006: Climatology and forcing of the quasi-biennial oscillation in the MAECHAM5 model. J. Climate, 19, 3882-3901. 
Giorgi, F., and W. L. Chameides, 1985: The rainout parameterization in a photochemical model. J. Geophys. Res., 90, 7872 7880.

Gnanadesikan, A., and Coauthors, 2006: GFDL's CM2 global coupled climate models. Part II: The baseline ocean simulation. J. Climate, 19, 675-697.

Golaz, J.-C., M. Salzmann, L. J. Donner, L. W. Horowitz, Y. Ming, and M. Zhao, 2011: Sensitivity of the aerosol indirect effect to subgrid variability in the cloud parameterization of the GFDL atmosphere general circulation model AM3. J. Climate, 24, 3145-3160.

Griffies, S. M., 2009: Elements of MOM4p1. GFDL Ocean Group Tech. Rep. 6, 377 pp. [Available online at http://data1. gfdl.noaa.gov/ arl/pubrel/o/old/doc/mom4p1_guide.pdf.]

_ M. J. Harrison, R. C. Pacanowski, and A. Rosati, 2004: A Technical Guide to MOM4. GFDL Ocean Group Tech. Rep. 5, $291 \mathrm{pp}$. [Available online at http://www.gfdl.noaa.gov/cmsfilesystem-action/model_development/ocean/guide4p0.pdf.]

- , and Coauthors, 2005: Formulation of an ocean model for global climate simulations. Ocean Sci., 1, 45-79.

_ , and Coauthors, 2009: Coordinated Ocean-Ice Reference Experiments (COREs). Ocean Modell., 26, 1-46.

_- and Coauthors, 2011: GFDL's CM3 coupled climate model: Characteristics of the ocean and sea ice simulations. J. Climate, 24, 3520-3544.

Grinnell, S. A., C. S. Bretherton, D. E. Stevens, and A. M. Fraser, 1996: Vertical mass flux calculations in Hawaiian trade cumulus clouds from dual-Doppler radar. J. Atmos. Sci., 53, 1870-1886.

Guo, H., J.-C. Golaz, L. J. Donner, V. E. Larson, D. P. Schanen, and B. M. Griffin, 2010: A dynamic probability density function treatment of cloud mass and number concentrations for low level clouds in GFDL SCM/GCM. Geosci. Model Dev., 3, 475-486.

Han, Q., W. B. Rossow, and A. A. Lacis, 1994: Near-global survey of effective droplet radii in liquid water clouds using ISCCP data. J. Climate, 7, 465-497.

Hanson, D. R., and K. Mauersberger, 1988: Laboratory studies of the nitric acid trihydrate: Implications for the south polar stratosphere. Geophys. Res. Lett., 15, 855-858.

Harrison, E. F., P. Minnis, B. R. Barkstrom, V. Ramanathan, R. D. Cess, and G. G. Gibson, 1990: Seasonal variation of cloud radiative forcing derived from the Earth Radiation Budget Experiment. J. Geophys. Res., 95, 18 687-18 703.

Haywood, J. M., and V. Ramaswamy, 1998: Global sensitivity studies of the direct radiative forcing due to anthropogenic sulfate and black carbon aerosols. J. Geophys. Res., 103, 6043 6058.

Held, I. M., R. S. Hemler, and V. Ramaswamy, 1993: Radiativeconvective equilibrium with explicit two-dimensional moist convection. J. Atmos. Sci., 50, 3909-3927.

Hess, M., P. Koepke, and I. Schult, 1998: Optical properties of aerosols and clouds: The software package OPAC. Bull. Amer. Meteor. Soc., 79, 831-844.

Hess, P. G., S. Flocke, J.-F. Lamarque, M. C. Barth, and S. Madronich, 2000: Episodic modeling of the chemical structure of the troposphere as revealed during the spring MLOPEX 2 intensive. J. Geophys. Res., 105, 26 809-26839.

Heymsfield, A. J., and L. J. Donner, 1990: A scheme for parameterizing ice-cloud water content in general circulation models. J. Atmos. Sci., 47, 1865-1877.

Holben, B. N., and Coauthors, 1998: AERONET-A federated instrument network and data archive for aerosol characterization. Remote Sens. Environ., 66, 1-16.
Horowitz, L. W., 2006: Past, present, and future concentrations of tropospheric ozone and aerosols: Methodology, ozone evaluation, and sensitivity to aerosol wet removal. J. Geophys. Res., 111, D22211, doi:10.1029/2005JD006937.

, and Coauthors, 2003: A global simulation of tropospheric ozone and related tracers: Description and evaluation of MOZART, version 2. J. Geophys. Res., 108, 4784, doi:10.1029/ 2002JD002853.

Huffman, G. J., and Coauthors, 1997: The Global Precipitation Climatology Project (GPCP) combined precipitation data set. Bull. Amer. Meteor. Soc., 78, 5-20.

, and Coauthors, 2007: The TRMM multisatellite precipitation analysis (TMPA): Quasi-global, multiyear, combined-sensor precipitation estimates at fine scales. J. Hydrometeor., 8, $38-55$.

Hurrell, J., J. Hack, D. Shea, J. Caron, and J. Rosinski, 2008: A new sea surface temperature and sea ice boundary data set for the Community Atmosphere Model. J. Climate, 21, 5145-5153.

Kalnay, E., and Coauthors, 1996: The NCEP/NCAR 40-Year Reanalysis Project. Bull. Amer. Meteor. Soc., 77, 437-471.

King, M. D., and Coauthors, 2003: Cloud and aerosol properties, precipitable water, and profiles of temperature and humidity. IEEE Trans. Geosci. Remote Sens., 41, 442-458, doi:10.1109/ TGRS.2002.808226.

Knutson, T. R., and Coauthors, 2006: Assessment of twentiethcentury regional surface trends using the GFDL CM2 coupled models. J. Climate, 19, 1624-1651.

Kopp, G., G. Lawrence, and G. Rottman, 2005: The Total Irradiance Monitor (TIM): Science results. Sol. Phys., 230, 129-140.

Lamarque, J.-F., and Coauthors, 2010: Historical (1850-2000) gridded anthropogenic and biomass burning emissions of reactive gases and aerosols: Methodology and application. Atmos. Chem. Phys. Discuss., 10, 4963-5019.

Large, W. G., and S. G. Yeager, 2009: The global climatology of an interannually varying air-sea flux data set. Climate Dyn., 33, 341-364.

Leary, C. A., and R. A. Houze Jr., 1980: The contribution of mesoscale motions to the mass and heat fluxes of an intense tropical convective system. J. Atmos. Sci., 37, 784-796.

Lee, S.-S., L. J. Donner, and V. T. J. Phillips, 2009: Sensitivity of aerosol and cloud effects on radiation to cloud types: Comparison between deep convective clouds and warm stratiform clouds over one-day period. Atmos. Phys. Chem., 9, 2555-2575.

Li, F., P. Ginoux, and V. Ramaswamy, 2008: Distribution, transport, and deposition of mineral dust in the Southern Ocean and Antarctica: Contribution of major sources. J. Geophys. Res., 113, D10207, doi:10.1029/2007JD009190.

Liebmann, B., and C. A. Smith, 1996: Description of a complete (interpolated) outgoing longwave radiation dataset. Bull. Amer. Meteor. Soc., 77, 1275-1277.

Lin, J.-L., and Coauthors, 2006: Tropical intraseasonal variability in 14 IPCC AR4 climate models. Part I: Convective signals. J. Climate, 19, 2665-2690.

Lin, S.-J., 1997: A finite-volume integration method for computing pressure-gradient force in general vertical coordinates. Quart. J. Roy. Meteor. Soc., 123, 1749-1762.

_ 2004: A "vertically Lagrangian" finite-volume dynamical core for global models. Mon. Wea. Rev., 132, 2293-2307.

, and R. B. Rood, 1996: Multidimensional flux-form semiLagrangian transport schemes. Mon. Wea. Rev., 124, 2046-2070. , and - 1997: An explicit flux-form semi-Lagrangian shallow water model on the sphere. Quart. J. Roy. Meteor. Soc., 123, 2477-2498. 
Lin, Y., L. J. Donner, and B. A. Colle, 2011: Parameterization of riming intensity and its impact on ice fall speed using ARM data. Mon. Wea. Rev., 139, 1036-1047.

Lock, A. P., A. R. Brown, M. R. Bush, M. Martin, and R. N. B. Smith, 2000: A new boundary layer mixing scheme. Part I: Scheme description and single-column model tests. Mon. Wea. Rev., 128, 3187-3199.

Loeb, N., B. A. Wielicki, D. R. Doelling, G. L. Smith, D. F. Keyes, S. Kato, N. Manalo-Smith, and T. Wong, 2009: Toward optimal closure of the earth's top-of-atmosphere radiation budget. J. Climate, 22, 748-766.

Louis, J.-F., 1979: A parametric model of vertical eddy fluxes in the atmosphere. Bound.-Layer Meteor., 17, 187-202.

Madronich, S., and S. Flocke, 1998: The role of solar radiation in atmospheric chemistry. Handbook of Environmental Chemistry, P. Boule, Ed., Springer-Verlag, 1-26.

Manabe, S., J. Smagorinsky, and R. F. Strickler, 1965: Simulated climatology of a general circulation model with hydrologic cycle. Mon. Wea. Rev., 93, 769-798.

Mapes, B. E., and R. A. Houze Jr., 1993: Cloud clusters and superclusters over the oceanic warm pool. Mon. Wea. Rev., 121, 1398-1415.

McFarquhar, G. M., A. J. Heymsfield, A. Macke, J. Iaquinta, and S. M. Aulenbach, 1999: Use of observed ice crystal sizes and shapes to calculate mean scattering properties and multispectral radiances: CEPEX April 4, 1993 case study. J. Geophys. Res., 104 (D24), 31 763-31 780.

Meehl, G. A., C. Covey, T. Delworth, M. Latif, B. McAvaney, J. F. B. Mitchell, R. J. Stouffer, and K. E. Taylor, 2007: The WCRP CMIP3 multi-model dataset: A new era in climate change research. Bull. Amer. Meteor. Soc., 88, 1383-1394.

Milly, P. C. D., and A. B. Shmakin, 2002: Global modeling of land water and energy balances. Part I: The land dynamics (LaD) model. J. Hydrometeor., 3, 283-299.

Ming, Y., and L. M. Russell, 2004: Organic aerosol effects on fog droplet spectra. J. Geophys. Res., 109, D10206, doi:10.1029/2003JD004427.

, V. Ramaswamy, P. A. Ginoux, and L. W. Horowitz, 2005: Direct radiative forcing of anthropogenic organic aerosols. J. Geophys. Res., 110, D20208, doi:10.1029/2004JD005573.

,-- L. J. Donner, and V. T. J. Phillips, 2006: A robust parameterization of cloud droplet activation. J. Atmos. Sci., 63, $1348-1356$.

Monahan, E. C., D. E. Spiel, and K. L. Davidsona, 1986: A model of marine aerosol generation via whitecaps and wave disruption. Oceanic Whitecaps, E. C. Monahan and G. Mac Niocaill, Eds., D. Reidel, 167-174.

O'Dowd, C. D., B. Langmann, S. Varghese, C. Scannell, D. Ceburnis, and M. C. Facchini, 2008: A combined organic-inorganic seaspray source function. Geophys. Res. Lett., 35, L01801, doi:10.1029/2007GL030331.

Paluch, I. R., 1979: The entrainment mechanism in Colorado cumuli. J. Atmos. Sci., 36, 2467-2478.

Perovich, D., T. C. Grenfell, B. Light, and P. V. Hobbs, 2002: Seasonal evolution of the albedo of multi-year arctic sea ice. J. Geophys. Res., 107, 8044, doi:10.1029/2000JC000438.

Pincus, R., H. W. Barker, and J. Morcrette, 2003: A fast, flexible, approximate technique for computing radiative transfer in inhomogeneous cloud fields. J. Geophys. Res., 108, 4376, doi:10.1029/2002JD003322.

, C. Hannay, S. A. Klein, K.-M. Xu, and R. Hemler, 2005: Overlap assumptions for assumed probability distribution function cloud schemes in large-scale models. J. Geophys. Res., 110, D15S09, doi:10.1029/2004JD005100.
— R. Remler, and S. A. Klein, 2006: Using stochastically generated subcolumns to represent cloud structure in a large-scale model. Mon. Wea. Rev., 134, 3644-3656.

— C. P. Batstone, R. J. P. Hofmann, K. E. Taylor, and P. J. Glecker, 2008: Evaluating the present-day simulation of clouds, precipitation, and radiation in climate models. J. Geophys. Res., 113, D14209, doi:10.1029/2007JD009334.

Putman, W. M., and S.-J. Lin, 2007: Finite-volume transport on various cubed-sphere grid. J. Comput. Phys., 227, 55-78.

Randel, W. J., and F. Wu, 1999: A stratospheric ozone trends data set for global modeling studies. Geophys. Res. Lett., 26, 30893092.

— 1979-2005: Variability, trends, and comparisons with column ozone data. J. Geophys. Res., 112, D06313, doi:10.1029/ 2006JD007339.

Rayner, N. A., D. E. Parker, E. B. Horton, C. K. Folland, L. V. Alexander, D. P. Rowell, E. C. Kent, and A. Kaplan, 2003: Global analyses of sea surface temperature, sea ice, and night marine air temperature since the late nineteenth century. J. Geophys. Res., 108, 4407, doi:10.1029/2002JD002670.

Reichler, T., and J. Kim, 2008: How well do coupled models simulate today's climate? Bull. Amer. Meteor. Soc., 89, 303-311.

Rotstayn, L. D., 1997: A physically based scheme for the treatment of stratiform clouds and precipitation in large-scale models. I: Description and evaluation of microphysical processes. Quart. J. Roy. Meteor. Soc., 123, 1227-1282.

, 2000: On the "tuning" of autoconversion parameterizations in climate models. J. Geophys. Res., 105, 15 495-15 507.

— B. F. Ryan, and J. Katzfey, 2000: A scheme for calculation of the liquid fraction in mixed-phase clouds in large-scale models. Mon. Wea. Rev., 128, 1070-1088.

Sadourny, R., 1972: Conservative finite-difference approximations of the primitive equations on quasi-uniform spherical grids. Mon. Wea. Rev., 100, 136-144.

Sander, S. P., and Coauthors, 2006: Chemical kinetics and photochemical data for use in atmospheric studies. Evaluation 15, JPL Publ. 06-2, Jet Propulsion Laboratory, 523 pp.

Schwarzkopf, M. D., and V. Ramaswamy, 1999: Radiative effects of $\mathrm{CH}_{4}, \mathrm{~N}_{2} \mathrm{O}$, halocarbons and the foreign-broadened $\mathrm{H}_{2} \mathrm{O}$ continuum: A GCM experiment. J. Geophys. Res., 104, $9467-$ 9488.

Shevliakova, E., and Coauthors, 2009: Carbon cycling under 300 years of land use change: Importance of the secondary vegetation sink. Global Biogeochem. Cycles, 23, GB2022, doi:10.1029/ 2007 GB003176.

Siebesma, A., and Coauthors, 2003: A large-eddy simulation intercomparison study of shallow cumulus convection. J. Atmos. Sci., 60, 1201-1219.

Simmons, A. J., and D. M. Burridge, 1981: An energy and angularmomentum conserving vertical finite-difference scheme and hybrid vertical coordinates. Mon. Wea. Rev., 109, 758-766.

Slingo, A., 1989: A GCM parameterization for the shortwave radiative properties of water clouds. J. Atmos. Sci., 46, 1419-1427.

Stenchikov, G., K. Hamilton, R. J. Stouffer, A. Robock, V. Ramaswamy, B. Santer, and H.-F. Graf, 2006: Arctic Oscillation response to volcanic eruptions in the IPCC AR4 climate models. J. Geophys. Res., 111, D07107, doi:10.1029/ 2005JD006286.

Stern, W. F., and R. T. Pierrehumbert, 1988: The impact of an orographic gravity wave drag parameterization on extended-range predictions with a GCM. Preprints, Eighth Conf. on Numerical Weather Prediction, Baltimore, MD, Amer. Meteor. Soc., 745-750. 
Stolarski, R. S., and S. Frith, 2006: Search for evidence of trend slow-down in the long-term TOMS/SBUV total ozone data record: The importance of instrument drift uncertainty. Atmos. Chem. Phys., 12, 4057-4065.

Tang, I. N., and H. R. Munkelwitz, 1994: Water activities, densities, and refractive indices of aqueous sulfates an sodium nitrate droplets of atmospheric importance. J. Geophys. Res., 99, 18 801-18 808 .

_ - A. C. Tridico, and K. H. Fung, 1997: Thermodynamic and optical properties of sea-salt aerosols. J. Geophys. Res., 102, 23 269-23 276.

Taylor, K. E., 2001: Summarizing multiple aspects of model performance in a single diagram. J. Geophys. Res., 106, 7183-7192.

Thompson, D. W. J., and S. Solomon, 2006: Interpretation of recent Southern Hemisphere climate change. Science, 296, 895-899.

Tie, X., and Coauthors, 2005: Assessment of the global impact of aerosols on tropospheric oxidants. J. Geophys. Res., 110, D03204, doi:10.1029/2004JD005359.

Tiedtke, M., 1993: Representation of clouds in large-scale models. Mon. Wea. Rev., 121, 3030-3061.

Trenberth, K. E., and J. M. Caron, 2001: Estimates of meridional atmosphere and ocean heat transports. J. Climate, 14, 3433 3443.

Uppala, S. M., and Coauthors, 2005: The ERA-40 Re-Analysis. Quart. J. Roy. Meteor. Soc., 131, 2961-3012, doi:10.1256/qj.04.176.

Vitart, F., J. L. Anderson, and W. F. Stern, 1997: Simulation of interannual variability of tropical storm frequency in an ensemble of GCM integrations. Mon. Wea. Rev., 129, 745-760.

Wesely, M. L., 1989: Parameterization of surface resistances to gaseous dry deposition in regional-scale numerical models Atmos. Environ., 23, 1293-1304.

Wheeler, M., and G. N. Kiladis, 1999: Convectively coupled equatorial waves: Analysis of clouds and temperature in the wavenumber-frequency domain. J. Atmos. Sci., 56, 374-399.
Wielicki, B. A., B. R. Barkstrom, E. F. Harrison, R. B. Lee III, G. L. Smith, and J. E. Cooper, 1996: Clouds and the Earth's Radiant Energy System (CERES): An earth observing system experiment. Bull. Amer. Meteor. Soc., 77, 853-868.

Wilcox, E. M., and L. J. Donner, 2007: The frequency of extreme rain events in satellite rain-rate estimates and an atmospheric general circulation model. J. Climate, 20, 53-69.

Winton, M., 2000: A reformulated three-layer sea ice model. J. Atmos. Oceanic Technol., 17, 525-531.

Woodruff, S. D., R. J. Slutz, R. L. Jenne, and P. M. Steurer, 1987: A Comprehensive Ocean-Atmosphere Dataset. Bull. Amer. Meteor. Soc., 68, 1239-1250.

Zhang, G., 2002: Convective quasi-equilibrium in mid-latitude continental environment and its effect on convective parameterization. J. Geophys. Res., 107, 4220, doi:10.1029/ 2001JD001005.

- 2009: Effects of entrainment on convective available potential energy and closure assumptions in convection parameterization. J. Geophys. Res., 114, D07109, doi:10.1029/ 2008JD10976.

Zhang, X., W. Lin, and M. Zhang, 2007: Toward understanding the double Intertropical Convergence Zone pathology in coupled ocean-atmosphere general circulation models. J. Geophys. Res., 112, D12102, doi:10.1029/2006JD007878.

Zhao, M., and P. H. Austin, 2005a: Life cycle of numerically simulated shallow cumulus clouds. Part I: Transport. J. Atmos. Sci., 62, 1269-1290.

— and - 2005b: Life cycle of numerically simulated shallow cumulus clouds. Part II: Mixing dynamics. J. Atmos. Sci., 62, 1291-1310.

— I. M. Held, S.-J. Lin, and G. A. Vecchi, 2009: Simulations of global hurricane climatology, interannual variability, and response to global warming using a $50-\mathrm{km}$ resolution GCM. J. Climate, 22, 6653-6678. 